Aus der Abteilung Pädiatrie III - Pädiatrische Kardiologie und Intensivmedizin (Prof. Dr. med. T. Paul)

im Zentrum Kinderheilkunde und Jugendmedizin der Medizinischen Fakultät der Universität Göttingen

\title{
Die Pathogenese der chronischen Herzinsuffizienz bei Säuglingen mit angeborenem Herzfehler und Links-Rechts-Shunt am Beispiel der klinischen Symptome Tachypnoe und Gedeihstörung
}

\author{
Inaugural-Dissertation \\ zur Erlangung des Doktorgrades \\ der Medizinischen Fakultät \\ der Georg-August-Universität zu Göttingen
}

vorgelegt von

Annette Hammersen

aus

Hannover

Göttingen 2012 
Dekan: Prof. Dr. med. M. P. Schön

I. Berichterstatter: PD Dr. med. M. Sigler

II. Berichterstatter: PD Dr. med. F. Edelmann

III. Berichterstatter/in: -

Tag der mündlichen Prüfung: 14. Januar 2013 


\section{Abkürzungsverzeichnis}

$\alpha \quad$ - Signifikanzniveau

ANOVA - analysis of variance, Varianzanalyse

ASD - Atrialer Septumdefekt

$\mathrm{AVDO}_{2} \quad$ - Arteriovenöse Sauerstoffdifferenz

AVSD － Atrioventrikulärer Septumdefekt

BNP - brain natriuretic peptide

bzw. - beziehungsweise

EF - Ejektionsfraktion

et al. $\quad$ - et alii

HF - Herzfrequenz

i. v. - intravenös

LAP - mean left atrial pressure, mittlerer linksatrialer Druck

LVedP - left ventricular enddiastolic pressure, linksventrikulärer enddiastolischer Druck

MAP - mean arterial pressure, mittlerer arterieller Druck

M. Down - Morbus Down

$\mathrm{N} \quad$ - Anzahl

NA - Noradrenalin

ns - nicht signifikant

NT-proBNP - N-terminal pro-brain natriuretic peptide

p - probability, Irrtumswahrscheinlichkeit

PAP - mean pulmonary artery pressure, mittlerer pulmonalarterieller Druck

PDA - Persistierender Ductus arteriosus Botalli

PRA - Plasma-Renin-Aktivität

PVRI - pulmonary vascular resistance index, pulmonalvaskulärer Widerstand bezogen auf die Körperoberfläche

$\mathrm{Q}_{\mathrm{p}} \quad$ - Pulmonales Herzzeitvolumen

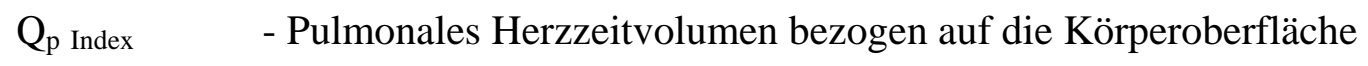

$\mathrm{Q}_{\mathrm{p}} / \mathrm{Q}_{\mathrm{s}} \quad$ - Verhältnis von pulmonalem zu systemischem Herzzeitvolumen

Qs - Systemisches Herzzeitvolumen

Q Index - Systemisches Herzzeitvolumen bezogen auf die Körperoberfläche

r $\quad$ - Korrelationskoeffizient

$\mathrm{R}^{2} \quad$ - Bestimmtheitsmaß in der multiplen Regression

RAAS - Renin-Angiotensin-Aldosteron-System 


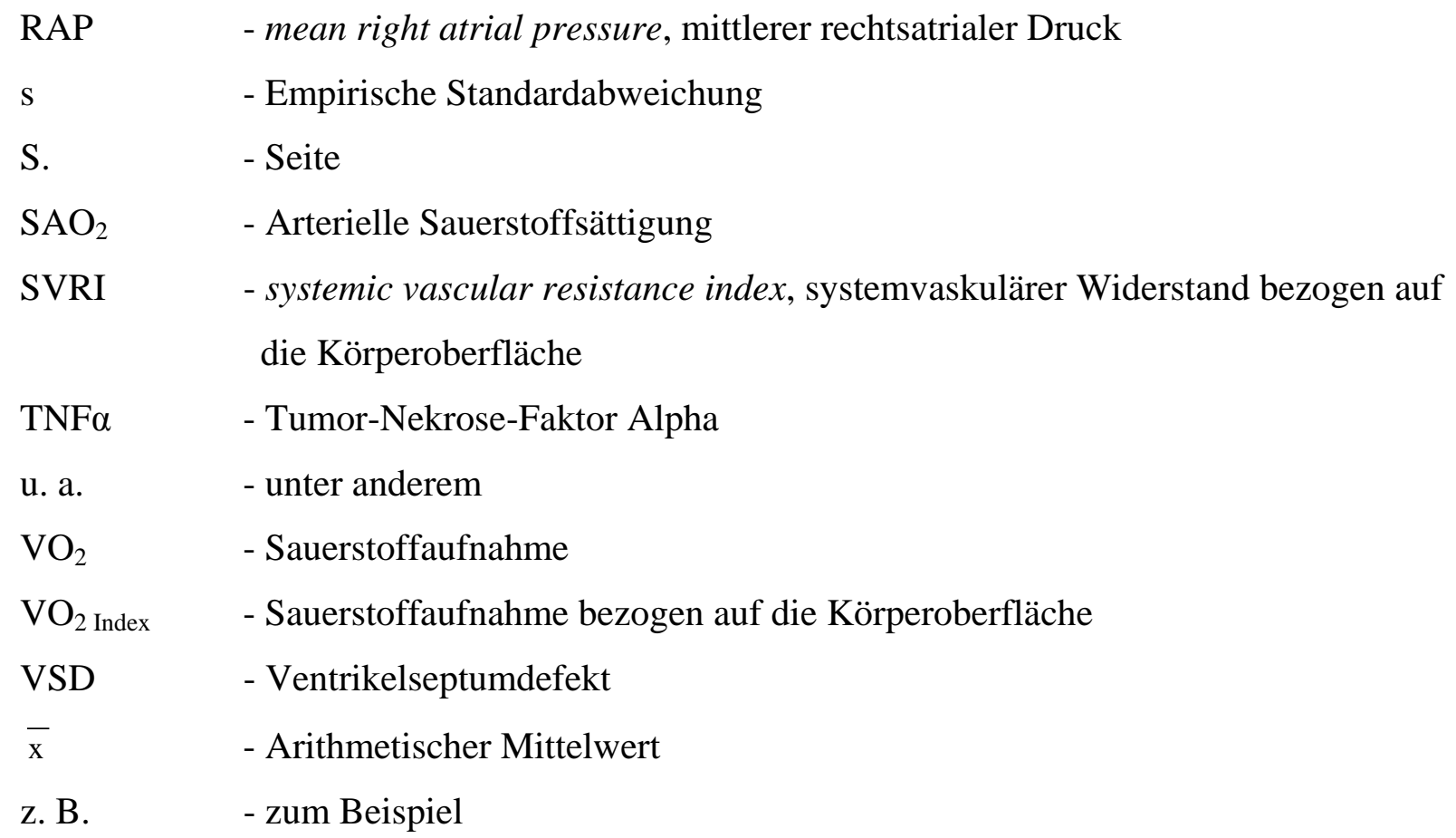

\section{Abkürzungen der Maßeinheiten}

d

- day, Tag

E - E bzw. WE = Wood-Einheit $(1 \mathrm{WE}=1 \mathrm{mmHg} / \mathrm{l} / \mathrm{min})$

g - - Gramm

h - hour, Stunde

kcal - Kilokalorien

$\mathrm{kg} \quad-$ Kilogramm $\left(10^{3} \mathrm{~g}\right)$

l - Liter

m - Meter

mg - Milligramm $\left(10^{-3} \mathrm{~g}\right)$

min - Minute

$\mathrm{ml} \quad-$ Milliliter $\left(10^{-3} \mathrm{l}\right)$

mmHg - Millimeter Quecksilbersäule

$\mu \mathrm{U} \quad-$ Mikro-Unit $\left(10^{-6}\right.$ Units $)$

ng - Nanogramm $\left(10^{-9} \mathrm{~g}\right)$

nmol - Nanomol $\left(10^{-9} \mathrm{~mol}\right)$

pg - Pikogramm $\left(10^{-12} \mathrm{~g}\right)$ 


\section{Inhaltsverzeichnis}

1 Einleitung .............................................................................................. 1

1.1 Einführung in die Problematik angeborener Herzfehler ........................................ 1

1.2 Einteilung und Häufigkeit angeborener Herzfehler ............................................. 2

1.3 Definition der Herzinsuffizienz und Klassifikationen zur Beurteilung ihres

Schweregrades................................................................................................................................ 3

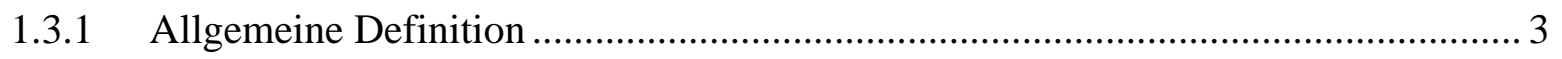

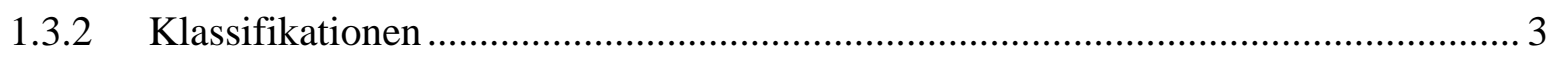

1.3.3 Spezielle Klassifikationen für Kinder.......................................................... 4

1.4 Tachypnoe bei Kindern mit angeborenem Herzfehler.............................................. 4

1.5 Gedeihstörung bei Kindern mit angeborenem Herzfehler .....................................5

1.6 Pathophysiologische Modelle zur Entstehung der Herzinsuffizienz

bei Kindern und Erwachsenen................................................................................................ 6

1.6.1 Traditionelle Erklärungsversuche bei Kindern mit Links-Rechts-Shunt-Vitien ....... 6

1.6.2 Pathophysiologische Modelle zur Entstehung der Herzinsuffizienz im

Erwachsenenalter nach PACKER (1993) ........................................................... 8

1.6.2.1 Kardiorenales Herzinsuffizienzmodell ....................................................... 8

1.6.2.2 Kardiozirkulatorisches Herzinsuffizienzmodell .............................................. 9

1.6.2.3 Neurohumorales Herzinsuffizienzmodell ..................................................... 9

1.7 Ausblick: Immunaktivierung und weitere neurohumorale Mechanismen .......... 11

1.8 Anwendbarkeit des neurohumoralen Herzinsuffizienzmodells

der Erwachsenen auf Kinder mit angeborenem Herzfehler .................................. 11

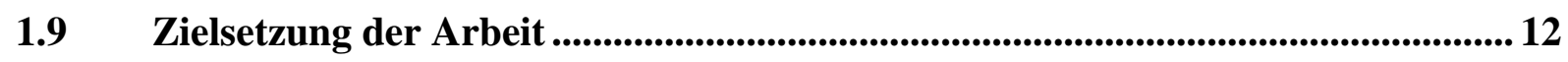

\section{Patienten, Material und Methoden ...............................................14}

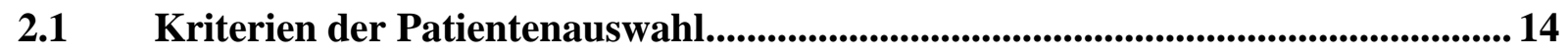

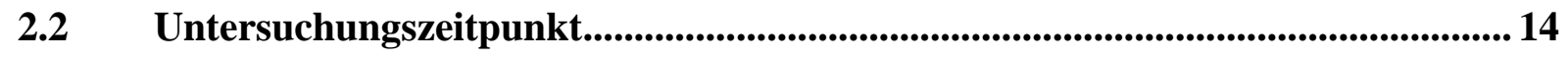

2.3 Erhebung der Untersuchungsparameter ....................................................................... 15

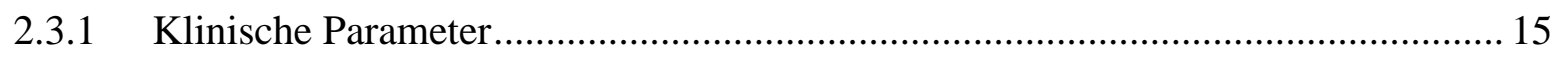

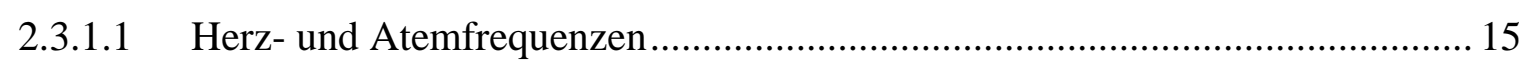

2.3.1.2 Gewichtsentwicklung und Kalorienzufuhr .................................................. 15

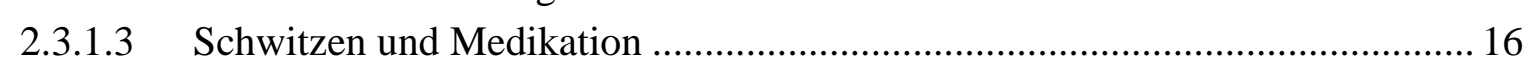

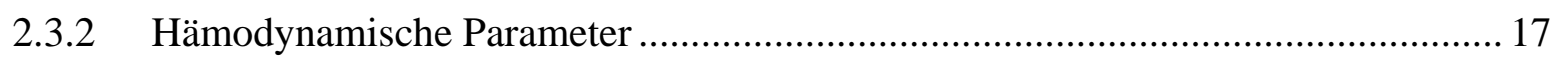


2.3.2.1 Berechnung des Herzzeitvolumens nach dem Fickschen Prinzip..................... 17

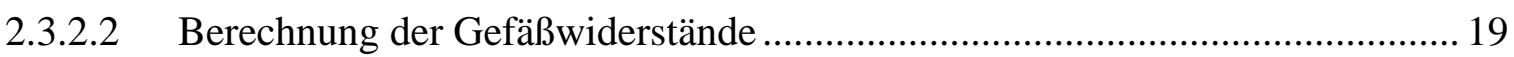

2.3.2.3 Weitere hämodynamische Parameter............................................................... 20

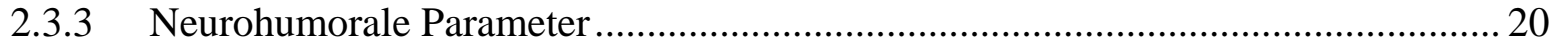

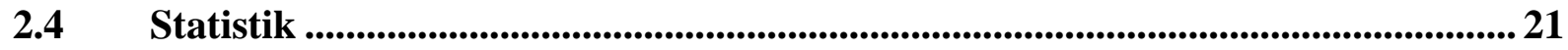

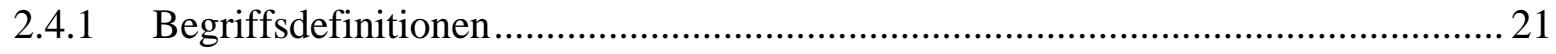

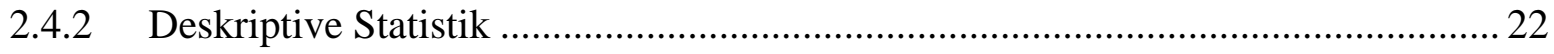

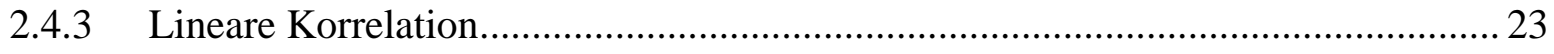

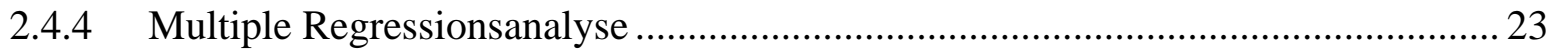

2.4.4.1 Aufbau eines Regressionsmodells zur Erklärung der Symptome

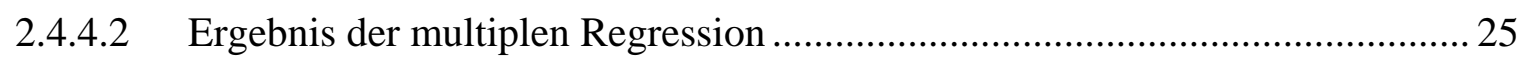

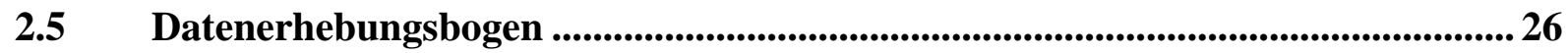

3 Darstellung der Untersuchungsergebnisse ..................................27

Charakterisierung der Studienpatienten ..................................................................... 27

3.2 Tachypnoe - Auswertung nach Atemfrequenzgruppen.......................................... 30

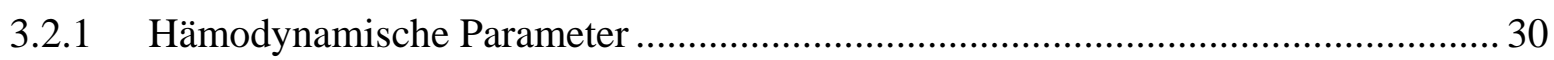

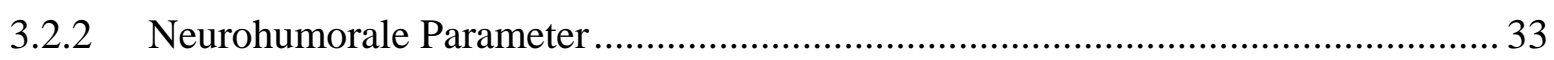

3.2.3 Gesonderte Auswertung für das erste und das zweite Trimenon ........................... 35

3.3 Tachypnoe - Lineare Korrelation und multiple Regressionsanalyse .................. 40

3.4 Gedeihstörung - Auswertung nach Gedeihgruppen .......................................... 42

3.4.1 Verteilung der Gewichtsperzentilen bei Geburt und zum Untersuchungszeitpunkt 42

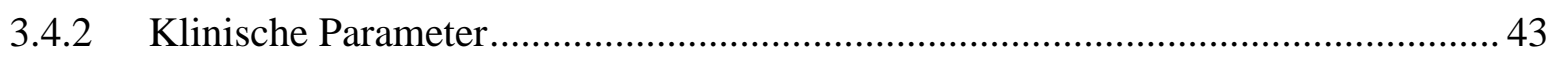

3.4.3 Hämodynamische und neurohumorale Parameter .............................................. 44

3.5 Gedeihstörung - Lineare Korrelation und multiple Regressionsanalyse............. 47

\section{Diskussion der Methodik und der Ergebnisse ..........................48}

$4.1 \quad$ Diskussion der Methodik...................................................................................................... 48

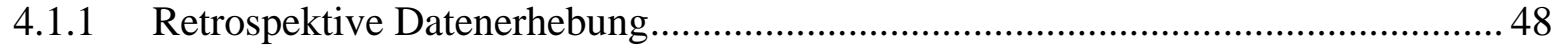

4.1.2 Erhebung der hämodynamischen Parameter ....................................................... 48

4.1.3 Mögliche Beeinflussung der Katecholaminspiegel durch Agitation ...................... 49

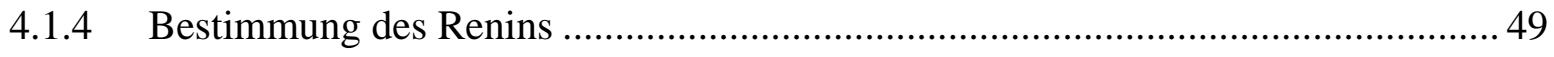

4.1.5 Festlegung von Referenzwerten für die neurohumoralen Parameter ..................... 49

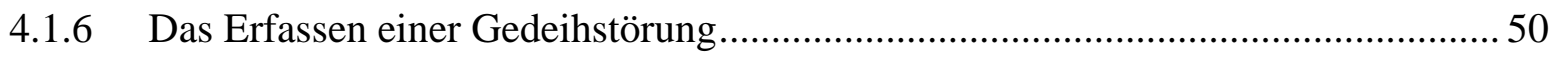




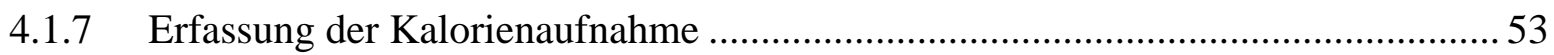

4.1.8 Angeborene gastrointestinale Fehlbildungen und genetische Syndrome ................. 53

4.2 Diskussion der Ergebnisse - Tachypnoe........................................................................ 54

4.2.1 Analyse der hämodynamischen Parameter ........................................................... 54

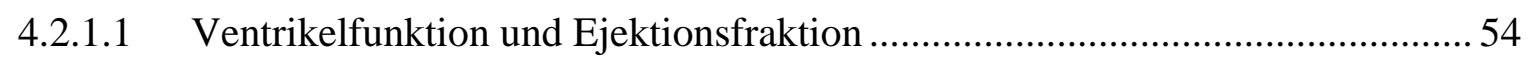

4.2.1.2 Pulmonale hämodynamische Parameter ........................................................... 54

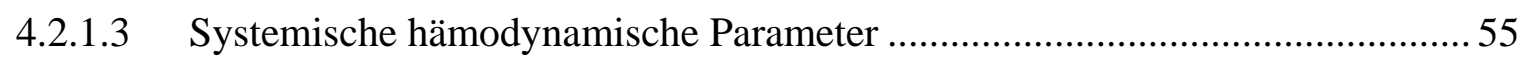

4.2.2 Die pathophysiologische Bedeutung eines niedrigen mittleren arteriellen Drucks. 55

4.2.3 Die Sauerstoffversorgung des peripheren Gewebes............................................ 56

4.2.4 Die neurohumorale Aktivierung bei Säuglingen mit Links-Rechts-Shunt und

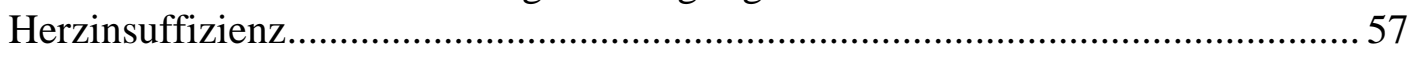

4.2.5 Die Bedeutung des Renin-Angiotensin-Aldosteron-Systems (RAAS) ................... 59

4.2.6 Die Bedeutung des sympathischen Nervensystems............................................. 59

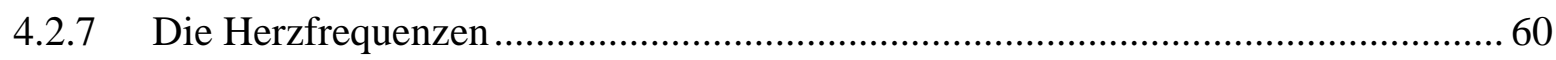

4.2.8 Herzfrequenzvariabilität und kardiorespiratorische Reflexe ............................... 61

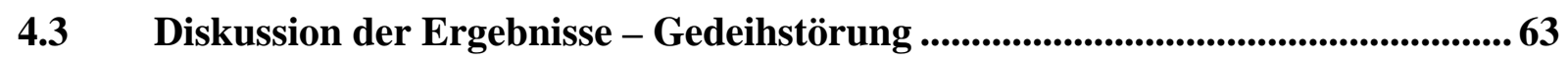

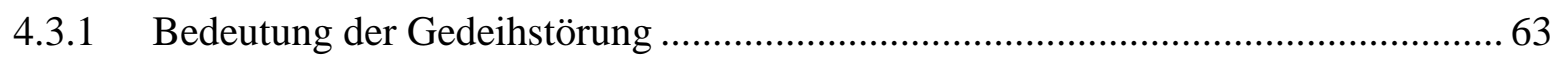

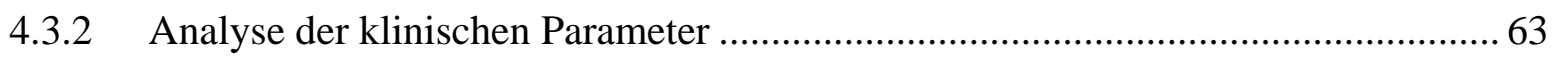

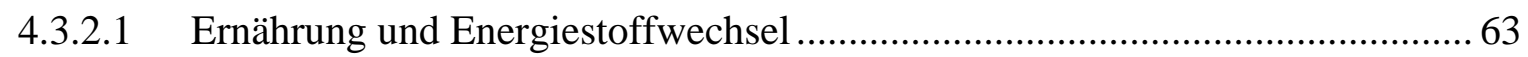

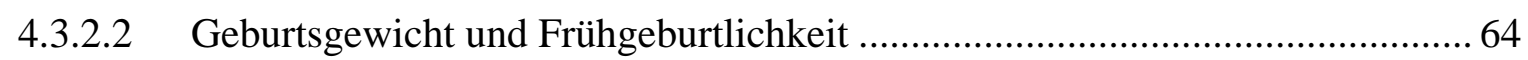

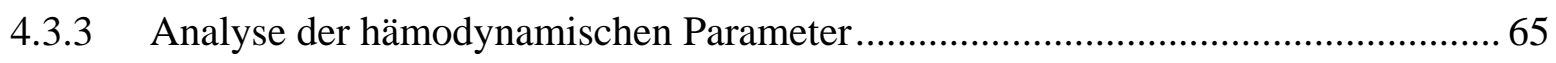

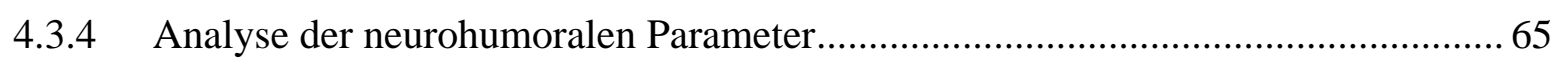

4.4 Ausblick: Immunaktivierung und erhöhtes BNP bei chronischer

Herzinsuffizienz..................................................................................................6 67

5 Zusammenfassung ..............................................................................69

6 Anhang: Urdatentabelle......................................................................71

7 Literaturverzeichnis ....................................................................... 75 


\section{Tabellenverzeichnis}

Tabelle 2.1 Einteilung der Säuglinge entsprechend ihren mittleren Atemfrequenzen zur Beurteilung des Schweregrades ihrer Herzinsuffizienz............................................. 22

Tabelle 2.2 Einteilung der Säuglinge entsprechend ihrer Gewichtsentwicklung über vier Wochen zur Beurteilung des Schweregrades ihrer Herzinsuffizienz ........................ 22

Tabelle 3.1 Charakterisierung der Studienpatienten ............................................................. 27

Tabelle 3.2 Hämodynamische und neurohumorale Parameter der 70 untersuchten Säuglinge mit angeborenem Herzfehler und Links-Rechts-Shunt .......................................... 28

Tabelle 3.3 Diagnosen der 70 Studienpatienten 29

Tabelle 3.4 Hämodynamische Parameter der untersuchten Säuglinge mit Links-RechtsShunt eingeteilt nach Atemfrequenzgruppen

Tabelle 3.5 Alter, Medikation und neurohumorale Aktivitäten der untersuchten Säuglinge mit Links-Rechts-Shunt eingeteilt nach Atemfrequenzgruppen . 34

Tabelle 3.6 Hämodynamische Parameter bei 31 untersuchten Säuglingen mit Links-RechtsShunt im ersten Trimenon eingeteilt nach Atemfrequenzgruppen. 36

Tabelle 3.7 Medikation und neurohumorale Aktivitäten bei 31 untersuchten Säuglingen mit Links-Rechts-Shunt im ersten Trimenon eingeteilt nach Atemfrequenzgruppen..... 37

Tabelle 3.8 Hämodynamische Parameter bei 36 untersuchten Säuglingen mit Links-RechtsShunt im zweiten Trimenon eingeteilt nach Atemfrequenzgruppen. 38

Tabelle 3.9 Medikation und neurohumorale Aktivitäten bei 36 untersuchten Säuglingen mit Links-Rechts-Shunt im zweiten Trimenon eingeteilt nach Atemfrequenzgruppen.. 39

Tabelle 3.10 Lineare Korrelationen und Ergebnisse der multiplen Regressionsanalyse bei 63 Säuglingen mit Links-Rechts-Shunt hinsichtlich der Bedeutung neurohumoraler und hämodynamischer Parameter für die Entstehung der Tachypnoe 41

Tabelle 3.11 Klinische und neurohumorale Parameter der untersuchten Säuglinge mit LinksRechts-Shunt eingeteilt entsprechend ihrer mittleren Gewichtsentwicklung 45

Tabelle 3.12 Hämodynamische Parameter der untersuchten Säuglinge mit Links-RechtsShunt eingeteilt entsprechend ihrer mittleren Gewichtsentwicklung. 46

Tabelle 3.13 Lineare Korrelation und Ergebnisse der multiplen Regressionsanalyse bei 63 Säuglingen mit Links-Rechts-Shunt hinsichtlich der Bedeutung neurohumoraler und hämodynamischer Parameter für die Entstehung der kardialen Gedeihstörung.. 


\section{Abbildungsverzeichnis}

Abbildung 3.1 Signifikanter Abfall des mittleren arteriellen Drucks (MAP) bei zunehmender Tachypnoe im untersuchten Patientenkollektiv..................................................... 32

Abbildung 3.2 Verhältnis von pulmonalem zu systemischem Herzzeitvolumen $\left(Q_{p} / Q_{s}\right)$ bei zunehmender Tachypnoe im untersuchten Patientenkollektiv

Abbildung 3.3 Signifikanter Anstieg des Plasma-Noradrenalinspiegels bei zunehmender Tachypnoe im untersuchten Patientenkollektiv.

Abbildung 3.4 Verteilung der Gewichtsperzentilen zum Zeitpunkt der Geburt bei den untersuchten Säuglingen mit angeborenem Herzfehler und Links-Rechts-Shunt 42

Abbildung 3.5 Verteilung der Gewichtsperzentilen zum Untersuchungszeitpunkt bei den untersuchten Säuglingen mit angeborenem Herzfehler und Links-Rechts-Shunt 43 


\section{Einleitung}

\subsection{Einführung in die Problematik angeborener Herzfehler}

Angeborene Herzfehler treten mit einer Häufigkeit von etwa 4-12 pro 1000 lebend geborener Kinder auf (HOFFMAN 1995). Neuere Veröffentlichungen schätzen die Inzidenz mittelschwerer und schwerer Formen angeborener Herzfehler auf 6 pro 1000 Lebendgeburten. Die Inzidenz aller, d.h. auch milder, erst mit moderner Technik wie Farbdopplerechokardiographie diagnostizierbarer Formen, wird auf bis zu 75 pro 1000 Lebendgeburten geschätzt (HOFFMAN und KAPLAN 2002).

Etwa 20 Prozent der betroffenen Kinder entwickeln im Verlauf eine klinische Symptomatik, etwa 90 Prozent davon bereits im ersten Lebensjahr (APITZ 1978). Außer einer Tachydyspnoe kommt es dabei typischerweise zu zum Teil schweren Trink- und Gedeihschwierigkeiten, einer Belastungsintoleranz mit vermehrtem Schwitzen, einer Tachykardie, einer Hepatomegalie sowie eventuell zu peripheren Ödemen und einer vermehrten bronchopulmonalen Infektneigung (ARTMAN und GRAHAM 1982). Diese Symptomatik wird angesichts großer Ähnlichkeit mit der Symptomatik chronisch herzinsuffizienter Erwachsener ebenfalls als Herzinsuffizienz bezeichnet. Sie stellt die häufigste Todesursache dieser Kinder im natürlichen Krankheitsverlauf dar (APITZ und STOERMER 1967).

Durch erhebliche Fortschritte in der modernen Herzchirurgie und der interventionellen Therapie besteht zunehmend die Möglichkeit, strukturelle Fehlbildungen des Herzens oder der Gefäße frühzeitig operativ oder interventionell zu korrigieren. Eine erfolgreiche Korrektur stellt so für viele Kinder die kausale Therapie der Herzinsuffizienz dar.

Problematisch bleibt die Situation für Kinder mit komplexen, nicht korrigierbaren Herzfehlern und Kinder nach palliativen Eingriffen, bei denen keine definitiv korrektive Operation möglich ist. Diese Kinder sind langfristig auf eine effiziente medikamentöse Therapie angewiesen. Als Herausforderung stellt sich auch bei Kindern mit korrigierbaren Herzfehlern die zu überbrückende Zeit bis zu einer Operation dar, da viele dieser Kinder eine ausgeprägte klinische Symptomatik trotz einer medikamentösen Therapie zeigen.

Naheliegend ist eine möglichst frühe Operation, um diese kritische Zeitspanne zu begrenzen, da sich ein präoperativ schlechter klinischer Zustand und ein mangelndes Gedeihen prognostisch ungünstig auf das Auftreten perioperativer Komplikationen und somit auf das Outcome nach korrektiven Operationen auswirken (CHOUDHARY et al. 1999). Andererseits erhöht eine Operation bereits in jungem Alter ebenfalls das Risiko perioperativ auftretender Komplikationen sowie die perioperative Mortalität (NAJM et al. 1997). 
Angesichts dieser Problematik ist daher auf der einen Seite die Wahl des richtigen Operationszeitpunkts für die Kinder von prognostischer Bedeutung. Auf der anderen Seite spielt eine effiziente konservative, insbesondere medikamentöse Therapie eine entscheidende Rolle. Diese bedarf zu ihrer Optimierung immer wieder einer aktuellen Auseinandersetzung mit ihren pathophysiologischen Grundlagen.

\subsection{Einteilung und Häufigkeit angeborener Herzfehler}

Die angeborenen Herz- und Gefäßfehlbildungen können auf der Grundlage hämodynamischer Überlegungen in vier große Gruppen unterteilt werden: Neben den Obstruktionen im Bereich des Ein- und Ausflußtraktes des linken sowie des rechten Herzens (Links- bzw. Rechtsobstruktionen) werden septale Defekte und vaskuläre Fehlbildungen mit primärem LinksRechts-Shunt sowie Ursprungsanomalien der großen Arterien unterschieden (SCHUMACHER und SCHREIBER 2001).

Dabei spielen die septalen Defekte und vaskulären Fehlbildungen mit primärem LinksRechts-Shunt, die in dieser Arbeit untersucht wurden, zahlenmäßig die größte Rolle. Diese Fehlbildungen allein machen etwa die Hälfte aller angeborenen Herzgefäßfehlbildungen aus (HOFFMAN 1995; SCHUMACHER und SCHREIBER 2001).

Je nach Literaturquelle divergieren die prozentualen Häufigkeiten der einzelnen Herzvitien zum Teil deutlich. Die im Folgenden angegebenen Häufigkeiten für die Vitien mit primärem Links-Rechts-Shunt beziehen sich auf die Veröffentlichungen von SAMANEK et al. (1989) und HOFFMAN (1995). Letzterer wertet dabei in seiner Arbeit über 20 internationale Studien der letzten Jahrzehnte aus und gibt als relative Häufigkeiten der einzelnen Herzfehler den jeweiligen Median an.

Ventrikelseptumdefekte treten hiernach mit etwa $31 \%$ aller angeborenen Herzgefäßfehlbildungen am häufigsten auf, gefolgt von Vorhofseptumdefekten vom Sekundumtyp mit etwa 7,5-11,4 \%. Ein persistierender Ductus arteriosus findet sich in etwa 4,8-7,1 \% aller angeborenen Herzgefäßfehlbildungen. Partielle und komplette atrioventrikuläre Septumdefekte treten mit einer Häufigkeit von zusammen etwa 4,4 \% auf. Totale Lungenvenenfehlkonnektionen und ein Truncus arteriosus communis liegen bei jeweils etwa 1,4 \% der Kinder mit angeborenen Herzfehlern vor, ein aortopulmonaler Septumdefekt bei $<1 \%$. Hinzu kommen die septalen Defekte mit Links-Rechts-Shunt im Rahmen komplexer Herzvitien. 


\subsection{Definition der Herzinsuffizienz und Klassifikationen zur Beurteilung ihres Schweregrades}

\subsubsection{Allgemeine Definition}

Pathophysiologisch wird die Herzinsuffizienz laut Weltgesundheitsorganisation (WHO) allgemein als ein Unvermögen des Herzens definiert, das zum Erreichen einer ausreichenden Sauerstoffversorgung des Körpers notwendige Herzzeitvolumen in Ruhe und unter Belastung zu fördern. Klinisch besteht dann eine Herzinsuffizienz, wenn typische Symptome wie Dyspnoe, Müdigkeit und Flüssigkeitsretention vorhanden sind, die durch eine kardiale Funktionsstörung verursacht sind (WHO 1995; HOPPE et al. 2005).

Die aktuellen Leitlinien des American College of Cardiology und der American Heart Association für Erwachsene konkretisieren diese Definition, indem sie die chronische Herzinsuffizienz als ein komplexes klinisches Syndrom beschreiben, das aus jeglicher strukturellen oder funktionellen Störung des Herzens resultieren kann, die das Vermögen des Ventrikels, sich zu füllen bzw. Blut auszuwerfen, herabsetzt (HUNT et al. 2009). Herzinsuffizienz wird hiernach als eine chronische Erkrankung betrachtet, die nach einem initialen schädigenden Ereignis durch myokardiale Umbauvorgänge (sogenanntes Remodeling) fortschreitet.

Während die Ursache der chronischen Herzinsuffizienz bei Erwachsenen primär eine myokardiale Insuffizienz und damit eine Pumpschwäche ist, liegt bei Kindern überwiegend eine pathologische Kreislaufsituation als Folge eines angeborenen Herzfehlers vor. Nur bei einem kleinen Teil der Kinder findet sich primär eine myokardiale Grunderkrankung, z. B. eine Kardiomyopathie oder eine Myokarditis.

\subsubsection{Klassifikationen}

Zur Beurteilung des Schweregrades der Herzinsuffizienz hat sich bei Erwachsenen international die New York Heart Association (NYHA)-Klassifikation durchgesetzt, die die Patienten entsprechend ihrer körperlichen Belastbarkeit in vier Gruppen einteilt (THE CRITERIA COMMITTEE OF THE NEW YORK HEART ASSOCIATION 1964). Als ein Schwachpunkt dieser Klassifikation wurde die mangelnde Objektivität kritisiert. In spätere Fassungen sind deshalb präzisierende Kriterien, wie zum Beispiel Rhythmusstörungen, Luftnot oder Angina pectoris, mit in die Bewertung aufgenommen (HOPPE et al. 2005).

Ergänzend kann auch eine Einteilung der Herzinsuffizienz nach einer neueren Klassifikation des American College of Cardiology und der American Heart Association (HUNT et al. 2009) erfolgen, die neben den symptomatischen auch asymptomatische Patienten erfaßt und so vermehrt die Entstehung und die Progredienz der Erkrankung mit einbezieht. Diese Klassifikati- 
on wurde inzwischen auch in die Leitlinien der Deutschen Gesellschaft für Kardiologie aufgenommen (HOPPE et al. 2005).

\subsubsection{Spezielle Klassifikationen für Kinder}

Die Anwendung der genannten Klassifikationen gestaltet sich bei Kleinkindern und Säuglingen zum Teil als schwierig, da die angewandten Kriterien, wie z. B. eine belastungsabhängige Ermüdbarkeit, Palpitationen oder eine Angina pectoris, auf ältere Patienten abgestimmt und bei Säuglingen und Kleinkindern häufig nicht zuverlässig zu beurteilen sind (ROSS et al. 1992). Deshalb wurden in Studien spezielle Scores für Säuglinge entwickelt, die Kriterien wie zum Beispiel die Trinkmenge und Zeitdauer einer Mahlzeit, Atem- und Herzfrequenz, periphere Durchblutung, zusätzliche Herzgeräusche und die Lebergröße (ROSS et al. 1992) bzw. die Gewichtsentwicklung pro Monat, den Diuretikabedarf und eine vermehrte Schwitzneigung berücksichtigen (BUCHHORN et al. 1998; BUCHHORN et al. 2000b). Für das Kindesund Jugendalter wurde die NYHA-Klassifikation entsprechend angepaßt (BUCHHORN 2006).

\subsection{Tachypnoe bei Kindern mit angeborenem Herzfehler}

Eine „oberflächliche und frequente Atmung“, eine „Dyspnoe“ und „Orthopnoe“ wurden schon in den 40er Jahren des letzten Jahrhunderts in den Lehrbüchern der Pädiatrie als Ausdruck einer Herzkreislaufinsuffizienz bei Kindern beschrieben (LUST und VON PFAUNDLER 1947). Bis heute bestätigt sich diese Bedeutung der Tachypnoe als charakteristisches klinisches Symptom der Herzinsuffizienz bei Säuglingen mit angeborenem Herzfehler (ROSS et al. 1992). Tachypnoe ist allgemein definiert als ein beschleunigtes Atmen. Sie ist zum Teil assoziiert mit einer erschwerten Atemtätigkeit und dem Gefühl der Luftnot. Der Begriff bezeichnet kein eigenständiges Krankheitsbild, sondern eine Symptomatik, die bei unterschiedlichen Erkrankungen auftreten kann. Zu den Ursachen der Tachypnoe werden allgemein ein erhöhter arterieller Kohlendioxidpartialdruck (Hyperkapnie) und ein erniedrigter Sauerstoffpartialdruck (Hypoxie) gezählt (GROSSMANN 2011). Je nach Alter eines Menschen werden verschiedene Atemfrequenzen als normal angesehen. Für Kinder im ersten Lebensjahr gelten laut den gängigen pädiatrischen Lehrbüchern Frequenzen von 25 bis 40 Atemzügen pro Minute als normwertig (BAUMANN 2002), darüber liegende Frequenzen als erhöht.

Die Atemfrequenz eines Menschen läßt sich mit wenig technischem Aufwand valide bestimmen und ist im klinischen Alltag als häufig dokumentierter Parameter retrospektiv gut erfassbar. Sie hat sich als wichtiger Parameter zur Beurteilung der Schwere der Herzinsuffizienz bei Säuglingen bewährt (ROSS et al. 1992; BUCHHORN et al. 1998; BUCHHORN et al. 2000b) 
und wurde in der vorliegenden Arbeit als besonders geeigneter Parameter zur Untersuchung der Pathogenese der Herzinsuffizienz bei Säuglingen mit Links-Rechts-Shunt herangezogen.

\subsection{Gedeihstörung bei Kindern mit angeborenem Herzfehler}

Säuglinge mit angeborenem Herzfehler fallen im Verlauf ihrer Erkrankung häufig durch eine verminderte Gewichtszunahme, reduziertes Längenwachstum und einen konsekutiven Perzentilenabfall auf (SALZER et al. 1989; KIMBALL et al. 1991). Dieses unzureichende Gedeihen wird wie die Tachypnoe als eines der typischen klinischen Symptome der Herzinsuffizienz bei Säuglingen mit angeborenem Herzfehler, wie zum Beispiel auch Links-RechtsShunt-Vitien, angesehen (MITCHELL et al. 1995).

Als Gedeihstörung bezeichnet man allgemein eine Verzögerung der somatischen und im Verlauf häufig damit verbunden auch der motorischen und psychosozialen Entwicklung bei Kindern. Der Begriff beschreibt ebenfalls kein eigenständiges Krankheitsbild, sondern eine Symptomatik, der unterschiedliche Krankheiten zugrunde liegen. Entscheidende Ursachen können eine unzureichende Nahrungsaufnahme, eine mangelnde Resorption von Nährstoffen sowie ein erhöhter Energieumsatz sein (NÜTZENADEL und ZIMMER 2007). Als normale Gewichtszunahme für Säuglinge gelten entsprechend den aktualisierten Referenzkurven der WHO für das kindliche Wachstum altersabhängig Werte zwischen 190 und 300 Gramm pro Woche im zweiten Lebensmonat, 90 und 125 Gramm pro Woche im sechsten und 50 bis 75 Gramm pro Woche im zwölften Lebensmonat (WHO MULTICENTRE GROWTH REFERENCE STUDY GROUP 2006).

Wie bei Säuglingen konnte auch bei Erwachsenen mit chronischer Herzinsuffizienz gezeigt werden, daß bis zu 50 \% der Patienten Zeichen einer Mangelernährung aufweisen (CARR et al. 1989). Diese wird in der Literatur häufig als „kardiale Kachexie“ (cardiac cachexia) bezeichnet (ANKER et al. 1999). Analog hierzu wird die Gedeihstörung bei Säuglingen und Kindern mit angeborenen Herzfehlern auch als „kardiale Dystrophie“ bezeichnet (BUCHHORN 2002).

Das Auftreten einer Gedeihstörung bzw. kardialen Kachexie hat große Bedeutung für die Prognose der Patienten: Herzinsuffiziente Erwachsene mit kardialer Kachexie wiesen in verschiedenen Studien wesentlich geringere Überlebensraten als nicht-kachektische Patienten auf (50 \% Mortalität innerhalb von 18 Monaten) (ANKER et al. 1997a), auch das Auftreten postoperativer Komplikationen war erhöht (POTAPOV et al. 2003). Auch bei Kindern mit angeborenen Herzfehlern korrelierte das Vorliegen einer Gedeihstörung signifikant mit der perioperativen Mortalität und der Prognose (CHOUDHARY et al. 1999). 
Als typisches klinisches Symptom und wichtiger prognostischer Parameter wird die kardiale Gedeihstörung bei Säuglingen in Scores zur Beurteilung der Schwere der Herzinsuffizienz eingesetzt (ROSS et al. 1992; BUCHHORN et al. 1998; BUCHHORN et al. 2000b). In der vorliegenden Studie wurde sie als zweiter Untersuchungsparameter verwendet.

\subsection{Pathophysiologische Modelle zur Entstehung der Herzinsuffizienz bei Kindern und Erwachsenen}

Die häufigste Ursache einer chronischen Herzinsuffizienz bei Erwachsenen ist in den westlichen Ländern eine myokardiale Insuffizienz auf dem Boden einer koronaren Herzerkrankung, oft einher gehend mit einer arteriellen Hypertonie (Mc MURRAY und STEWART 2000). Im Gegensatz dazu liegt der kindlichen Symptomatik überwiegend ein angeborener Herzfehler mit struktureller Anomalie des Herzaufbaus und damit einer veränderten Kreislaufsituation zu Grunde. Angesichts der Ähnlichkeit der klinischen Symptome bei Kindern und Erwachsenen und der so unterschiedlichen auslösenden Grunderkrankungen stellt sich die Frage, welche pathophysiologischen Mechanismen zur Entstehung der Herzinsuffizienzsymptomatik führen. Traditionelle und aktuelle Vorstellungen hierzu sollen im Folgenden erläutert werden, wobei besonders auf den sich während der letzten Jahrzehnte bei herzinsuffizienten Kindern und Erwachsenen vollzogenen Wandel der pathophysiologischen Vorstellungen eingegangen wird.

\subsubsection{Traditionelle Erklärungsversuche bei Kindern mit Links-Rechts-Shunt-Vitien}

Die Ursache der Herzinsuffizienzsymptomatik bei Kindern mit angeborenen Herzfehlern wurde lange Zeit im Bereich der hämodynamischen Veränderungen von Fluß-, Druck- und Widerstandsparametern gesucht. Als weitere Aspekte wurden eine verminderte Kontraktilität des Myokards sowie eine inadäquate Sauerstoffversorgung des Gewebes als Ursachen diskutiert (KIMBALL et al. 1991; GIDDING und BESSEL 1993). Therapeutisch stand eine Verbesserung der einzelnen hämodynamischen Parameter im Vordergrund.

Bei Kindern mit Links-Rechts-Shunt-Vitium besteht eine pathologische Kreislaufsituation mit einer Volumenbelastung des Herzens und einem Ungleichgewicht zwischen Lungen- und Körperperfusion, nämlich einer Lungenüberflutung einerseits und einer Minderdurchblutung des Körperkreislaufs andererseits (WESSEL et al. 2000).

Bereits Ende des 19. Jahrhunderts hatte VON BASCH (1887) einen „gestörte[n] Gaswechsel bei der Ueberfüllung der Lunge mit Blut“ beschrieben. Er hatte vermutet, daß „unter abnormen Kreislaufsverhältnissen, welche eine Ueberfüllung der Lungencapillaren bedingen, die 
Starrheit der Lungenalveolen wächst, und dass hiermit die Ausdehnbarkeit, also die Athmungsfähigkeit der Lunge abnimmt“ (VON BASCH 1887, S. 465-467).

In Anlehnung hieran wurde in späteren Arbeiten postuliert, daß bei Patienten mit LinksRechts-Shunt primär eine gestörte Lungenmechanik, zum Beispiel die häufig beobachtete verminderte Lungencompliance, zu einer erhöhten Atemarbeit führe und damit zu den respiratorischen Symptomen beitrage (GAZETOPOULOS und DAVIES 1966). Als Ursache der verminderten Lungencompliance wurden unter anderem der erhöhte pulmonale Blutfluß, ein erhöhter pulmonalarterieller Druck oder eine Kombination aus beiden diskutiert (HOWLETT 1972; BANCALARI et al. 1977; YAU et al. 1996).

Auch in späteren Untersuchungen wurden der Lungenüberflutung und der im Verlauf entstehenden pulmonalen Widerstandserhöhung als Folge des Links-Rechts-Shunts eine bedeutende Rolle bei der Entstehung der Herzinsuffizienzsymptomatik bei Kindern eingeräumt. So vermuteten LEVY et al. (1978) einen kausalen Zusammenhang zwischen den erhöhten pulmonalarteriellen Drücken bzw. der Höhe des Links-Rechts-Shunts der untersuchten Kinder und dem Auftreten einer Gedeihstörung. Bei KIMBALL et al. (1991) erwies sich die Größe eines Ventrikelseptumdefekts als stärkster Prädiktor für das Auftreten von Tachypnoe und Gedeihstörung bei Säuglingen und Kleinkindern mit Ventrikelseptumdefekt.

Verbreitet war daneben auch die Vorstellung, eine eingeschränkte Kontraktilität sei wie bei Erwachsenen auch bei Kindern primär Ursache der Herzinsuffizienzsymptomatik. KIMBALL et al. (1991) widerlegten dies durch den Nachweis normaler Kontraktilitätsparameter bei den von ihnen untersuchten Säuglingen und Kleinkindern mit Ventrikelseptumdefekt. Sie bestätigten damit frühere Ergebnisse WAGGONERs et al. (1985), die unbeeinträchtigte Ventrikelfunktionen bei Säuglingen und älteren Kindern mit Ventrikelseptumdefekt und klinischer Herzinsuffizienz beobachtetet hatten. BUCHHORN et al. (2001b) zeigten entsprechende Ergebnisse für Säuglinge mit verschiedenen Links-Rechts-Shunt-Vitien.

Ein weiterer Ansatz stellte die periphere Sauerstoffversorgung in den Vordergrund der Überlegungen: GIDDING und BESSEL (1993) postulierten, daß bei Kleinkindern mit Ventrikelseptumdefekt ein peripherer Sauerstoffmangel, verursacht durch den erniedrigten systemischen Blutfluß infolge des Links-Rechts-Shunts, eine bedeutendere Rolle für das Auftreten der Symptomatik spiele als die klassischen hämodynamischen Parameter des Links-RechtsShunts. Die Arbeitsgruppe um BERMAN et al. (1987) hatte zuvor bereits die physiologischen Anpassungsmechanismen an einen veränderten Sauerstofftransport bei Säuglingen und Kindern mit angeborenen Herzfehlern untersucht. Bei Patienten mit vermindertem systemischen 
Herzzeitvolumen konnte die periphere Sauerstoffaufnahme zunächst innerhalb eines gewissen Spektrums durch Veränderungen der Herzfrequenz, der arteriovenösen Sauerstoffausschöpfung und zum Beispiel der Sauerstoffbindungskurve aufrechterhalten werden, bevor es zu einem Abfall kam.

Studien zum Gedeihen herzkranker Kinder diskutierten insbesondere eine unzureichende Energiezufuhr, einen erhöhten Energieumsatz, gastrointestinale Resorptionsstörungen durch einen reduzierten peripheren Blutfluß sowie rezidivierende respiratorische Infekte im $\mathrm{Zu}$ sammenhang mit der Herzinsuffizienz als Ursache der Gedeihstörung (MENON und POSKITT 1985; SALZER et al. 1989; FORCHIELLI et al. 1994).

Diese hämodynamisch geprägten Vorstellungen zur Entstehung der klinischen Herzinsuffizienz bei Kindern mit angeborenen Herzfehlern und Links-Rechts-Shunt bestimmten bis in die 1990er Jahre hinein die medikamentöse Therapie der Patienten. Mit dem therapeutischen Ansatz einer Verbesserung der einzelnen hämodynamischen Parameter wurden Medikamente wie Schleifendiuretika, Digitalisglykoside und später auch Aldosteronantagonisten eingesetzt. Prospektiv-randomisierte Studien zur Überprüfung dieser Therapien bei Kindern fehlten.

\subsubsection{Pathophysiologische Modelle zur Entstehung der Herzinsuffizienz im Erwachsenenalter nach PACKER (1993)}

Einen Überblick über die Entwicklungen der letzten 70 Jahre gibt PACKER (1993) in einem differenzierten Review: Er beschreibt anhand verschiedener Modelle das gewandelte pathophysiologische Verständnis für die Entstehung der Herzinsuffizienz und ihrer Symptome bei Erwachsenen im Laufe der letzten 70 Jahre, ausgehend von einem rein hämodynamischen Ansatz zu einem komplexeren Verständnis, welches neurohumorale Mechanismen mit berücksichtigt und das Zusammenspiel dieser und hämodynamischer Faktoren betont.

\subsubsection{Kardiorenales Herzinsuffizienzmodell}

In den 40-60er Jahren des 20. Jahrhunderts wurde die Herzinsuffizienz als eine Erkrankung angesehen, bei der es primär durch eine gestörte Funktion des Herzens zu Veränderungen der intravaskulären Volumina und Drücke und damit zu einer verminderten Nierenperfusion mit Wasser- und Salzretention kam (PACKER 1993). Diese führte entsprechend der Theorie zur klinischen Manifestation der Erkrankung, als deren Hauptsymptome periphere und pulmonale Ödeme galten. Die Herzinsuffizienz wurde als akutes Geschehen betrachtet, das behoben war, wenn die Ödeme behandelt waren. Digitalis und später vor allem Diuretika fanden entsprechend breite therapeutische Anwendung. 


\subsubsection{Kardiozirkulatorisches Herzinsuffizienzmodell}

In den 60er, 70er und 80er Jahren des 20. Jahrhunderts setzte sich die Vorstellung durch, daß die Herzinsuffizienz eine chronische Erkrankung sei, die auch nach erfolgreicher Therapie der Ödeme zu persistierenden hämodynamischen Veränderungen und klinischen Einschränkungen im Alltag führe (PACKER 1993).

Dies veränderte den Blickwinkel auf die Erkrankung: Die Herzinsuffizienz wurde nicht mehr als eine Erkrankung aufgefaßt, bei der allein die Funktion des Herzens beeinträchtigt ist. Der Fokus des neuen Modells lag jetzt auf dem als gestört erachteten Zusammenspiel zwischen Herz und peripherer Zirkulation. Insbesondere einer Vasokonstriktion peripherer Arterien und Venen wurde eine zentrale Rolle zugesprochen. Diese Vasokonstriktion sowie eine Abnahme der kardialen Auswurfleistung führten entsprechend der Theorie zu einem verminderten Blutfluß zu den peripheren Organen, so u.a. der Nieren und der Skelettmuskulatur, und damit zu klinischen Symptomen wie peripheren und pulmonalen Ödemen und Belastungsintoleranz. Als therapeutische Konsequenz wurden jetzt verstärkt peripher vasodilatatorisch wirkende Medikamente sowie positiv inotrope Substanzen eingesetzt.

Während sich unter diesem Therapieregime in prospektiv-randomisierten Studien zwar eine Verbesserung der hämodynamischen Veränderungen zeigte, blieb die erwartete klinische Besserung bei den Patienten aus. Es zeigte sich vielmehr ein Anstieg der Morbidität und Mortalität (FRANCIOSA et al. 1984; ELKAYAM et al. 1990).

\subsubsection{Neurohumorales Herzinsuffizienzmodell}

Bereits Anfang der 1960er Jahre waren bei herzinsuffizienten Erwachsenen erstmals erhöhte Noradrenalinspiegel im Blut beobachtet worden (CHIDSEY et al. 1962). Angesichts zunehmender Zweifel an der alleinigen Gültigkeit des kardiorenalen und kardiozirkulatorischen Herzinsuffizienzmodells und basierend auf der wiederholten Beobachtung erhöhter Katecholamin-, sowie auch Renin- und Aldosteronspiegel bei symptomatischer Herzinsuffizienz (ANAND et al. 1989), erfolgte in den späten 1980er und 1990er Jahren ein erneuter Paradigmenwechsel:

Die Herzinsuffizienz wird seitdem als eine progrediente und lebensbedrohliche Erkrankung angesehen, die nicht allein durch hämodynamische Veränderungen verursacht wird, sondern bei der es nach einer initialen Schädigung des Myokards zu einer gesteigerten Aktivierung endogener neurohumoraler Systeme, wie zum Beispiel des Renin-Angiotensin-AldosteronSystems und des sympathischen Nervensystems, kommt. Diese neurohumorale Aktivierung tritt zunächst als sinnvoller Kompensationsversuch des Organismus auf, um die reduzierte kardiale Pumpleistung auszugleichen. Sie trägt jedoch über eine systemische Vasokonstrikti- 
on und Salz- und Wasserretention zu einer Manifestation der Symptomatik bei und führt bei anhaltender Stimulierung auch unabhängig von ihren hämodynamischen Effekten direkt zu einer progredienten Schädigung der myokardialen Zellen und damit zu einem Fortschreiten der Erkrankung durch myokardiale Umbauvorgänge (sogenanntes Remodeling) (PACKER 1993). Bereits früh wurde Noradrenalin so als unabhängiger Risikofaktor für Mortalität und Prognose bei Erwachsenen mit chronischer Herzinsuffizienz erkannt (COHN et al. 1984).

Therapeutisch werden jetzt Medikamente wie ACE (angiotensin-converting-enzyme)Hemmer, Aldosteronantagonisten und Beta-Rezeptorenblocker im Sinne einer neurohumoralen Blockade eingesetzt. Diese bewiesen in prospektiv-randomisierten Studien einen positiven Einfluß auf die Morbidität und Mortalität der Patienten und unterstützen so das neurohumorale Herzinsuffizienzmodell (SWEDBERG et al.1990; TJEERDSMA et al. 2001). Auch eine Meta-Analyse klinischer Studien bestätigte die positive Wirkung der Beta-Rezeptorenblocker auf die Mortalität und Morbidität bei Erwachsenen mit stabiler chronischer Herzinsuffizienz (BROPHY et al. 2001).

PACKER faßt zusammen: „Herzinsuffizienz ist [demnach] nicht nur eine hämodynamische Störung und ihre physiologischen Abnormalitäten lassen sich nicht allein durch die Messung von Parametern wie Druck, Volumen und Fluß feststellen. Neurohumorale Systeme lenken die Funktionen des Herzens und des Kreislaufs sowohl bei Gesunden als auch bei Kranken. Das Vermögen des kardiovaskulären Systems, sich an Störungen anzupassen und Streß zu tolerieren, wird bestimmt durch die Freisetzung lokaler und systemischer neurohumoraler Signale und ihrer Wechselwirkungen sowie durch Veränderungen in der Aktivierung und Effektivität ihrer intrazellulären Botenstoffe. Es ist das Wechselspiel dieser neurohumoralen und hämodynamischen Kräfte, die das Syndrom der Herzinsuffizienz definieren.“ (PACKER 1992, S. 253, eigene Übersetzung).

„The central message of the neurohormonal hypothesis is that heart failure is not simply a hemodynamic disorder and its physiologic abnormalities cannot be simply assessed by the measurement of pressure, volume and flow. Neurohormonal systems govern the functions of the heart and circulation in both health and disease. The ability of the cardiovascular system to adapt to injury and tolerate stress is determined by the release and interaction of local and systemic neurohormonal signals and by changes in the activation and effectiveness of their intracellular messengers. It is the interplay of these neurohormonal and hemodynamic forces that defines the syndrome of heart failure. " (PACKER 1992, S. 253). 


\subsection{Ausblick: Immunaktivierung und weitere neurohumorale Mechanismen}

Im Rahmen des neurohumoralen Herzinsuffizienzmodells wird auch die Bedeutung einer erhöhten Ausschüttung weiterer körpereigener Substanzen bei herzinsuffizienten Erwachsenen diskutiert, wie zum Beispiel der Zytokine, des Stickstoffmonoxids, Endothelins und Vasopressins, sowie auch des BNPs bzw. NT-proBNPs (brain natriuretic peptide bzw. N-terminal pro-brain natriuretic peptide) (Mc MURRAY et al. 1992; PACKER 1995; MIDDLEKAUFF und MARK 1998; CARDARELLI und LUMICAO 2003; MAYER et al. 2005). So wurden erhöhte Zytokinspiegel als Ausdruck einer generellen Immunaktivierung bei herzinsuffizienten Erwachsenen beschrieben. Insbesondere den erhöhten Tumor-Nekrose-FaktorAlpha ( $T N F \alpha)$-Spiegeln wird dabei eine wichtige Rolle bei der Entstehung der Herzinsuffizienz und speziell der kardialen Kachexie zugesprochen (ZHAO und ZENG 1997; ANKER und COATS 1999). Erhöhte Spiegel der löslichen TNF-Rezeptoren korrelieren mit der Schwere der Erkrankung und ihrer Mortalität (PACKER 1995; NOZAKI et al. 1997). Wechselwirkungen zwischen Zytokinen und sympathischer Aktivierung sind auch therapeutisch von Interesse. LOPPNOW et al. (2002) beschrieben einen Abfall zuvor erhöhter TNF-Rezeptor-Spiegel unter einer Therapie mit Beta-Rezeptorenblockern parallel zu einer klinischen Besserung der Patienten.

In den letzten Jahren sind zudem das kardiale Peptid BNP bzw. sein aminoterminales ProPeptid NT-proBNP in das Zentrum des Interesses gerückt: Die Bedeutung dieser unter anderem diuretisch, natriuretisch und vasodilatatorisch wirkenden Peptide als Marker für eine linksventrikuläre Dysfunktion bei chronisch herzinsuffizienten Erwachsenen wurde bestätigt, insbesondere hinsichtlich der Diagnosestellung, Prognoseeinschätzung und Therapieoptimierung (CARDARELLI und LUMICAO 2003; NOZOHOOR et al. 2011).

\subsection{Anwendbarkeit des neurohumoralen Herzinsuffizienzmodells der Erwachsenen auf Kinder mit angeborenem Herzfehler}

Analog zu den Beobachtungen bei Erwachsenen wurden auch bei Kindern mit angeborenen Herzfehlern und Herzinsuffizienz hohe Renin-, Noradrenalin- und Aldosteronwerte im Blut nachgewiesen (ROSS et al. 1987; BUCHHORN et al. 2001b). Dies führte zu der Vermutung, daß das neurohumorale Herzinsuffizienzmodell der Erwachsenen auch für Kinder gelten könnte (WU JR et al. 1996).

Entsprechend wurden Beta-Rezeptorenblocker in kleinen Fallstudien erstmals auch bei herzinsuffizienten Säuglingen und Kindern eingesetzt. So wurden im Universitätsklinikum Göttingen 1996 sechs schwer herzinsuffiziente Säuglinge mit großem Links-Rechts-Shunt zu- 
sätzlich zur Standardtherapie mit Beta-Rezeptorenblockern erfolgreich behandelt (BUCHHORN et al. 1998). Im Rahmen einer ersten prospektiv-randomisierten, klinischen Studie an zehn Säuglingen mit Links-Rechts-Shunt (CHF-PRO-INFANT) konnte die positive Wirkung einer zusätzlichen Therapie mit Beta-Rezeptorenblockern untermauert werden (BUCHHORN et al. 2001c). Die Ergebnisse unterstützten die Gültigkeit des neurohumoralen Herzinsuffizienzmodells auch für Kinder. Weitere kleine prospektive und retrospektive Fallstudien bei Säuglingen und Kindern mit ätiologisch differierender Herzinsuffizienz berichteten ebenfalls über positive Ergebnisse einer ergänzenden Betablocker-Therapie (SHADDY et al. 1999; BRUNS et al. 2001; LÄER et al. 2002; BUCHHORN et al. 2003; BLUME et al. 2006; BAJCETIC et al. 2008; NISHIYAMA et al. 2009). Die einzige größere, prospektiv-randomisierte, placebo-kontrollierte Multicenter-Studie an 161 Kindern und Jugendlichen mit chronischer Herzinsuffizienz infolge unterschiedlicher angeborener Herzfehler und Kardiomyopathien konnte jedoch keinen Vorteil einer zusätzlichen Betablocker-Therapie zeigen (SHADDY et al. 2007).

Im Gegensatz zum Erwachsenenalter, für das es zahlreiche große, prospektiv-randomisierte klinische Studien gibt, ist die Datenlage für das Säuglings- und Kindesalter somit recht dünn. Die vorhandenen Studien sind häufig retrospektiv, beruhen überwiegend auf kleinen Fallzahlen und weisen eine große Inhomogenität hinsichtlich der Patientencharakteristika (Alter, Ätiologie und Schweregrad der Herzinsuffizienz u.a.) sowie auch der Studienbedingungen auf (FILIPPO 2007; FROBEL et al. 2009). Die theoretischen Hintergründe einer BetablockerTherapie bei herzinsuffizienten Kindern werden deshalb nach wie vor überwiegend von Erkenntnissen an Erwachsenen abgeleitet (PICCHIO et al. 2008; BAUTISTA-HERNANDEZ et al. 2011).

Angesichts der beobachteten neurohumoralen Aktivierung auch bei Kindern und der klinischen Erfolge einer Betablocker-Therapie im Rahmen von Studien werden BetaRezeptorenblocker in den letzten Jahren jedoch zunehmend routinemäßig in der pädiatrischen Praxis eingesetzt. Die Betablocker-Therapie ist in die Leitlinie „Chronische Herzinsuffizienz im Kindesalter“ der Deutschen Gesellschaft für Kinder- und Jugendmedizin von 2006 aufgenommen worden (BUCHHORN 2006).

\subsection{Zielsetzung der Arbeit}

Angesichts der beschriebenen Datenlage sollte im Rahmen der vorliegenden Arbeit die Gültigkeit des neurohumoralen Herzinsuffizienzmodells für das Säuglingsalter am eigenen Patientengut überprüft werden. 
Es wurde die Hypothese aufgestellt, daß das ursprünglich für Erwachsene formulierte, neurohumorale Herzinsuffizienzmodell auch für Säuglinge mit angeborenem Herzfehler und LinksRechts-Shunt gilt.

Zur Überprüfung dieser Hypothese wurde die Beziehung zwischen klinischer Symptomatik einerseits und klassischen hämodynamischen Parametern bzw. der neurohumoralen Aktivierung andererseits am Beispiel der typischen klinischen Symptome Tachypnoe und Gedeihstörung bei 70 Säuglingen mit angeborenem Herzfehler und Links-Rechts-Shunt im Rahmen einer retrospektiven Analyse untersucht. 


\section{Patienten, Material und Methoden}

Zur Überprüfung der in Kapitel 1.9 formulierten Arbeitshypothese wurden die Daten von 70 Säuglingen mit angeborenem Herzfehler und Links-Rechts-Shunt, die zwischen Januar 1996 und Januar 2000 in der Abteilung für Pädiatrische Kardiologie des Universitätsklinikums Göttingen betreut wurden, hinsichtlich verschiedener klinischer, hämodynamischer und neurohumoraler Parameter mittels retrospektiver Analyse ausgewertet und in die Datenbank aufgenommen.

\subsection{Kriterien der Patientenauswahl}

In die Studie aufgenommen wurden diejenigen im ausgewählten Zeitraum im Universitätsklinikum Göttingen betreuten Säuglinge, die einen angeborenen, hämodynamisch bedeutsamen Herzfehler mit prädominierendem Links-Rechts-Shunt hatten und zum Zeitpunkt der Untersuchung jünger als zwölf Monate alt waren. Anatomische Ursache der Shunts waren atriale, ventrikuläre oder atrioventrikuläre Septumdefekte, persistierende Ductus arteriosi Botalli oder komplexere Herzfehler. Alle untersuchten Patienten waren für eine kardiale Operation während des Säuglings- oder jungen Kleinkindalters vorgesehen.

Patienten nach definitiven Korrekturoperationen wurden aus der Analyse ausgeschlossen. Dagegen wurden Säuglinge nach palliativen Eingriffen in der Auswertung berücksichtigt, sofern sie weiterhin einen Links-Rechts-Shunt aufwiesen. Dies war beispielsweise nach einem Banding der Pulmonalarterie, nach einer Ballon-Atrioseptostomie sowie bei Säuglingen mit zusätzlicher Aortenisthmusstenose und Zustand nach Resektion derselben der Fall. Einbezogen in die Auswertung wurden nur Säuglinge in stabilem Kreislaufzustand und mit stabil eingestellter Medikation. Kinder, die sich in intensivmedizinischer Behandlung befanden und einer mechanischen Beatmung und/oder einer intravenösen, positiv inotropen Medikation bedurften, wurden ausgeschlossen, ebenso wie Patienten mit Kardiomyopathien.

Alle Säuglinge wurden enteral mit Muttermilch oder altersadaptierter Säuglingsnahrung ernährt. Kinder mit zusätzlicher angeborener Fehlbildung des Gastrointestinaltraktes, wie z. B. einer Duodenalstenose, wurden nur nach erfolgreich abgeschlossener operativer Korrektur in der Auswertung berücksichtigt.

\subsection{Untersuchungszeitpunkt}

Die Datenerhebung erfolgte zum Zeitpunkt der präoperativen Herzkatheteruntersuchung innerhalb eines Intervalls von zwei bis sechs Wochen während eines stationären Aufenthalts. Die Herzkatheteruntersuchungen wurden bei Patienten mit Links-Rechts-Shunt und modera- 
ten Zeichen der Herzinsuffizienz routinemäßig im Alter von circa sechs Monaten durchgeführt. Dabei wurden unter anderem die studienrelevanten hämodynamischen Parameter bestimmt. Bei ausgeprägter klinischer Symptomatik trotz medikamentöser Therapie erfolgten Untersuchung und Operation zu einem früheren Zeitpunkt.

Die Blutentnahme für die Hormonbestimmung fand in einem engen zeitlichen Zusammenhang mit der Herzkatheteruntersuchung statt (meist am gleichen Tag, maximal \pm 6 Wochen). Zu diesem Zeitpunkt wurden auch die klinischen Parameter erhoben. Die Daten von sieben Säuglingen wurden aus der multiplen Regressionsanalyse ausgeschlossen, da bei ihnen Herzkatheteruntersuchung und Blutentnahme mehr als sechs Wochen auseinander lagen.

\subsection{Erhebung der Untersuchungsparameter}

\subsubsection{Klinische Parameter}

\subsubsection{Herz- und Atemfrequenzen}

Die Herz- und Atemfrequenzen wurden während des stationären Aufenthalts routinemäßig durch das Pflegepersonal bestimmt: Beim ruhigen Säugling wurden dazu dreimal täglich die Herzaktionen und Atemexkursionen über mindestens eine Minute gezählt. Die so bestimmten Herzfrequenzen wurden über einen repräsentativen Zeitraum (in der Regel Blutentnahme \pm vier Tage) gemittelt, um Verfälschungen der Ergebnisse durch kurzfristige physiologische Schwankungen zu vermeiden. Entsprechend wurde für jeden Patienten das mittlere Atemfrequenzniveau über eine Woche bestimmt.

Als Normwerte der mittleren Herzfrequenzen wurden die Ergebnisse einer bereits veröffentlichten Untersuchung an 210 gesunden Säuglingen und Kindern herangezogen, deren Rohdaten uns freundlicherweise zur Verfügung gestellt worden waren (MASSIN und VON BERNUTH 1997). Als normale Atemfrequenzen für Kinder im ersten Lebensjahr gelten laut den gängigen pädiatrischen Lehrbüchern Frequenzen von 25 bis 40 Atemzügen pro Minute (BAUMANN 2002). Als erhöht wurden in dieser Arbeit Atemfrequenzen von mehr als 50 pro Minute angesehen. Zur weiteren graduellen Einteilung einer Tachypnoe wurden die im Herzinsuffizienz-Score von ROSS et al. (1992) veröffentlichten Intervalle benutzt (Tabelle 2.1).

\subsubsection{Gewichtsentwicklung und Kalorienzufuhr}

Alle Säuglinge wurden während des stationären Aufenthalts täglich gewogen. Aus diesen Werten wurde die Gewichtsentwicklung der Kinder über einen Zeitraum von zwei bis sechs Wochen zeitgleich zu Hormonbestimmung und Herzkatheteruntersuchung berechnet. Alternativ wurden ambulante Gewichtsbestimmungen aus der Poliklinik herangezogen. Kurzfristi- 
ge Gewichtsschwankungen wurden durch die Wahl des langen Erhebungszeitraumes ausgeglichen. Das Geburtsgewicht der Säuglinge wurde den Krankenakten entnommen.

Als normale Gewichtszunahme für Säuglinge gelten entsprechend den aktualisierten Referenzkurven der WHO für das kindliche Wachstum, wie schon auf Seite 5 erwähnt, altersabhängig Werte zwischen 190 und 300 Gramm pro Woche im zweiten Lebensmonat, 90 und 125 Gramm pro Woche im sechsten und 50 bis 75 Gramm pro Woche im zwölften Lebensmonat (WHO MULTICENTRE GROWTH REFERENCE STUDY GROUP 2006). Als verminderte Gewichtszunahme wurden in dieser Arbeit Werte von weniger als 400 Gramm pro Monat angenommen.

Zur weiteren Einordnung des Gedeihens wurden Gewichtsintervalle in Anlehnung an den Herzinsuffizienz-Score von BUCHHORN et al. (1998) gewählt (Tabelle 2.2). Als Referenzwerte für das aktuelle Körpergewicht und das Geburtsgewicht wurden die in der Kinderklinik zur Zeit der Datenerhebung verwendeten Perzentilenkurven der Firma milupa (milupa MEDICAL SERVICE, Milupa AG, Friedrichsdorf/Taunus, Deutschland) für gesunde, gleichaltrige Säuglinge verwendet (BRANDT 1979).

Die tägliche Kalorienzufuhr der Säuglinge wurde aus den Nahrungsdokumentationen in der Pflegeakte und den anamnestischen Angaben der Eltern berechnet. Dabei wurden die unterschiedlichen Nährwerte von Muttermilch und verschiedenen Säuglingsnahrungen berücksichtigt. Als durchschnittlicher Nährwert für Muttermilch wurden 70 Kilokalorien pro 100 Milliliter Milch angenommen (SCHMIDT 1997). Die Nährwerte der Säuglingsnahrungen wurden den Herstellerangaben auf den Verpackungen entnommen. Schlecht gedeihende Säuglinge erhielten zum Teil kaloriensteigernde Nahrungszusätze (z. B. Maltodextrin), die in den Berechnungen berücksichtigt wurden. Mögliche Fehlerquellen, wie beispielsweise ein Erbrechen der Nahrung, wurden dokumentiert, ebenso das Vorhandensein einer nasogastralen Sonde. Als Richtwerte für den Kalorienbedarf wurden die Leitlinien der Weltgesundheitsorganisation (WHO) (FLEISCHER MICHAELSEN et al. 2003) sowie die D-A-CH-Referenzwerte (DEUTSCHE GESELLSCHAFT FÜR ERNÄHRUNG et al. 2008) für gleichaltrige, gesunde Säuglinge verwendet.

\subsubsection{Schwitzen und Medikation}

Als weiteres Symptom der Herzinsuffizienz wurde ein vermehrtes Schwitzen der Säuglinge erfaßt. Dabei wurde unterschieden, ob das Schwitzen lediglich bei Belastung, wie z. B. beim Füttern und Schreien, bereits in Ruhe oder gar nicht auftrat.

Die in den Patientenakten dokumentierten Medikamentendosierungen wurden auf das aktuelle 
Körpergewicht des jeweiligen Säuglings bezogen und in Milligramm pro Kilogramm Körpergewicht pro Tag [mg/kg KG/d] bzw. im Falle des $\beta$-Methyldigoxins als Plasmaspiegel in Nanomol pro Liter [nmol/l] angegeben.

\subsubsection{Hämodynamische Parameter}

Die relevanten hämodynamischen Parameter wurden im Rahmen der präoperativen Herzkatheteruntersuchung erhoben, die in Lokalanästhesie und Sedierung mit gering dosiertem Midazolam (0,1-0,5 mg/kg KG i. v.) durchgeführt wurde.

\subsubsection{Berechnung des Herzzeitvolumens nach dem Fickschen Prinzip}

Die Herzzeitvolumina (HZV) im pulmonalen und im systemischen Kreislauf ( $\mathrm{Q}_{\mathrm{p}}$ bzw. $\mathrm{Q}_{\mathrm{s}}$ ) wurden nach dem Fickschen Prinzip als die Quotienten aus der jeweiligen Sauerstoffaufnahme $\left(\mathrm{VO}_{2}\right)$ und der arteriovenösen Differenz des Sauerstoffgehaltes $\left(\mathrm{AVDO}_{2}\right)$ berechnet (PARK 1999; SCHUMACHER 2001):

$\begin{array}{ll}\text { (1) } \mathrm{HZV} & =\frac{\text { Sauerstoffaufnahme }\left(\mathrm{VO}_{2}\right)[\mathrm{ml} / \mathrm{min}]}{\mathrm{AVDO}_{2}[\mathrm{ml} / 100 \mathrm{ml}] \times 10} \\ & \\ \mathrm{HZV} & \text { - Herzzeitvolumen }[1 / \mathrm{min}] \\ \mathrm{VO}_{2} & \text { - Sauerstoffaufnahme }[\mathrm{ml} / \mathrm{min}] \\ \mathrm{AVDO}_{2} & \text { - Arteriovenöse Differenz des Sauerstoffgehaltes }[\mathrm{ml} / 100 \mathrm{ml}] \\ \text { Ficksches Prinzip } & \text { - Nach Adolf E. Fick, Physiologe, Zürich, Würzburg, } 1829-1901\end{array}$

Seit 1998 wird die Sauerstoffaufnahme $\left(\mathrm{VO}_{2}\right)$ im Herzkatheterlabor der Abteilung für Pädiatrische Kardiologie Göttingen während der Herzkatheteruntersuchung direkt gemessen (Deltatrac $^{\text {TM }}$ II, HOYER Medizintechnik, Bremen, Deutschland). Bis 1998 wurde sie anhand von Normtabellen geschätzt (HILL und RAHIMTULLA 1965). In den Ergebnistabellen dieser Arbeit sind ausschließlich die direkt gemessenen $\mathrm{VO}_{2}$-Werte aufgeführt. Sofern keine gemessenen $\mathrm{VO}_{2}$-Werte zur Verfügung standen, wurden für die Berechnungen die genannten Normtabellen verwendet.

Die arteriovenöse Differenz des Sauerstoffgehaltes $\left(\mathrm{AVDO}_{2}\right)$ wird als Differenz zwischen dem arteriellen und venösen Sauerstoffgehalt $\left(\mathrm{O}_{2}\right.$-Gehalt) des Blutes ermittelt.

Der Sauerstoffgehalt des Blutes ergibt sich als Summe aus hämoglobingebundenem und physikalisch gelöstem Sauerstoff nach folgender Formel: 
(2)

$$
\begin{aligned}
& \mathrm{O}_{2} \text {-Gehalt }=\left(\mathrm{O}_{2}-\text { Kapazität }[\mathrm{ml} / \mathrm{dl}] \times \mathrm{SO}_{2}[\%]\right)+\left(\alpha \times \mathrm{P}_{\mathrm{O} 2}\right) \quad[\mathrm{ml} / 100 \mathrm{ml}] \\
& =\left(1,34 \times \mathrm{Hb}[\mathrm{g} / \mathrm{dl}] \times \mathrm{SO}_{2}[\%]+\left(\alpha \times \mathrm{P}_{\mathrm{O} 2}\right)\right. \\
& \text { [ml/100ml] }
\end{aligned}
$$

Unter Raumluftatmung ist der Anteil physikalisch gelösten Sauerstoffs im Blut im Vergleich zum chemisch gebundenen verschwindend gering, so daß er in der Berechnung vernachlässigt werden darf. Ausgehend von Formel (2) ergibt sich so für die arteriovenöse Sauerstoffdifferenz:

$$
\begin{array}{llr}
\mathrm{AVDO}_{2 \text { syst }} & =\text { Arterieller } \mathrm{O}_{2}-\text { Gehalt }- \text { Gemischtvenöser } \mathrm{O}_{2} \text {-Gehalt } & {[\mathrm{ml} / 100 \mathrm{ml}]} \\
& =\left(1,34 \times \mathrm{Hb}[\mathrm{g} / \mathrm{dl}] \times \mathrm{SAO}_{2}[\%]\right)-\left(1,34 \times \mathrm{Hb}[\mathrm{g} / \mathrm{dl}] \times \mathrm{SmvO}_{2}[\%]\right) & {[\mathrm{ml} / 100 \mathrm{ml}]} \\
& =1,34 \times \mathrm{Hb}[\mathrm{g} / \mathrm{dl}] \times\left(\mathrm{SAO}_{2}[\%]-\mathrm{SmvO}_{2}[\%]\right) & {[\mathrm{ml} / 100 \mathrm{ml}]} \\
& & \\
\mathrm{AVDO}_{2 \text { syst }} & - \text { Arteriovenöse Sauerstoffdifferenz im systemischen Kreislauf }[\mathrm{ml} / 100 \mathrm{ml}] & \\
\mathrm{SAO}_{2} & - \text { Arterielle Sauerstoffsättigung im systemischen Kreislauf [\%] } & \\
\mathrm{SmvO}_{2} & - \text { Mittlere Hohlvenensättigung [\%] } &
\end{array}
$$$$
=1,34 \times \mathrm{Hb}[\mathrm{g} / \mathrm{dl}] \times\left(\mathrm{SAO}_{2}[\%]-\mathrm{SmvO}_{2}[\%]\right) \quad[\mathrm{ml} / 100 \mathrm{ml}]
$$

Die arterielle Sauerstoffsättigung $\left(\mathrm{SAO}_{2}\right)$ wurde während der Herzkatheteruntersuchung invasiv gemessen. Die mittlere Hohlvenensättigung $\left(\mathrm{SmvO}_{2}\right)$ wurde nach der folgenden Formel berechnet (SCHUMACHER 2001):

$$
\text { (4) } \begin{array}{ll}
\mathrm{SmvO}_{2} & =\frac{\left(2 \times \mathrm{SO}_{2} \mathrm{VCS}[\%]+1 \times \mathrm{SO}_{2} \mathrm{VCI}[\%]\right)}{3} \\
& \text { - Sauerstoffsättigung in der Vena cava superior [\%] } \\
\mathrm{SO}_{2} \mathrm{VCS} & \text { - Sauerstoffsättigung in der Vena cava inferior [\%] }
\end{array}
$$

Aus der Formel (2) ergibt sich für die pulmonale Sauerstoffdifferenz $\left(\mathrm{AVDO}_{2}\right.$ pulm):

(5) $\quad \mathrm{AVDO}_{2}$ pulm $=$ Pulmonalvenöser $\mathrm{O}_{2}$-Gehalt - Pulmonalarterieller $\mathrm{O}_{2}$-Gehalt[ml/100 ml]

$$
\begin{array}{ll}
\left.=(1,34 \times \mathrm{Hb}[\mathrm{g} / \mathrm{d}]] \times \mathrm{SO}_{2} \mathrm{PV}[\%]\right)-\left(1,34 \times \mathrm{Hb}[\mathrm{g} / \mathrm{dl}] \times \mathrm{SO}_{2} \mathrm{PA}[\%]\right) & {[\mathrm{ml} / 100 \mathrm{ml}]} \\
=1,34 \times \mathrm{Hb}[\mathrm{g} / \mathrm{dl}] \times\left(\mathrm{SO}_{2} \mathrm{PV}[\%]-\mathrm{SO}_{2} \mathrm{PA}[\%]\right) & {[\mathrm{ml} / 100 \mathrm{ml}]}
\end{array}
$$

\footnotetext{
$\mathrm{AVDO}_{2 \text { pulm }}$ - Arteriovenöse Sauerstoffdifferenz im pulmonalen Kreislauf [ml/100 ml]

$\mathrm{SO}_{2} \mathrm{PA}$ - Pulmonalarterielle Sauerstoffsättigung [\%]

$\mathrm{SO}_{2} \mathrm{PV} \quad$ - Pulmonalvenöse Sauerstoffsättigung [\%]
} 
Durch Einsetzen der entsprechenden Sauerstoffdifferenzen $\mathrm{AVDO}_{2 \text { syst }}$ bzw. $\mathrm{AVDO}_{2 \text { pulm }}$ in Formel (1) ergibt sich für das systemische bzw. pulmonale Herzzeitvolumen ( $\mathrm{Q}_{\mathrm{s}}$ bzw. $\left.\mathrm{Q}_{\mathrm{p}}\right)$ :

$\mathrm{Q}_{\mathrm{s}}$

$$
=\frac{\mathrm{VO}_{2}[\mathrm{ml} / \mathrm{min}]}{\mathrm{AVDO}_{2 \text { syst }}[\mathrm{ml} / 100 \mathrm{ml}] \times 10}
$$

$\mathrm{Q}_{\mathrm{s}}$

(7)

$$
\begin{aligned}
& =\frac{\mathrm{VO}_{2}[\mathrm{ml} / \mathrm{min}]}{\mathrm{AVDO}_{2 \text { pulm }}[\mathrm{ml} / 100 \mathrm{ml}] \times 10} \\
& \text { - Herzzeitvolumen im pulmonalen Kreislauf }[1 / \mathrm{min}]
\end{aligned}
$$

Um die unterschiedliche körperliche Entwicklung der Kinder zu berücksichtigen, wurden die Herzzeitvolumina sowie die Sauerstoffaufnahme auf die Körperoberfläche (KOF) bezogen und als Indizes $\mathrm{Q}_{\mathrm{s} \text { Index }}$ bzw. $\mathrm{Q}_{\mathrm{p} \text { Index }}$ in $\mathrm{l} / \mathrm{min} / \mathrm{m}^{2}$ und $\mathrm{VO}_{2}$ Index $\mathrm{in} \mathrm{ml} / \mathrm{min} / \mathrm{m}^{2}$ angegeben. Auch in den Ergebnistabellen der Arbeit ist diese Art der Darstellung gewählt.

\subsubsection{Berechnung der Gefäßwiderstände}

Die Gefäßwiderstände (R) im systemischen und pulmonalen Kreislauf werden in Anlehnung an das Ohmsche Gesetz ( $\mathrm{R}$ = U/I = Spannung/Stromstärke) als Quotienten aus der Druckdifferenz über einem Kreislaufabschnitt $(\Delta \mathrm{P})$ und dem entsprechenden Herzzeitvolumen $\left(\mathrm{Q}_{\mathrm{s}}\right.$ bzw. $\mathrm{Q}_{\mathrm{p}}$ ) berechnet. Für die Berechnungen werden dabei die jeweiligen Mitteldrücke verwendet. Zur besseren Vergleichbarkeit wurden auch hier die Ergebnisse auf die Körperoberfläche bezogen und als Indizes angegeben (SVRI bzw. PVRI in $\mathrm{mmHg} / \mathrm{l} / \mathrm{min} / \mathrm{m}^{2}$ ). Dabei wird die Einheit [mmHg/l/min] nach dem englischen Kardiologen Paul Wood auch als Wood-Einheit [WE bzw. E] bezeichnet, so daß die Indizes SVRI und PVRI in $\mathrm{E} \times \mathrm{m}^{2}$ angegeben werden.

$\mathrm{R}$

$$
=\frac{\text { Druckdifferenz } \Delta \mathrm{P}[\mathrm{mmHg}]}{\text { Herzzeitvolumen }[\mathrm{l} / \mathrm{min}]}
$$$$
=\frac{(\text { Mittlerer arterieller Druck }- \text { Mitteldruck re. Vorhof) }[\mathrm{mmHg}]}{\mathrm{Q}_{\text {s Index }}\left[\mathrm{l} / \mathrm{min} / \mathrm{m}^{2}\right]}
$$$$
=\frac{(\mathrm{MAP}-\mathrm{RAP})[\mathrm{mmHg}]}{\mathrm{Q}_{\mathrm{s} \text { Index }}\left[\mathrm{l} / \mathrm{min} / \mathrm{m}^{2}\right]}
$$

$[\mathrm{mmHg} / \mathrm{l} / \mathrm{min}]$

$\left[\mathrm{E} \times \mathrm{m}^{2}\right]$

$\left[\mathrm{E} \times \mathrm{m}^{2}\right]$ 
(10) PVRI

$$
\begin{array}{ll}
=\frac{(\text { Mitteldruck Pulmonalarterie }- \text { Mitteldruck li. Vorhof) }[\mathrm{mmHg}]}{\mathrm{Q}_{\mathrm{p} \text { Index }}\left[\mathrm{l} / \mathrm{min} / \mathrm{m}^{2}\right]}\left[\mathrm{E} \times \mathrm{m}^{2}\right] \\
=\frac{(\mathrm{PAP}-\mathrm{LAP}(\mathrm{PCP}))[\mathrm{mmHg}]}{\mathrm{Q}_{\mathrm{p} \text { Index }}\left[\mathrm{l} / \mathrm{min} / \mathrm{m}^{2}\right]} & {\left[\mathrm{E} \times \mathrm{m}^{2}\right]}
\end{array}
$$

SVRI - Index für den systemvaskulären Widerstand $\left[\mathrm{mmHg} / \mathrm{l} / \mathrm{min} / \mathrm{m}^{2} \mathrm{bzw}\right.$. E x m $\left.{ }^{2}\right]$

PVRI - Index für den pulmonalvaskulären Widerstand [mmHg/l/min $/ \mathrm{m}^{2}$ bzw. E x m²]

MAP - Mittlerer arterieller Druck [mmHg]

RAP - Mitteldruck im rechten Vorhof [mmHg]

PAP - Mitteldruck in der Pulmonalarterie [mmHg]

LAP $\quad$ - Mitteldruck im linken Vorhof [mmHg]

PCP - Bei verschlossenem Vorhofseptum wird der Druck im linken Vorhof über den pulmonalkapillären Druck in „Wedgeposition“ abgeschätzt.

Als Referenzwerte für die hämodynamischen Parameter wurden Untersuchungsergebnisse von Säuglingen und Kindern mit hämodynamisch wenig bedeutsamen Herzfehlern herangezogen, die unter den gleichen methodischen Bedingungen in der eigenen Abteilung gewonnen worden waren (HEXEL 1996). Referenzwerte für dort nicht aufgeführte Parameter wurden aus einem etablierten Lehrbuch der pädiatrischen Kardiologie ergänzt (APITZ 2002).

\subsubsection{Weitere hämodynamische Parameter}

Folgende weitere Parameter wurden bestimmt: Der mittlere rechtsatriale Druck (RAP), sowie auch der pulmonalarterielle (PAP) und der mittlere arterielle Druck (MAP) wurden invasiv gemessen. Der mittlere linksatriale Druck (LAP) wurde direkt gemessen oder bei Patienten mit geschlossenem Vorhofseptum über den pulmonalkapillären Druck in Verschlußposition („Wedgeposition“) abgeschätzt. Die Ejektionsfraktion (EF) wurde angiographisch mit Hilfe einer biplanen volumetrischen Analyse des systemischen Ventrikels bestimmt.

\subsubsection{Neurohumorale Parameter}

Im Rahmen der Routinediagnostik bei Herzinsuffizienz wurden in der kinderkardiologischen Abteilung des Universitätsklinikums Göttingen regelmäßig neurohumorale Parameter wie Plasma-Renin-Aktivität, Reninkonzentration, Aldosteron und Katecholamine bestimmt. Die venösen Blutproben wurden beim nicht sedierten Säugling durch einen erfahrenen Kinderarzt gewonnen. Bei allen Kindern wurden die Plasma-Renin- und Katecholaminspiegel im Zentrallabor des Universitätsklinikums mit Hilfe von Routinemethoden bestimmt. Die Noradrenalin- und Adrenalinspiegel wurden mit Hilfe der HPLC-Technik (high-performance liquid chromatography with detection of fluorescence) gemessen (MITSUI et al. 1985). Bis 1997 wurde das Plasma-Renin indirekt über die Enzymaktivität [in $\mathrm{ng} / \mathrm{ml} / \mathrm{h}$ ] bestimmt (DiaSorin GmbH, Düsseldorf, Deutschland, Sensitivität $>0,2 \mathrm{ng} / \mathrm{ml} / \mathrm{h}$ ). Später wurde diese Methode durch die Bestimmung des immunreaktiven Renins [in $\mu \mathrm{U} / \mathrm{ml}$ ] abgelöst (Nichols Institute 
Diagnostika GmbH, Bad Nauheim, Sensitivität > 1,4 $\mu \mathrm{U} / \mathrm{ml}$ ). Beide Bestimmungen erfolgten mit kommerziellen Immunoradio-Assays und wurden in der statistischen Analyse getrennt ausgewertet. Die Ergebnisse wurden mit publizierten Normwerten für Säuglinge und Kleinkinder verglichen (FISELIER et al. 1983; EICHLER et al. 1989; KRÜGER et al. 1998).

\section{$2.4 \quad$ Statistik}

Die Daten wurden mit Hilfe der Programme Microsoft Excel und STATISTICA ausgewertet. Dazu wurde eine Urdatentabelle in Microsoft Excel erstellt, aus der Datenteile zur weiteren Auswertung in STATISTICA übertragen wurden. Mit verschiedenen Filterfunktionen wurden dann ausgewählte Patientenuntergruppen hinsichtlich interessierender Parameter untersucht.

\subsubsection{Begriffsdefinitionen}

Zur Charakterisierung der erhobenen Daten wurden die arithmetischen Mittelwerte $\overline{\mathrm{x}}$ und die Standardabweichungen s für alle Parameter in den Patientenuntergruppen (Kapitel 2.4.2) berechnet und die Ergebnisse in der Form $\overline{\mathrm{x}} \pm \mathrm{s}$ wiedergegeben.

Der Mittelwert $\overline{\mathrm{x}}$ berechnet sich als die Summe aller Beobachtungswerte $\left(\mathrm{x}_{1}, \mathrm{x}_{2}, \mathrm{x}_{3}, \ldots.\right)$ eines Merkmals X dividiert durch die Anzahl aller Beobachtungen (N):

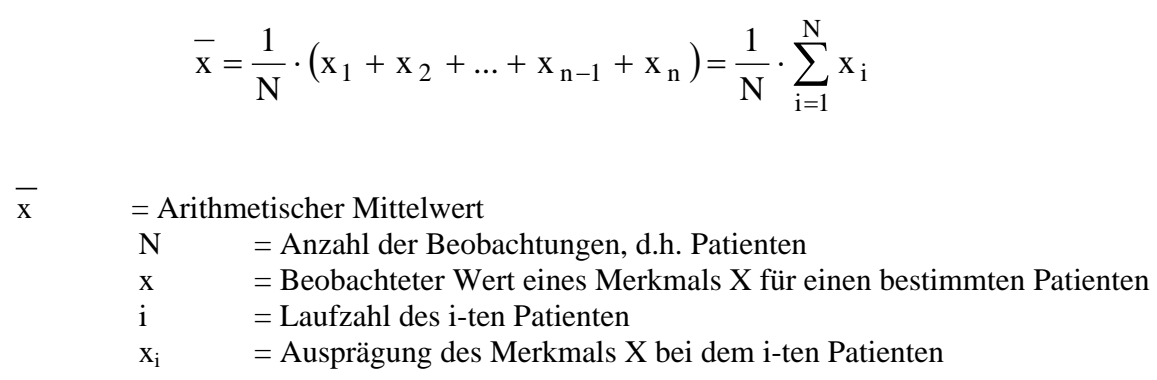

Die empirische Standardabweichung s berechnet sich als die positive Quadratwurzel der empirischen Variabilität $\mathrm{s}^{2}$ :

$$
\begin{aligned}
\mathrm{s}= & +\sqrt{\mathrm{s}^{2}}=\sqrt{\frac{1}{\mathrm{~N}-1} \cdot \sum_{\mathrm{i}=1}^{\mathrm{N}}\left(\mathrm{x}_{\mathrm{i}}-\overline{\mathrm{X}}\right)^{2}} \\
\mathrm{~s}^{2} & =\text { Empirische Variabilität } \\
\mathrm{s} & =\text { Empirische Standardabweichung } \\
\mathrm{N} & =\text { Anzahl der Beobachtungen, d.h. Patienten } \\
\mathrm{X} & =\text { Beobachteter Wert eines Merkmals X für einen bestimmten Patienten } \\
\mathrm{i} & =\text { Laufzahl des i-ten Patienten } \\
\frac{\mathrm{x}_{\mathrm{i}}}{\mathrm{X}} & =\text { Ausprägung des Merkmals X bei dem i-ten Patienten } \\
& =\text { Arithmetischer Mittelwert }
\end{aligned}
$$

Zur Veranschaulichung der Ergebnisse wurden Box-Whisker-Plots verwendet. Darin wurde das 50\%-Quantil (Median) als mittlere Querlinie und das 25\%- bzw. 75\%-Quantil als untere 
bzw. obere Begrenzung der Box eingetragen, sowie Minimum und Maximum der beobachteten Meßwerte eingezeichnet. Das q \%-Quantil bezeichnet dabei denjenigen Wert $\mathrm{x}_{\mathrm{q}}$ der Meßwerte, an dem q \% der Meßwerte kleiner oder gleich diesem Wert sind. Der Median ist definiert als derjenige Wert, für den gilt, daß gleich viele Meßwerte oberhalb wie unterhalb dieses Wertes liegen.

\subsubsection{Deskriptive Statistik}

Zur Untersuchung der Fragestellung der Arbeit wurden die Studienpatienten entsprechend dem Schweregrad der Symptome Tachypnoe bzw. Gedeihstörung in je drei Untergruppen geteilt, deren Intervalle sich an den speziellen Herzinsuffizienz-Scores für Säuglinge von ROSS et al. (1992), BUCHHORN et al. (1998) und BUCHHORN et al. (2000b) orientierten (Tabelle 2.1 und 2.2). In diesen Untergruppen wurden Mittelwerte $\bar{x}$ und Standardabweichungen s aller hämodynamischen und neurohumoralen Parameter berechnet. Die hämodynamischen Parameter wurden mit Hilfe einer unifaktoriellen Varianzanalyse (ANOVA) auf signifikante Gruppenunterschiede überprüft. Für die neurohumoralen Parameter wurde ein Testverfahren für nicht parametrische Daten gewählt (Rang-Varianz-Analyse, KruskalWallis-Test), da für sie keine Gaußsche Normalverteilung angenommen werden konnte. Alle Ergebnisse wurden in der Form $\overline{\mathrm{x}} \pm \mathrm{s}$ dargestellt. Generell wurde in allen Tests jeder Unterschied als „statistisch signifikant“ definiert, für den die im Test errechnete Irrtumswahrscheinlichkeit p für eine Ablehnung der Nullhypothese „kein Unterschied der Mittelwerte“ unter dem allgemein üblichen Signifikanzniveau von $\alpha=5 \%$ lag.

Tabelle 2.1: Einteilung der Säuglinge entsprechend ihren mittleren Atemfrequenzen zur Beurteilung des Schweregrades ihrer Herzinsuffizienz. Nach ROSS et al. (1992).

\begin{tabular}{|c|c|c|}
\hline \multicolumn{3}{|c|}{ Mittlere Atemfrequenzen [min } \\
\hline \multicolumn{2}{|c|}{ ] } \\
\hline Gruppe 0 & Gruppe 1 & Gruppe 2 \\
$<50$ & $50-60$ & $>60$ \\
\hline
\end{tabular}

Tabelle 2.2: Einteilung der Säuglinge entsprechend ihrer Gewichtsentwicklung über vier Wochen zur Beurteilung des Schweregrades ihrer Herzinsuffizienz. Modifiziert nach BUCHHORN et al. (1998) und BUCHHORN et al. (2000b).

\begin{tabular}{|c|c|c|}
\hline \multicolumn{3}{|c|}{ Gewichtsentwicklung [g/Monat] } \\
\hline Gruppe 0 & Gruppe 1 & Gruppe 2 \\
$+>400$ & $+200-400$ & $<0$ bis $+<200$ \\
\hline
\end{tabular}




\subsubsection{Lineare Korrelation}

Zur weiteren Analyse wurden die linearen Korrelationen zwischen den Variablen Atemfrequenz bzw. Gewichtsentwicklung und den erhobenen, hämodynamischen und neurohumoralen Parametern untersucht. Die Korrelationskoeffizienten $\mathrm{r}$ und die entsprechenden Irrtumswahrscheinlichkeiten p wurden in STATISTICA berechnet.

\subsubsection{Multiple Regressionsanalyse}

\subsubsection{Aufbau eines Regressionsmodells zur Erklärung der Symptome Tachypnoe und Gedeihstörung}

Die jetzt große Anzahl unabhängiger, möglicherweise die Zielgrößen Atemfrequenz bzw. Gewichtsentwicklung beeinflussender Variablen führte zur Ablehnung einer multifaktoriellen Varianzanalyse. Für die weitere Datenauswertung wurde eine multiple Regressionsanalyse gewählt, um mit Hilfe dieser diejenige Kombination unabhängiger Variablen zu ermitteln, die am besten die Zielgröße Atemfrequenz bzw. Gewichtsentwicklung voraussagt. Dabei wurden hier die gemessenen Werte (Atemexkursionen pro Minute, Gramm pro Monat) verwendet.

Die Daten von sieben Säuglingen wurden aus der Regressionsanalyse ausgeschlossen, da bei ihnen Herzkatheteruntersuchung und Hormonbestimmung mehr als sechs Wochen auseinander lagen. Auch das Renin wurde auf Grund der zwei verschiedenen verwendeten Bestimmungsmethoden (Plasma-Renin-Aktivität bzw. Reninkonzentration) nicht in die multiple Regressionsanalyse aufgenommen.

In einem ersten Schritt wurden die Parameter Atemfrequenz bzw. Gewichtsentwicklung als Zielgröße y (abhängige Variable) einer zu bestimmenden Gleichung

$$
\mathrm{y}=\mathrm{a} \times \mathrm{x}_{1}+\mathrm{b} \times \mathrm{x}_{2}+\mathrm{c} \times \mathrm{x}_{3}+\ldots+\mathrm{i} \times \mathrm{x}_{\mathrm{i}}+\mathrm{k}
$$

gesetzt und diejenigen Variablen als unabhängige Variablen $\mathrm{x}_{1}, \mathrm{x}_{2}, \ldots, \mathrm{x}_{\mathrm{i}}$ berücksichtigt, die eine statistisch signifikante lineare Korrelation mit der jeweiligen Zielgröße gezeigt hatten.

In einem nächsten Schritt wurden zwei verschiedene Vorgehensweisen gewählt, die miteinander verglichen und zur Bestätigung der erhaltenen Ergebnisse herangezogen wurden: Zum einen wurde die oben genannte Gleichung einmal „von unten“ her entwickelt, indem mit wenigen unabhängigen Variablen begonnen und nacheinander einzelne dazu genommen wurden. An Hand ihrer p-Werte und ihres Einflusses auf den R²-Wert (Kapitel 2.4.4.2) wurde entschieden, ob sie in der Gleichung belassen wurden. Zum anderen wurde die Gleichung „von oben“ her aufgebaut, indem mit einer größeren Anzahl unabhängiger Variablen begonnen und schrittweise dann die Variable mit der jeweils höchsten Irrtumswahrscheinlichkeit p aus der 
Gleichung herausgenommen wurde.

Dieses schrittweise Verfahren wurde bei beiden Vorgehensweisen so lange durchgeführt, bis die Irrtumswahrscheinlichkeiten p aller in der Gleichung befindlichen Variablen kleiner 0,3 waren bei gleichzeitig möglichst hohem R²-Wert der Gleichung. Beide Vorgehensarten („von oben“ und „von unten“) führten zu vergleichbaren Ergebnissen und bestätigten so die Variablenauswahl.

Als Entscheidungskriterium dafür, ob ein erarbeitetes Modell als geeignet erachtet wurde, die klinischen Symptome Tachypnoe bzw. Gedeihstörung zu erklären, galt ein erreichtes Bestimmtheitsmaß $\mathrm{R}^{2}$ von größer als 0,5.

Die Auswahl eines p-Wertes von < 0,3 ist ein bei dieser Vorgehensart geeigneter Wert (KIRK 1968), mit dem erreicht werden soll, daß Variablen mit sicherem Einfluß auf die Zielgröße auf jeden Fall in die Gleichung aufgenommen werden. Der p-Wert gibt die Irrtumswahrscheinlichkeit p dafür an, daß einer unabhängigen Variablen ein Einfluß zugesprochen wird, obwohl ihr Einfluß eigentlich gleich Null ist. Die Entscheidung für $\mathrm{p}<0,3$ spiegelt, im Gegensatz zu einem ebenfalls denkbaren Wert $\mathrm{p}<0,2$, einen etwas vorsichtigeren Ansatz wider, der auch Variablen mit einem eventuellen Einfluß auf die Zielgröße nicht von vornherein ausschließt, sondern ihr Verhalten in der Gleichung untersucht.

Unterschiede in den Ergebnissen ergaben sich zum Teil im Vergleich der Modi „Fallweiser Ausschluß“, „Ersetzen durch Mittelwerte“ und „Paarweiser Ausschluß“ des Programms STATISTICA. Das lag daran, daß bei manchen Säuglingen einzelne Parameter nicht zu bestimmen gewesen waren und die Urdatentabelle deshalb leere Zellen aufwies.

Der Modus „Fallweiser Ausschluß“ berücksichtigte in der Auswertung nur die Fälle (Säuglinge), deren Parameter vollständig vorhanden waren. Das bedeutete, daß eine mehr oder weniger große Anzahl an Kindern nicht in die Analyse einging und die Anzahl an Beobachtungen entsprechend kleiner wurde. Andererseits waren die Ergebnisse jedoch schärfer in der Aussage als die der übrigen Methoden.

Der Modus „Ersetzen durch Mittelwerte“ ersetzte alle fehlenden Werte einer unabhängigen Variablen durch den Mittelwert, der sich aus den vorhandenen Werten dieser Variable errechnete. Die Werte der entsprechenden Variablen wurden durch diesen Modus einheitlicher, d. h. die Streuung der Werte wurde künstlich verringert. Vorteil dieser Vorgehensweise war die große Anzahl an Beobachtungen (N).

Der Modus „Paarweiser Ausschluß“ stellte einen Mittelweg dar: Hier wurden Säuglinge mit leeren Zellen einer Variablen nicht vollständig aus der Analyse ausgeschlossen, sondern nur in der Analyse der jeweiligen, betroffenen Variable nicht berücksichtigt. Nachteil war hier 
eine sehr wechselnde Fallzahl zwischen den einzelnen Variablen.

In der Studie wurde der Modus „Fallweiser Ausschluß““ verwendet, um möglichst aussagekräftige Ergebnisse zu bekommen, wobei eine entsprechend verringerte Anzahl an Beobachtungen in Kauf genommen wurde.

\subsubsection{Ergebnis der multiplen Regression}

Als Ergebnis der Regressionsgleichung $\mathrm{y}=\mathrm{a} \times \mathrm{x}_{1}+\mathrm{b} \times \mathrm{x}_{2}+\mathrm{c} \times \mathrm{x}_{3}+\ldots+\mathrm{i} \times \mathrm{x}_{\mathrm{i}}+\mathrm{k}$ ergaben sich die Regressionskoeffizienten a, b, c,... i, die die Gewichtungen der verschiedenen berücksichtigten, unabhängigen Variablen $\mathrm{x}_{1}, \mathrm{x}_{2}, \mathrm{x}_{3} \ldots, \mathrm{x}_{\mathrm{i}}$ repräsentierten, sowie deren jeweilige Irrtumswahrscheinlichkeit $\mathrm{p}$ und eine den Achsenabschnitt angebende Konstante $\mathrm{k}$.

Der Wert R² (Bestimmtheitsmaß) gab dabei den Anteil der durch die in die Gleichung aufgenommenen, unabhängigen Variablen erklärten Streuung an der Gesamtstreuung der Zielgröße Atemfrequenz bzw. Gewichtsentwicklung an. 


\subsection{Datenerhebungsbogen}

Name:

Geburtsdatum:
Patientennummer:

Diagnosen:

\begin{tabular}{|c|c|}
\hline Gedeih-Score (Datum): & Atmungs-Score (Datum): \\
\hline $\begin{array}{l}\text { Gewichtszunahme in vier } \\
\text { Wochen [g/Monat] }\end{array}$ & Atemfrequenzniveau $\left[\mathrm{min}^{-1}\right]$ \\
\hline \multicolumn{2}{|l|}{ Ernährung/Tag } \\
\hline \multirow[t]{2}{*}{ Kalorien/Tag [kcal/d] } & Gewicht [kg]: \\
\hline & Perzentile: \\
\hline Erbrechen ja/nein & Geburtsgewicht [kg]: \\
\hline \multirow[t]{2}{*}{ Sondierung ja/nein } & Perzentile bei Geburt: \\
\hline & Herzfrequenz $\left[\mathrm{min}^{-1}\right]$ : \\
\hline \multicolumn{2}{|l|}{ Schwitzneigung: } \\
\hline Nein & Medikamente (Datum): \\
\hline Bei Belastung: ja & Furosemid [mg/kg KG/d] \\
\hline \multirow[t]{2}{*}{ In Ruhe: ja } & Spironolacton [mg/kg KG/d] \\
\hline & $\beta$-Methyldigoxin-Spiegel [nmol/l] \\
\hline Hämodynamik (Datum, Nr.): & Propanolol [mg/kg KG/d] \\
\hline $\mathrm{EF}[\%]$ & Captopril [mg/kg KG/d] \\
\hline \multicolumn{2}{|l|}{ LVedP [mmHg] } \\
\hline RAP [mmHg] & Neurohumorale Aktivität (Dat.): \\
\hline LAP [mmHg] & Plasma-Renin-Aktivität [ng/ml/h] \\
\hline PAP [mmHg] & Reninkonzentration $[\mu \mathrm{U} / \mathrm{ml}]$ \\
\hline MAP [mmHg] & Aldosteron [pg/ml] \\
\hline $\mathrm{Q}_{\mathrm{p}} / \mathrm{Q}_{\mathrm{s}}$ & Noradrenalin [ng/l] \\
\hline $\mathrm{Q}_{\mathrm{p} \text { Index }}\left[\mathrm{l} / \mathrm{min} / \mathrm{m}^{2}\right]$ & Adrenalin [ng/l] \\
\hline \multicolumn{2}{|l|}{$\mathrm{Q}_{\text {s Index }}\left[\mathrm{l} / \mathrm{min} / \mathrm{m}^{2}\right]$} \\
\hline \multicolumn{2}{|l|}{$\mathrm{SAO}_{2}[\%]$} \\
\hline \multicolumn{2}{|l|}{$\mathrm{VO}_{2 \text { Index }}\left[\mathrm{ml} / \mathrm{min} / \mathrm{m}^{2}\right]$} \\
\hline \multicolumn{2}{|l|}{ SVRI $\left[E \times \mathrm{m}^{2}\right]$} \\
\hline PVRI $\left[E \times \mathrm{m}^{2}\right]$ & \\
\hline
\end{tabular}




\section{Darstellung der Untersuchungsergebnisse}

\subsection{Charakterisierung der Studienpatienten}

Untersucht wurden die Daten von 70 Säuglingen im Alter von 0,3 bis 11,8 Monaten (mittleres Alter 4,4 2,3 Monate) mit angeborenem Herzfehler (Tabelle 3.1). 67 dieser 70 Säuglinge waren dabei bis zu acht Monate alt. Hämodynamisch lag bei den Kindern prädominierend ein Links-Rechts-Shunt vor. Die meist bedeutsame Lungenüberflutung spiegelte sich in einem signifikant erhöhten Verhältnis von pulmonalem zu systemischem Herzzeitvolumen $\left(\mathrm{Q}_{\mathrm{p}} / \mathrm{Q}_{\mathrm{s}}\right)$ von im Mittel 3,7 $\pm 2,2$ und erhöhten mittleren pulmonalarteriellen Drücken (PAP, $34 \pm 13 \mathrm{mmHg}$ ) wider, ohne daß Zeichen einer fixierten pulmonalen Hypertonie bestanden (PVRI, 3,5 \pm 1,9 $\mathrm{E} \times \mathrm{m}^{2}$ ) (Tabelle 3.2).

Tabelle 3.1: Charakterisierung der Studienpatienten

\begin{tabular}{|c|c|c|c|c|c|c|}
\hline & $\mathrm{N}$ & $\begin{array}{l}\text { Anteil der } \\
\text { Gruppe }\end{array}$ & $\mathrm{x}$ & $\pm \mathrm{s}$ & \multicolumn{2}{|c|}{ Minimum - Maximum } \\
\hline Geschlecht & 32 & $46 \%$ & & & & \\
\hline männlich & 38 & $54 \%$ & & & & \\
\hline \multicolumn{7}{|l|}{ Klinische Parameter } \\
\hline Alter [Monate] & 70 & & 4,4 & $\pm 2,3$ & $0,3-$ & $-11,8$ \\
\hline Gewicht [kg]: & 70 & & 5,0 & $\pm 1,3$ & $1,9-$ & $-7,2$ \\
\hline$<3$. Perzentile & 35 & $50 \%$ & & & & \\
\hline 3. bis $<=10$. Perzentile & 18 & $26 \%$ & & & & \\
\hline Geburtsgewicht [kg] & 65 & & 3,1 & $\pm 0,6$ & $1,8-$ & $-4,4$ \\
\hline Gewichtszu-/abnahme [g/Monat] & 69 & & 326 & \pm 224 & $-373-$ & -840 \\
\hline Atemfrequenz $\left[\mathrm{min}^{-1}\right]$ & 70 & & 54 & \pm 11 & $35-$ & -86 \\
\hline Erbrechen & 19 & $27 \%$ & & & & \\
\hline Nasogastrale Sonde & 18 & $26 \%$ & & & & \\
\hline \multicolumn{7}{|l|}{ Schwitzen: } \\
\hline - nicht: & 31 & $44 \%$ & & & & \\
\hline - nur bei Belastung: & 13 & $19 \%$ & & & & \\
\hline - bereits in Ruhe: & 24 & $34 \%$ & & & & \\
\hline \multicolumn{7}{|l|}{ Medikamentöse Therapie } \\
\hline $\begin{array}{l}\text { regelmäßig erhalten: } \\
\text { davon: }\end{array}$ & 52 & $74 \%$ & & & & \\
\hline Furosemid [mg/kg KG/d] & 31 & $44 \%$ & & & & \\
\hline Spironolacton [mg/kg KG/d] & 40 & $57 \%$ & & & & \\
\hline ß-Methyldigoxin [nmol/1] & 44 & $63 \%$ & & & & \\
\hline Propanolol [mg/kg KG/d] & 10 & $14 \%$ & & & & \\
\hline Captopril [mg/kg KG/d] & 2 & $3 \%$ & & & & \\
\hline
\end{tabular}


Die systemischen Herzzeitvolumina pro Körperoberfläche $\left(\mathrm{Q}_{\mathrm{s} \text { Index }}\right)$ waren als Folge der Links-Rechts-Shunts vermindert $\left(2,5 \pm 0,8 \mathrm{l} / \mathrm{min} / \mathrm{m}^{2}\right)$ bei mittleren arteriellen Drücken (MAP) von $59 \pm 10 \mathrm{mmHg}$. Die Säuglinge zeigten zum großen Teil eine vermehrte neurohumorale Stimulation mit erhöhten Hormonwerten im Blut (Plasma-Renin-Aktivität: $45 \pm 55$ ng/ml/h; Reninkonzentration: $422 \pm 576 \mu \mathrm{U} / \mathrm{ml}$; Noradrenalin: $561 \pm 475$ ng/l; Aldosteron $938 \pm 1141$ pg/ml) (Tabelle 3.2; für Normwerte s. Tabelle 3.5).

Tabelle 3.2: Hämodynamische und neurohumorale Parameter der 70 untersuchten Säuglinge mit angeborenem Herzfehler und Links-Rechts-Shunt

\begin{tabular}{|c|c|c|c|c|}
\hline & $\mathrm{N}$ & $\mathrm{x}$ & $\pm s$ & Minimum - Maximum \\
\hline \multicolumn{5}{|l|}{ Hämodynamische Parameter } \\
\hline Herzfrequenz $\left[\mathrm{min}^{-1}\right]$ & 70 & 128 & \pm 12 & $80-158$ \\
\hline Ejektionsfraktion [\%] & 58 & 65 & \pm 7 & $46-81$ \\
\hline LVedP [mmHg] & 66 & 9 & \pm 3 & $3-16$ \\
\hline $\mathrm{VO}_{2 \text { Index }}\left[\mathrm{ml} / \mathrm{min} / \mathrm{m}^{2}\right]$ & 31 & 130 & \pm 23 & $81-180$ \\
\hline RAP [mmHg] & 69 & 5 & \pm 2 & $0-10$ \\
\hline LAP [mmHg] & 59 & 9 & \pm 3 & $3-20$ \\
\hline PAP [mmHg] & 66 & 34 & \pm 13 & $12-67$ \\
\hline MAP [mmHg] & 69 & 59 & \pm 10 & $40-90$ \\
\hline $\mathrm{Q}_{\mathrm{p}} / \mathrm{Q}_{\mathrm{s}}$ & 70 & 3,7 & $\pm 2,2$ & $0,6-13,5$ \\
\hline $\mathrm{Q}_{\mathrm{p} \text { Index }}\left[\mathrm{l} / \mathrm{min} / \mathrm{m}^{2}\right]$ & 69 & 8,2 & $\pm 3,7$ & $2,3-19,4$ \\
\hline $\mathrm{Q}_{\mathrm{s} \text { Index }}\left[\mathrm{l} / \mathrm{min} / \mathrm{m}^{2}\right]$ & 69 & 2,5 & $\pm 0,8$ & $1,4-5,5$ \\
\hline SVRI [E x m²] & 69 & 23,5 & $\pm 6,8$ & $10,3-42,1$ \\
\hline PVRI [E x m²] & 57 & 3,5 & $\pm 1,9$ & $0,9-10,2$ \\
\hline $\mathrm{SAO}_{2}[\%]$ & 69 & 93 & \pm 6 & $73-99$ \\
\hline \multicolumn{5}{|l|}{ Neurohumorale Parameter } \\
\hline Plasma-Renin-Aktivität [ng/ml/h] & 27 & 45 & \pm 55 & $2-194$ \\
\hline Reninkonzentration $[\mu \mathrm{U} / \mathrm{ml}]$ & 34 & 422 & \pm 576 & $25-2150$ \\
\hline Noradrenalin [ng/l] & 52 & 561 & \pm 475 & $44-2655$ \\
\hline Adrenalin [ng/l] & 53 & 99 & \pm 133 & $9-594$ \\
\hline Aldosteron $[\mathrm{pg} / \mathrm{ml}]$ & 54 & 938 & \pm 1141 & $15-6193$ \\
\hline
\end{tabular}

Abkürzungen: LVedP: left ventricular enddiastolic pressure, linksventrikulärer enddiastolischer Druck; $\mathrm{VO}_{2}$ Index: Sauerstoffaufnahme pro Körperoberfläche (KOF). RAP: mean right atrial pressure, mittlerer rechtsatrialer Druck; LAP: mean left atrial pressure, mittlerer linksatrialer Druck; PAP: mean pulmonary artery pressure, mittlerer Pulmonalarteriendruck; MAP: mean arterial pressure, mittlerer arterieller Druck; Qp/Qs: Verhältnis aus pulmonalem zu systemischem Herzzeitvolumen; $\mathrm{Q}_{\mathrm{p} \text { Index }}$ : Pulmonales Herzzeitvolumen pro KOF; $\mathrm{Q}_{\mathrm{s} \text { Index }}$ : Systemisches Herzzeitvolumen pro KOF; SVRI: systemic vascular resistance index, Index für den systemvaskulären Widerstand; PVRI: pulmonary vascular resistance index, Index für den pulmonalvaskulären Widerstand; $\mathrm{SAO}_{2}$ : Arterielle Sauerstoffsättigung. 
Siebzehn Säuglinge hatten isolierte Vorhof- oder Ventrikelseptumdefekte (ASD, N = 1 bzw. VSD, $N=16$ ), elf Säuglinge kombinierte Vorhof- und Ventrikelseptumdefekte. Persistierende Ductus arteriosi Botalli (PDA) fanden sich bei vier Säuglingen, atrioventrikuläre Septumdefekte (AVSD) sowie komplexere Herzfehler bei je 19 Kindern. Elf Säuglinge hatten zusätzlich eine Aortenisthmusstenose. Bei einigen Säuglingen waren zuvor palliative Operationen durchgeführt worden, wie zum Beispiel ein Banding der Pulmonalarterie, eine Atrioseptektomie nach Blalock-Hanlon oder eine Atrioseptostomie nach Rashkind-Miller, außerdem Resektionen einer zusätzlichen Aortenisthmusstenose $(\mathrm{N}=4)$ (Tabelle 3.3).

Tabelle 3.3: Diagnosen der 70 Studienpatienten

\begin{tabular}{|c|c|c|c|c|c|}
\hline Diagnosen & $\mathrm{N}$ & $\begin{array}{l}\text { Palliative } \\
\text { Operationen }\end{array}$ & $\begin{array}{l}\text { Zusätzliche } \\
\text { Aortenisthmus- } \\
\text { stenose }\end{array}$ & M. Down & $\begin{array}{c}\text { Weitere } \\
\text { Operationen }^{2}\end{array}$ \\
\hline ASD und/oder VSD & 28 & $2^{3}$ & 5 & 3 & 1 \\
\hline PDA & 4 & - & 1 & 1 & - \\
\hline AVSD & 19 & - & 3 & 15 & 3 \\
\hline Komplexer Herzfehler ${ }^{1}$ & 19 & $7^{4}$ & 2 & - & - \\
\hline \multicolumn{6}{|c|}{$\begin{array}{l}\text { Abkürzungen: ASD: Vorhofseptumdefekt; VSD: Ventrikelseptumdefekt; PDA: Persistierender Ductus arteriosus Botalli ; AVSD } \\
\text { Atrioventrikulärer Septumdefekt. }\end{array}$} \\
\hline \multicolumn{6}{|c|}{$\begin{array}{l}{ }^{1} \text { Zu den komplexen Herzfehlern zählten: Fallot- Tetralogie, Pulmonalatresie, Trikuspidalatresie, Truncus arteriosus communis, } \\
\text { funktionell singulärer Ventrikel vom rechtsventrikulären Typ, double outlet right ventricle (DORV), double inlet left ventricle } \\
\text { (DILV). }\end{array}$} \\
\hline \multicolumn{6}{|c|}{$\begin{array}{l}\text { ² Z.n. Pylorotomie (ein Patient mit VSD), Z.n. Operation einer Duodenalstenose (drei Patienten mit AVSD), jeweils in den ersten } \\
\text { Lebenstagen operiert. }\end{array}$} \\
\hline \multicolumn{6}{|c|}{${ }^{3}$ Z.n. Verschluß eines persistierenden Ductus arteriosus Botalli bzw. Z.n. Banding der Pulmonalarterie. } \\
\hline \multicolumn{6}{|c|}{$\begin{array}{l}{ }^{4} \text { Z.n. Ballon-Atrioseptostomie nach Rashkind-Miller (vier Patienten), Z.n. Ballon-Valvuloplastie (ein Patient), Z.n. Banding der } \\
\text { Pulmonalarterie nach Muller-Damann (zwei Patienten) und Z.n. Atrioseptektomie nach Blalock-Hanlon, Verschluß der } \\
\text { Trikuspidalklappe, Anlage eines aortopulmonalen Shunts sowie Ligatur eines persistierenden Ductus arteriosus Botalli (ein } \\
\text { Patient). Zum Teil Mehrfachnennungen. }\end{array}$} \\
\hline
\end{tabular}

Klinisch waren alle Säuglinge in stabilem Allgemeinzustand, zeigten jedoch trotz medikamentöser Standardtherapie (74 \%; Tabelle 3.1) zum Teil deutliche klinische Symptome: So waren 57 \% der Kinder bereits in Ruhe tachypnoeisch mit Atemfrequenzen von > 50 pro Minute (Tabelle 3.4), 53 \% schwitzten vermehrt. Neunzehn Säuglinge (27 \%) erbrachen gehäuft. Achtzehn Kinder wurden unterstützend über eine nasogastrale Sonde ernährt. Fünfzig Prozent der Patienten lagen zum Untersuchungszeitpunkt mit ihrem Gewicht unterhalb der 3. Perzentile und 26 \% zwischen der 3. und 10. Perzentile (Tabelle 3.1, Abbildung 3.5).

Zehn Patienten bekamen zusätzlich den Beta-Rezeptorenblocker Propanolol im Rahmen der prospektiv-randomisierten Studie CHF-PRO-INFANT in der eigenen Abteilung (BUCH- 
HORN et al. 2001c).

Neunzehn der Säuglinge hatten eine Trisomie 21, je ein Kind ein Turnersyndrom, ein Di George-Syndrom bzw. eine partielle Trisomie 8q+, zwei Säuglinge hatten unklare Syndrome. Einer dieser Säuglinge litt an zerebralen Krampfanfällen.

Die übrigen klinischen, hämodynamischen und neurohumoralen Parameter sowie Diagnosen werden in den Tabellen 3.1, 3.2 und 3.3 aufgeführt.

\subsection{Tachypnoe - Auswertung nach Atemfrequenzgruppen}

Zunächst wird das Gesamtkollektiv der Säuglinge hinsichtlich eventueller Unterschiede ihrer hämodynamischen und neurohumoralen Parameter in den verschiedenen Atemfrequenzgruppen betrachtet (Tabelle 3.4 und 3.5). Danach werden die Ergebnisse für jedes Trimenon einzeln aufgeschlüsselt (Tabelle 3.6 bis 3.9). Zur Charakterisierung der Variablen in den Gruppen sind jeweils ihre Mittelwerte und Standardabweichungen wiedergegeben.

\subsubsection{Hämodynamische Parameter}

Wie in Tabelle 3.4 dargestellt, erwiesen sich von den untersuchten hämodynamischen Parametern nur die Herzfrequenzen, der mittlere arterielle Druck sowie der Index des systemischen Herzzeitvolumens als signifikant verschieden zwischen den Atemfrequenzgruppen.

Es zeigte sich ein signifikanter Anstieg der Herzfrequenzen bei zunehmender Tachypnoe von $122 \pm 11 / \mathrm{min}$ auf $127 \pm 8 / \mathrm{min}$ bzw. $137 \pm 10 / \mathrm{min}(\mathrm{p}<0,001)$. Der MAP fiel dagegen von $63 \pm 9 \mathrm{mmHg}$ auf $60 \pm 8 \mathrm{mmHg}$ bzw. $54 \pm 9 \mathrm{mmHg}(\mathrm{p}=0,004)$. Auch der $\mathrm{Q}_{\mathrm{s}}$-Index sank mit zunehmender Atemfrequenz statistisch signifikant von 2,7 $\pm 1,0 \mathrm{l} / \mathrm{min} / \mathrm{m}^{2}$ auf 2,6 $\pm 0,6 \mathrm{l} / \mathrm{min} / \mathrm{m}^{2}$ bzw. 2,1 $\pm 0,5 \mathrm{l} / \mathrm{min} / \mathrm{m}^{2}(\mathrm{p}=0,02)$. Der mittlere $\mathrm{Q}_{\mathrm{s}}$-Index lag in allen Gruppen unterhalb des altersentsprechenden Normbereichs.

Die $\mathrm{Q}_{\mathrm{p}} / \mathrm{Q}_{\mathrm{s}}$-Werte waren sowohl bei den eu- als auch bei den tachypnoeischen Säuglingen erhöht, wobei eine Tendenz zu höheren $\mathrm{Q}_{\mathrm{p}} / \mathrm{Q}_{\mathrm{s}}$-Werten bei den tachypnoeischen Säuglingen erkennbar war, die jedoch keine statistische Signifikanz zwischen den Gruppen erreichte (p = 0,07) (Abbildung 3.2).

Die arterielle Sauerstoffsättigung $\left(\mathrm{SAO}_{2}\right)$, die Sauerstoffaufnahme $\left(\mathrm{VO}_{2}\right.$ Index $)$, der mittlere pulmonalarterielle Druck sowie auch die Indizes des system- und pulmonalvaskulären Widerstands (SVRI bzw. PVRI) waren nicht signifikant verschieden zwischen den Gruppen.

Normwertige Ejektionsfraktionen (EF) und linksventrikuläre enddiastolische Drücke (LVedP) sowie mittlere atriale Drücke (RAP und LAP) waren Ausdruck einer normalen Ventrikelfunktion in allen drei Patientengruppen. 
Tabelle 3.4: Hämodynamische Parameter der untersuchten Säuglinge mit Links-Rechts-Shunt eingeteilt nach Atemfrequenzgruppen

\begin{tabular}{|c|c|c|c|c|c|c|c|c|c|c|c|c|}
\hline \multirow[t]{2}{*}{ Atemfrequenz $\left[\mathrm{min}^{-1}\right]$ : } & \multirow[t]{2}{*}{ Richtwerte $^{1}$} & \multicolumn{3}{|c|}{$<50$} & \multicolumn{3}{|c|}{$50-60$} & \multicolumn{3}{|c|}{$>60$} & \multirow[b]{2}{*}{ Signifikanz } & \multirow[b]{2}{*}{ p-Wert } \\
\hline & & $\mathrm{N}$ & & $\pm s$ & $\mathrm{~N}$ & & $\pm \mathrm{s}$ & $\mathrm{N}$ & $\mathrm{x} \pm$ & $\mathrm{s}$ & & \\
\hline Herzfrequenz $\left[\mathrm{min}^{-1}\right]$ & $135-165$ & 30 & 122 & \pm 11 & 18 & 127 & \pm 8 & 22 & $137 \pm$ & 10 & $* * *$ & $<0,001$ \\
\hline Ejektionsfraktion [\%] & $64-83$ & 27 & 64 & \pm 7 & 15 & 65 & \pm 7 & 16 & $68 \pm$ & 9 & ns & 0,17 \\
\hline LVedP [mmHg] & $7-10$ & 30 & 9 & \pm 3 & 17 & 10 & \pm 2 & 19 & $9 \pm$ & 3 & ns & 0,51 \\
\hline $\mathrm{VO}_{2 \text { Index }}\left[\mathrm{ml} / \mathrm{min} / \mathrm{m}^{2}\right]$ & $110-150$ & 16 & 129 & \pm 19 & 7 & 139 & \pm 19 & 8 & $125 \pm$ & 33 & ns & 0,49 \\
\hline $\mathrm{Q}_{\mathrm{p}} / \mathrm{Q}_{\mathrm{s}}$ & 1 & 30 & 3,0 & $\pm 1,7$ & 18 & 3,9 & $\pm 2,5$ & 22 & $4,4 \pm$ & 2,5 & ns & 0,07 \\
\hline $\mathrm{Q}_{\mathrm{p} \text { Index }}\left[1 / \mathrm{min} / \mathrm{m}^{2}\right]$ & $3,7-5,5$ & 30 & 7,2 & $\pm 3,3$ & 18 & 9,4 & $\pm 4,4$ & 21 & $8,6 \pm$ & 3,5 & ns & 0,11 \\
\hline $\mathrm{Q}_{\text {s Index }}\left[1 / \mathrm{min} / \mathrm{m}^{2}\right]$ & $3,7-5,5$ & 30 & 2,7 & $\pm 1,0$ & 18 & 2,6 & $\pm 0,6$ & 21 & $2,1 \pm$ & 0,5 & * & 0,02 \\
\hline RAP [mmHg] & $1-4$ & 30 & & \pm 2 & 18 & & \pm 2 & 21 & $6 \pm$ & 2 & ns & 0,16 \\
\hline LAP [mmHg] & $4-7$ & 27 & 10 & \pm 4 & 14 & 8 & \pm 3 & 18 & $8 \pm$ & 2 & ns & 0,36 \\
\hline $\mathrm{PAP}$ [mmHg] & $12-20$ & 30 & 33 & \pm 13 & 18 & 38 & \pm 15 & 18 & $31 \pm$ & 8 & ns & 0,20 \\
\hline MAP [mmHg] & $65-80$ & 30 & 63 & \pm 9 & 18 & 60 & \pm 8 & 21 & $54 \pm$ & 9 & $* *$ & 0,004 \\
\hline SVRI $\left[E \times m^{2}\right]$ & $12-22$ & 30 & 23,2 & $\pm 6,5$ & 18 & 22,8 & $\pm 6,9$ & 21 & $24,4 \pm$ & 7,4 & ns & 0,76 \\
\hline PVRI [E $\left.\times m^{2}\right]$ & $1,3-2,9$ & 27 & 3,8 & $\pm 1,8$ & 14 & 3,6 & $\pm 2,7$ & 16 & $2,7 \pm$ & 1,2 & ns & 0,17 \\
\hline $\mathrm{SAO}_{2}[\%]$ & $93-97$ & 30 & 94 & \pm 7 & 18 & 94 & \pm 5 & 21 & $92 \pm$ & 5 & ns & 0,33 \\
\hline
\end{tabular}

Ergebnisse der unifaktoriellen Varianzanalyse (ANOVA): Statistisch signifikante Mittelwertunterschiede zwischen den Atemfrequenzgruppen: ${ }^{* * *} \mathrm{p}<0,001 ; * * \mathrm{p}=0,001$ bis $<0,01$; * $\mathrm{p}=0,01$ bis 0,05 ; ns = nicht signifikant.

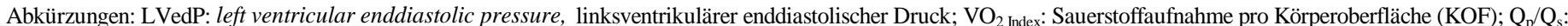

Verhältnis aus pulmonalem zu systemischem Herzzeitvolumen; $\mathrm{Q}_{\mathrm{p} \text { Index: }}$ Pulmonales Herzzeitvolumen pro KOF; $\mathrm{Q}_{\mathrm{s}}$ Index: Systemisches Herzzeitvolumen pro KOF; RAP: mean right atrial pressure, mittlerer rechtsatrialer Druck; LAP: mean left atrial pressure, mittlerer linksatrialer Druck; PAP: mean pulmonary artery pressure, mittlerer

Pulmonalarteriendruck: MAP: mean arterial pressure, mittlerer arterieller Druck; SVRI: systemic vascular resistance index, Index für den systemvaskulären Widerstand; PVRI:

pulmonary vascular resistance index, Index für den pulmonalvaskulären Widerstand; $\mathrm{SAO}_{2}$ : Arterielle Sauerstoffsättigung.

${ }^{1}$ : In Anlehnung an HEXEL (1996), MASSIN und VON BERNUTH (1997), PARK (1999) und APITZ (2002). 
Die folgenden Box-Whisker-Plots veranschaulichen das Verhalten des mittleren arteriellen Drucks sowie das Verhältnis von pulmonalem zu systemischem Herzzeitvolumen bei zunehmenden Atemfrequenzen.

Abbildung 3.1: Signifikanter Abfall des mittleren arteriellen Drucks (MAP) bei zunehmender Tachypnoe im untersuchten Patientenkollektiv $(p=0,004)$
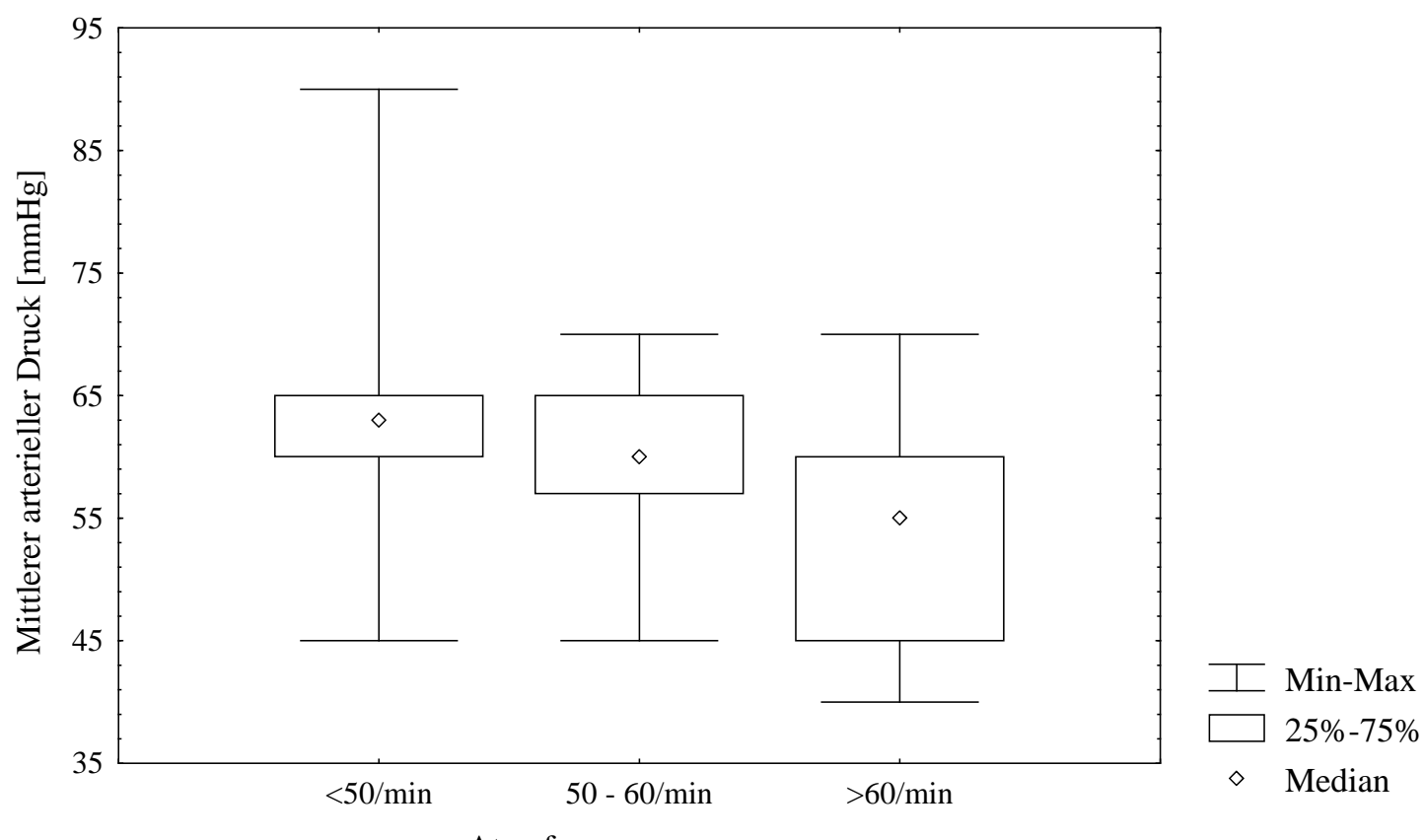

Atemfrequenzgruppen

Abbildung 3.2: Verhältnis von pulmonalem zu systemischem Herzzeitvolumen $\left(\mathrm{Q}_{\mathrm{p}} / \mathrm{Q}_{\mathrm{s}}\right)$ bei zunehmender Tachypnoe im untersuchten Patientenkollektiv $(p=0,07)$
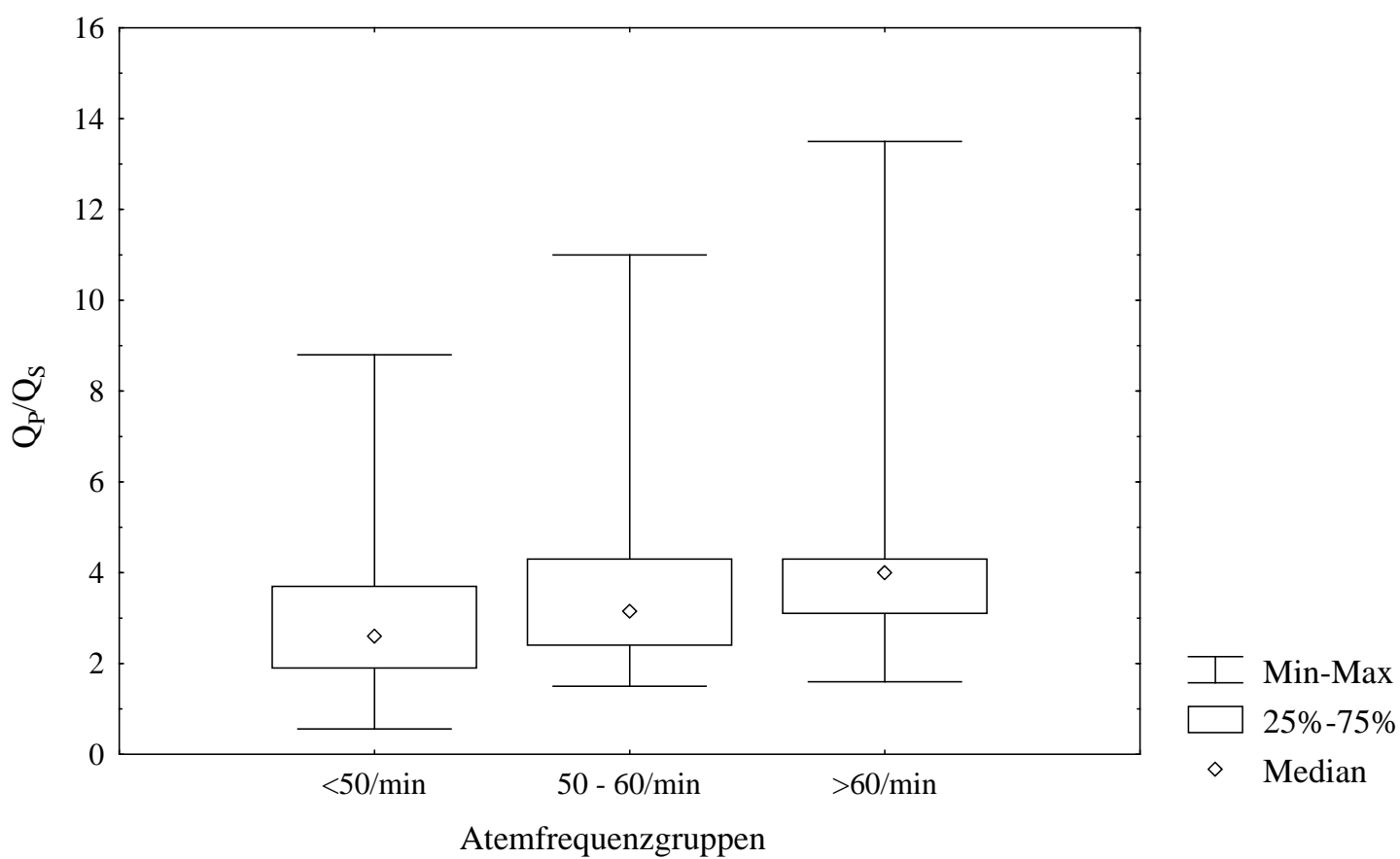

$\diamond \quad$ Median 


\subsubsection{Neurohumorale Parameter}

Die Säuglinge mit normwertigen Atemfrequenzen wiesen im Mittel altersentsprechend normale Renin- und Noradrenalinspiegel auf, trotz auch in dieser Gruppe deutlich erhöhter $\mathrm{Q}_{\mathrm{p}} / \mathrm{Q}_{\mathrm{s}}$-Werte von 3,0 \pm 1,7 (Tabelle 3.5).

Verglichen damit wiesen Säuglinge mit einer Atemfrequenz von > 60 pro Minute im Durchschnitt eine 8,8-fach höhere Plasma-Renin-Aktivität auf (88 \pm 64 ng/ml/h), eine 5,1-fach höhere Konzentration des Renins (907 $\pm 654 \mu \mathrm{U} / \mathrm{ml}$ ), 2,8-fach höhere Spiegel an Noradrenalin (1041 $\pm 622 \mathrm{ng} / \mathrm{l})$ und eine 2,3-fach höhere Konzentration des Aldosterons (1460 \pm 1508 pg/ml). Diese Ergebnisse entsprachen statistisch signifikanten Mittelwertunterschieden zwischen den Atemfrequenzgruppen im Kruskal-Wallis-Test (Plasma-ReninAktivität: $\mathrm{p}=0,005$; Reninkonzentration: $\mathrm{p}=0,003$; Noradrenalin: $\mathrm{p}<0,001$; Aldosteron: $\mathrm{p}=0,01$ ). Das Adrenalin hingegen zeigte keine statistisch signifikanten Unterschiede zwischen den Gruppen.

Der Anstieg des Noradrenalins bei zunehmender Tachypnoe wird in der folgenden Abbildung veranschaulicht:

Abbildung 3.3: Signifikanter Anstieg des Plasma-Noradrenalinspiegels bei zunehmender Tachypnoe im untersuchten Patientenkollektiv ( $\mathrm{p}<0,001)$

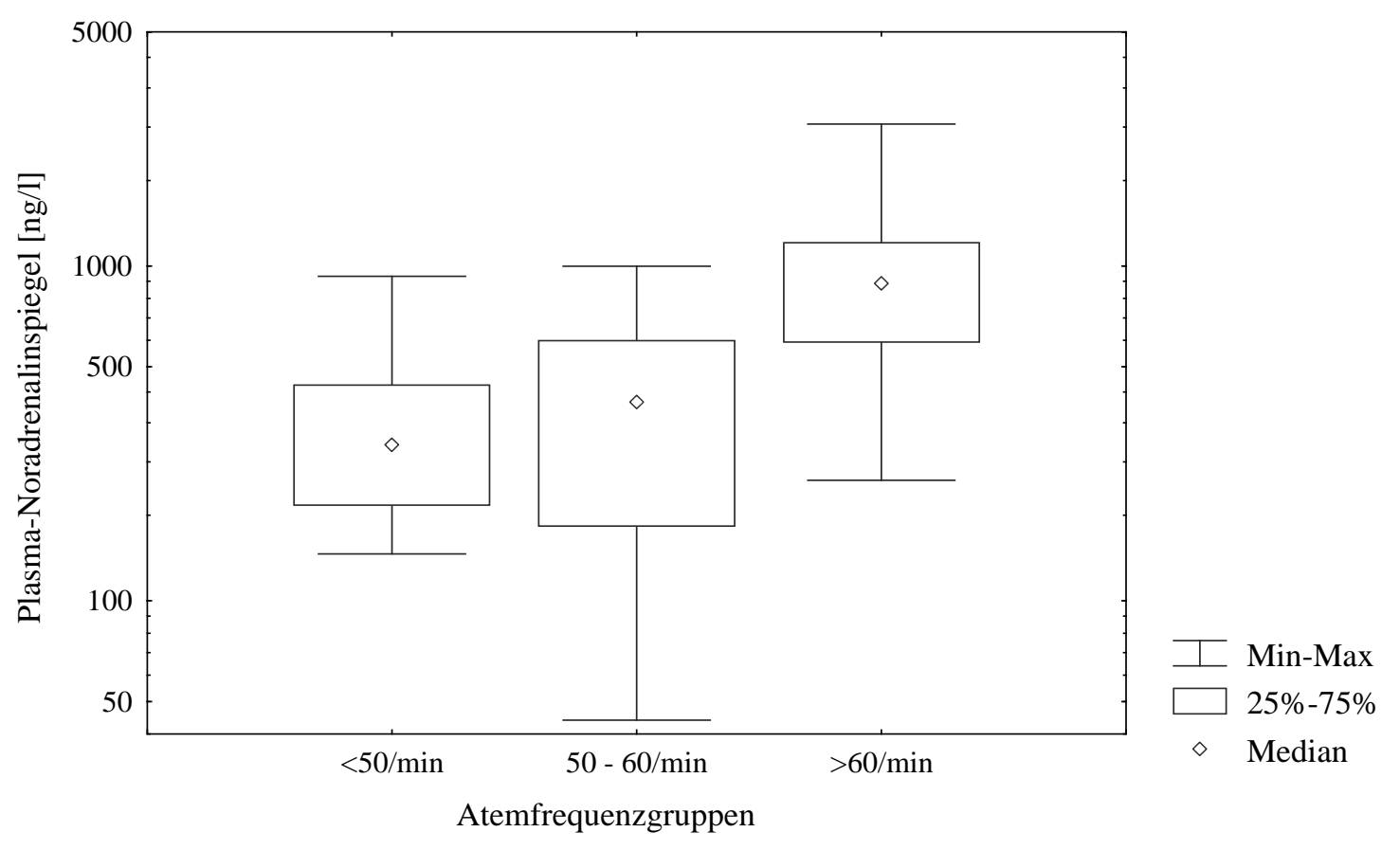


Tabelle 3.5: Alter, Medikation und neurohumorale Aktivitäten der untersuchten Säuglinge mit Links-Rechts-Shunt eingeteilt nach Atemfrequenzgruppen

\begin{tabular}{|c|c|c|c|c|c|c|c|c|c|c|c|c|c|c|c|}
\hline \multirow[t]{2}{*}{ Atemfrequenz $\left[\mathrm{min}^{-1}\right]$ : } & \multicolumn{2}{|c|}{ Richtwerte $^{1}$} & \multicolumn{4}{|c|}{$<50$} & \multicolumn{3}{|c|}{$50-60$} & \multicolumn{4}{|c|}{$>60$} & \multirow[b]{2}{*}{ Signifikanz } & \multirow[b]{2}{*}{ p-Wer } \\
\hline & 1. Trimenon & 2. Trimenon & $\mathrm{N}$ & $\mathrm{x}$ & \pm & $\mathrm{s}$ & $\mathrm{N}$ & $\mathrm{x} \pm$ & $\mathrm{s}$ & $\mathrm{N}$ & $\mathrm{x}$ & \pm & $\mathrm{s}$ & & \\
\hline Alter [Monate] & $0-4$ & $5-8$ & 30 & 5,7 & \pm 1 & 1,8 & 18 & $4,4 \pm$ & 2,4 & 22 & 2,6 & \pm & 1,7 & $* * *$ & $<0,001$ \\
\hline \multicolumn{16}{|l|}{ Medikamente } \\
\hline Furosemid [mg/kg KG/d] & \multirow{2}{*}{\multicolumn{2}{|c|}{$\begin{array}{c}1-2 \mathrm{mg} / \mathrm{kg} \mathrm{KG} / \mathrm{ED} 1-3 \mathrm{x} / \mathrm{d} \\
3-5\end{array}$}} & 8 & 1,5 & \pm 0 & 0,6 & 6 & $1,5 \pm$ & 0,4 & 17 & 2,5 & \pm & 1,4 & ns & 0,12 \\
\hline Spironolacton [mg/kg KG/d] & & & 10 & 2,6 & \pm 1 & 1,4 & 12 & $2,6 \pm$ & 0,5 & 18 & 2,8 & \pm & 0,6 & ns & 0,23 \\
\hline Propanolol [mg/kg KG/d] & \multicolumn{2}{|c|}{$2-3$} & 4 & 1,8 & \pm 0 & 0,6 & 4 & $1,7 \pm$ & 0,3 & 2 & 2,1 & \pm & 0,4 & ns & 0,58 \\
\hline Captopril [mg/kg KG/d] & \multicolumn{2}{|c|}{$1-2$} & 0 & & & & 0 & & & 2 & 0,7 & \pm & 0,5 & & \\
\hline \multicolumn{16}{|l|}{ Neurohumorale Aktivität } \\
\hline Plasma-Renin-Aktivität [ng/ml/h] & $7-24$ & $2-10$ & 10 & 10 & \pm 7 & & 7 & $35 \pm$ & 40 & 10 & 88 & \pm & 64 & $* *$ & 0,005 \\
\hline Reninkonzentration $[\mu \mathrm{U} / \mathrm{ml}]$ & $11-148$ & $17-174$ & 16 & 177 & \pm 2 & 227 & 9 & $373 \pm$ & 677 & 9 & 907 & \pm & 654 & $* *$ & 0,003 \\
\hline Noradrenalin [ng/l] & $509-855$ & $341-505$ & 24 & 362 & \pm 2 & 219 & 14 & $420 \pm$ & 268 & 14 & 1041 & \pm & 622 & $* * *$ & $<0,001$ \\
\hline
\end{tabular}

Ergebnisse im Kruskal-Wallis -Test: Statistisch signifikante Mittelwertunterschiede zwischen den Atemfrequenzgruppen: ${ }^{* * *} \mathrm{p}<0,001 ; * * \mathrm{p}=0,001$ bis $<0,01 ; * \mathrm{p}=0,01$ bis 0,$05 ;$ ns $=$ nicht signifikant.

${ }^{1}$ : Für Furosemid: mg/kg KG/ED 1 - 3 x/d: Milligramm pro Kilogramm Körpergewicht pro Einzeldosis 1 - 3 x pro Tag. Plasma-Renin-Aktivität und Aldosteron in Anlehnung an FISELIER et al. 1983; Reninkonzentration: KRÜGER et al. 1998; Noradrenalin und Adrenalin: EICHLER et al. 1989. 


\subsubsection{Gesonderte Auswertung für das erste und das zweite Trimenon}

In der Gesamtauswertung aller Patienten fiel auf, daß die Säuglinge mit den höchsten Atemfrequenzen im Mittel jünger waren als die Säuglinge mit normalen oder gering erhöhten Atemfrequenzen (Tabelle 3.5). Da für einige der untersuchten Parameter eine Altersabhängigkeit bekannt ist, wurden die Patientendaten in einer zweiten Analyse getrennt für das erste und zweite Trimenon ausgewertet, wobei die Aussagekraft dieser Untersuchung durch die zum Teil entstehende kleine Gruppenstärke begrenzt ist.

Auch für die Säuglinge im ersten Trimenon konnte ein signifikanter Herzfrequenzanstieg bei zunehmender Tachypnoe beobachtet werden $(\mathrm{p}=0,002)$ (Tabelle 3.6). Die übrigen systemischen und pulmonalen hämodynamischen Parameter sowie die Parameter der Sauerstoffversorgung erwiesen sich als nicht signifikant verschieden zwischen den Gruppen eupnoeischer und tachypnoeischer Säuglinge. Der wie in der Gesamtauswertung auffallende Abfall des MAP bei schwerer Tachypnoe war nicht statistisch signifikant. Es wurde ein deutlicher Anstieg der neurohumoralen Aktivität bei zunehmender Tachypnoe beobachtet, wobei jedoch nur der Anstieg des Noradrenalins statistische Signifikanz zwischen den Gruppen erreichte $(\mathrm{p}=0,01)$ (Tabelle 3.7).

Im zweiten Trimenon waren die mittleren Herzfrequenzen nicht signifikant verschieden zwischen den Atemfrequenzgruppen. Der $\mathrm{Q}_{\mathrm{p}} / \mathrm{Q}_{\mathrm{s}}$-Quotient wies als einziger hämodynamischer Parameter statistisch signifikante Unterschiede zwischen den Gruppen auf $(p=0,02)$ und stieg bei zunehmender Tachypnoe an (Tabelle 3.8). Die neurohumorale Aktivität lag in dieser Altersgruppe zusammenfassend bei den schwer tachypnoeischen Säuglingen höher als bei den eupnoeischen Säuglingen (Tabelle 3.9).

Auf Grund der geringen Fallzahl $(\mathrm{N}=3)$ wurden die Säuglinge im dritten Trimenon nicht separat ausgewertet. 
Tabelle 3.6: Hämodynamische Parameter bei 31 untersuchten Säuglingen mit Links-Rechts-Shunt im ersten Trimenon eingeteilt nach Atemfrequenzgruppen

\begin{tabular}{|c|c|c|c|c|c|c|c|c|c|}
\hline \multirow[t]{2}{*}{ Atemfrequenz $\left[\mathrm{min}^{-1}\right]$} & \multicolumn{3}{|c|}{$<50$} & \multicolumn{2}{|r|}{$50-60$} & \multicolumn{2}{|r|}{$>60$} & \multirow[b]{2}{*}{ Signifikanz } & \multirow[b]{2}{*}{ p-Wert } \\
\hline & $\mathrm{N}$ & & $\pm \mathrm{s}$ & $\mathrm{N}$ & $\mathrm{x} \pm \mathrm{s}$ & $\mathrm{N}$ & $\mathrm{x} \pm \mathrm{s}$ & & \\
\hline Herzfrequenz $\left[\mathrm{min}^{-1}\right]$ & 4 & 120 & \pm 6 & 8 & $127 \pm 12$ & 19 & $138 \pm 10$ & ** & 0,002 \\
\hline Ejektionsfraktion [\%] & 4 & 61 & \pm 11 & 6 & $66 \pm 9$ & 13 & $67 \pm 10$ & ns & 0,54 \\
\hline LVedP [mmHg] & 4 & & \pm 2 & 7 & $10 \pm 3$ & 16 & $10 \pm 3$ & ns & 0,58 \\
\hline $\mathrm{VO}_{2 \text { Index }}\left[\mathrm{ml} / \mathrm{min} / \mathrm{m}^{2}\right]$ & 1 & 108 & \pm & 3 & $124 \pm 6$ & 6 & $119 \pm 36$ & ns & 0,91 \\
\hline $\mathrm{Q}_{\mathrm{p}} / \mathrm{Q}_{\mathrm{s}}$ & 4 & 4,0 & $\pm 1,9$ & 8 & $5,1 \pm 3,3$ & 19 & $4,0 \pm 1,5$ & ns & 0,46 \\
\hline $\mathrm{Q}_{\mathrm{p} \text { Index }}\left[\mathrm{l} / \mathrm{min} / \mathrm{m}^{2}\right]$ & 4 & 7,6 & $\pm 3,5$ & 8 & $11,1 \pm 5,3$ & 18 & $8,0 \pm 2,7$ & ns & 0,12 \\
\hline $\mathrm{Q}_{\text {s Index }}\left[\mathrm{l} / \mathrm{min} / \mathrm{m}^{2}\right]$ & 4 & 1,9 & $\pm 0,3$ & 8 & $2,4 \pm 0,8$ & 18 & $2,1 \pm 0,4$ & ns & 0,28 \\
\hline RAP [mmHg] & 4 & & \pm 1 & 8 & $5 \pm 2$ & 18 & $6 \pm 2$ & ns & 0,53 \\
\hline LAP [mmHg] & 3 & 7 & \pm 1 & 6 & $9 \pm 4$ & 15 & $8 \pm 2$ & ns & 0,34 \\
\hline PAP [mmHg] & 4 & & \pm 6 & 8 & $38 \pm 12$ & 15 & $30 \pm 7$ & ns & 0,14 \\
\hline MAP [mmHg] & 4 & 59 & \pm 7 & 8 & $60 \pm 8$ & 18 & $53 \pm 9$ & ns & 0,16 \\
\hline SVRI $\left[E \times m^{2}\right]$ & 4 & 28,3 & $\pm 2,6$ & 8 & $25,3 \pm 9,6$ & 18 & $23,7 \pm 6,6$ & ns & 0,51 \\
\hline PVRI [E $\left.x \mathrm{~m}^{2}\right]$ & 3 & 5,0 & $\pm 2,4$ & 6 & $3,0 \pm 2,8$ & 13 & $2,6 \pm 1,2$ & ns & 0,18 \\
\hline $\mathrm{SAO}_{2}[\%]$ & 4 & 95 & \pm 3 & 8 & $95 \pm 3$ & 18 & $91 \pm 5$ & ns & 0,09 \\
\hline
\end{tabular}

Ergebnisse der unifaktoriellen Varianzanalyse (ANOVA): Statistisch signifikante Mittelwertunterschiede zwischen den Atemfrequenzgruppen: ${ }^{* * *} \mathrm{p}$ $<0,001 ; * * \mathrm{p}=0,001$ bis $<0,01 ; * \mathrm{p}=0,01$ bis 0,05 ; ns = nicht signifikant.

Abkürzungen: LVedP: left ventricular enddiastolic pressure, linksventrikulärer enddiastolischer Druck; $\mathrm{VO}_{2}$ Index: Sauerstoffaufnahme pro Körperoberfläche (KOF); $\mathrm{Q}_{\mathrm{p}} / \mathrm{Q}_{\mathrm{s}}$ : Verhältnis aus pulmonalem zu systemischem Herzzeitvolumen; $\mathrm{Q}_{\mathrm{p}}$ Index: Pulmonales Herzzeitvolumen pro KOF; $\mathrm{Q}_{\mathrm{s}}$ Index: Systemisches Herzzeitvolumen pro KOF; RAP: mean right atrial pressure, mittlerer rechtsatrialer Druck; LAP: mean left atrial pressure, mittlerer linksatrialer Druck; PAP: mean pulmonary artery pressure, mittlerer Pulmonalarteriendruck; MAP: mean arterial pressure, mittlerer arterieller Druck; SVRI: systemic vascular resistance index, Index für den systemvaskulären Widerstand; PVRI: pulmonary vascular resistance index, Index für den pulmonalvaskulären Widerstand; $\mathrm{SAO}_{2}$ : Arterielle Sauerstoffsättigung. 
Tabelle 3.7: Medikation und neurohumorale Aktivitäten bei 31 untersuchten Säuglingen mit Links-Rechts-Shunt im ersten Trimenon eingeteilt nach Atemfrequenzgruppen

\begin{tabular}{|c|c|c|c|c|c|c|c|c|}
\hline \multirow[t]{2}{*}{ Atemfrequenz $\left[\min ^{-1}\right]$} & \multicolumn{2}{|r|}{$<50$} & \multicolumn{2}{|r|}{$50-60$} & \multicolumn{2}{|r|}{$>60$} & \multirow[b]{2}{*}{ Signifikanz } & \multirow[b]{2}{*}{ p-Wert } \\
\hline & $\mathrm{N}$ & $\mathrm{x} \pm \mathrm{s}$ & $\mathrm{N}$ & $x \pm s$ & $\mathrm{~N}$ & $x \pm s$ & & \\
\hline \multicolumn{9}{|l|}{ Medikamente } \\
\hline Furosemid [mg/kg KG/d] & 2 & $2,3 \pm 0,6$ & 4 & $1,6 \pm 0,4$ & 15 & $2,6 \pm 1,4$ & ns & 0,50 \\
\hline Spironolacton [mg/kg KG/d] & 2 & $4,8 \pm 1,9$ & 5 & $2,6 \pm 0,7$ & 15 & $2,9 \pm 0,6$ & ns & 0,15 \\
\hline$\beta$-Methyldigoxin [nmol/l] & 3 & $1,3 \pm 0,8$ & 4 & $1,4 \pm 0,7$ & 14 & $1,3 \pm 0,7$ & ns & 0,98 \\
\hline Propanolol [mg/kg KG/d] & 0 & & 1 & $1,6 \pm$ & 0 & & - & - \\
\hline Captopril [mg/kg KG/d] & 0 & & 0 & & 2 & $0,7 \pm 0,5$ & - & - \\
\hline \multicolumn{9}{|l|}{ Neurohumorale Aktivität } \\
\hline Plama-Renin-Aktivität [ng/ml/h] & 1 & $4 \pm$ & 3 & $66 \pm 47$ & 10 & $88 \pm 64$ & ns & 0,33 \\
\hline Reninkonzentration [ $\mu \mathrm{U} / \mathrm{ml}]$ & 2 & $64 \pm 19$ & 4 & $663 \pm 1010$ & 7 & $960 \pm 711$ & ns & 0,13 \\
\hline Noradrenalin [ng/l] & 3 & $366 \pm 189$ & 8 & $456 \pm 188$ & 12 & $1020 \pm 673$ & $*$ & 0,01 \\
\hline Adrenalin [ng/l] & 3 & $21 \pm 9$ & 8 & $108 \pm 111$ & 13 & $110 \pm 135$ & ns & 0,14 \\
\hline Aldosteron [pg/ml] & 2 & $125 \pm 80$ & 6 & $1086 \pm 845$ & 16 & $1538 \pm 1575$ & ns & 0,11 \\
\hline
\end{tabular}

Ergebnisse im Kruskal-Wallis- Test: Statistisch signifikante Mittelwertunterschiede zwischen den Atemfrequenzgruppen: *** $\mathrm{p}<0,001 ;{ }^{* *} \mathrm{p}=0,001$ bis $<0,01 ; * \mathrm{p}=0,01$ bis 0,05 ; ns $=$ nicht signifikant 
Tabelle 3.8: Hämodynamische Parameter bei 36 untersuchten Säuglingen mit Links-Rechts-Shunt im zweiten Trimenon eingeteilt nach Atemfrequenzgruppen

\begin{tabular}{|c|c|c|c|c|c|c|c|c|c|c|c|c|}
\hline \multirow[t]{2}{*}{ Atemfrequenz $\left[\mathrm{min}^{-1}\right]$} & \multicolumn{3}{|c|}{$<50$} & \multicolumn{3}{|c|}{$50-60$} & \multicolumn{4}{|c|}{$>60$} & \multirow[b]{2}{*}{ Signifikanz } & \multirow[b]{2}{*}{ p-Wert } \\
\hline & $\mathrm{N}$ & $\mathrm{x}$ & $\pm s$ & $\mathrm{~N}$ & $\mathrm{x}$ & $\pm s$ & $\mathrm{~N}$ & $\mathrm{x}$ & \pm & $\mathrm{s}$ & & \\
\hline Herzfrequenz $\left[\mathrm{min}^{-1}\right]$ & 24 & 124 & \pm 9 & 9 & 126 & \pm 3 & 3 & 129 & \pm & 1 & ns & 0,53 \\
\hline Ejektionsfraktion [\%] & 22 & 64 & $\pm 5,7$ & 8 & 64 & $\pm 4,7$ & 3 & 72 & \pm & 2,0 & ns & 0,08 \\
\hline LVedP [mmHg] & 24 & 9 & \pm 3 & 9 & 9 & \pm 1 & 3 & 8 & \pm & 3 & ns & 0,72 \\
\hline $\mathrm{VO}_{2 \text { Index }}\left[\mathrm{ml} / \mathrm{min} / \mathrm{m}^{2}\right]$ & 14 & 128 & \pm 17 & 3 & 148 & \pm 20 & 2 & 145 & \pm & 8 & ns & 0,13 \\
\hline $\mathrm{Q}_{\mathrm{p}} / \mathrm{Q}_{\mathrm{s}}$ & 24 & 3,0 & $\pm 1,6$ & 9 & 3,2 & $\pm 1,1$ & 3 & 6,8 & \pm & 5,8 & $*$ & 0,02 \\
\hline $\mathrm{Q}_{\mathrm{p} \text { Index }}\left[\mathrm{l} / \mathrm{min} / \mathrm{m}^{2}\right]$ & 24 & 7,5 & $\pm 3,2$ & 9 & 8,6 & $\pm 3,0$ & 3 & 12,2 & \pm & 6,4 & ns & 0,09 \\
\hline $\mathrm{Q}_{\mathrm{s} \text { Index }}\left[\mathrm{l} / \mathrm{min} / \mathrm{m}^{2}\right]$ & 24 & 2,7 & $\pm 0,9$ & 9 & 2,7 & $\pm 0,5$ & 3 & 2,2 & \pm & 0,9 & ns & 0,53 \\
\hline RAP [mmHg] & 24 & 5 & \pm 3 & 9 & 4 & \pm 2 & 3 & 6 & \pm & 2 & ns & 0,34 \\
\hline LAP [mmHg] & 22 & 9 & \pm 3 & 7 & 8 & \pm 3 & 3 & 8 & \pm & 3 & ns & 0,49 \\
\hline PAP [mmHg] & 24 & 34 & \pm 14 & 9 & 41 & \pm 17 & 3 & 39 & \pm & 4 & ns & 0,43 \\
\hline MAP [mmHg] & 24 & 64 & \pm 10 & 9 & 60 & \pm 8 & 3 & 61 & \pm & 6 & ns & 0,68 \\
\hline SVRI $\left[E x^{2}\right]$ & 24 & 23,3 & $\pm 6,1$ & 9 & 20,8 & $\pm 3,3$ & 3 & 28,5 & \pm & 12,2 & ns & 0,18 \\
\hline PVRI [E $\left.x \mathrm{~m}^{2}\right]$ & 22 & 3,8 & $\pm 1,7$ & 7 & 4,2 & $\pm 2,8$ & 3 & 3,0 & \pm & 1,3 & ns & 0,69 \\
\hline SAO2 [\%] & 24 & 96 & \pm 5 & 9 & 96 & \pm 2 & 3 & 96 & \pm & 2 & ns & 0,99 \\
\hline
\end{tabular}

Ergebnisse der unifaktoriellen Varianzanalyse (ANOVA): Statistisch signifikante Mittelwertunterschiede zwischen den Atemfrequenzgruppen: $* * * \mathrm{p}$ $<0,001 ; * * \mathrm{p}=0,001$ bis $<0,01 ; * \mathrm{p}=0,01$ bis 0,05 ; ns $=$ nicht signifikant.

Abkürzungen: LVedP: left ventricular enddiastolic pressure, linksventrikulärer enddiastolischer Druck; $\mathrm{VO}_{2 \text { Index }}$ : Sauerstoffaufnahme pro Körperoberfläche (KOF); $Q_{p} / Q_{s}$ : Verhältnis aus pulmonalem zu systemischem Herzzeitvolumen; $Q_{p}$ Index: Pulmonales Herzzeitvolumen pro KOF; $Q_{s}$ Index: Systemisches Herzzeitvolumen pro KOF; RAP: mean right atrial pressure, mittlerer rechtsatrialer Druck; LAP: mean left atrial pressure , mittlerer linksatrialer Druck; PAP: mean pulmonary artery pressure, mittlerer Pulmonalarteriendruck; MAP: mean arterial pressure, mittlerer arterieller Druck; SVRI: systemic vascular resistance index, Index für den systemvaskulären Widerstand; PVRI: pulmonary vascular resistance index , Index für den pulmonalvaskulären Widerstand; $\mathrm{SAO}_{2}$ : Arterielle Sauerstoffsättigung. 
Tabelle 3.9: Medikation und neurohumorale Aktivitäten bei 36 untersuchten Säuglingen mit Links-Rechts-Shunt im zweiten Trimenon eingeteilt nach Atemfrequenzgruppen

\begin{tabular}{|c|c|c|c|c|c|c|c|c|}
\hline \multirow[t]{2}{*}{ Atemfrequenz $\left[\mathrm{min}^{-1}\right]$} & \multicolumn{2}{|c|}{$<50$} & \multicolumn{2}{|c|}{$50-60$} & \multicolumn{2}{|r|}{$>60$} & & \\
\hline & $\mathrm{N}$ & $\mathrm{x} \pm \mathrm{s}$ & $\mathrm{N}$ & $x \pm s$ & $\mathrm{~N}$ & $\mathrm{x} \pm \mathrm{s}$ & Signifikanz & p-Wert \\
\hline
\end{tabular}

Medikamente

Furosemid [mg/kg KG/d]

Spironolacton [mg/kg KG/d]

$\beta$-Methyldigoxin [nmol/l]

Propanolol [mg/kg KG/d]

Captopril [mg/kg KG/d]

$\begin{array}{ll}6 & 1,3 \pm 0,4 \\ 8 & 2,0 \pm 0,7 \\ 9 & 0,7 \pm 0,4 \\ 4 & 1,8 \pm 0,6 \\ 0 & \end{array}$

2
6
6
2
0

$$
\begin{aligned}
& 1,3 \pm 0,3 \\
& 2,5 \pm 0,5 \\
& 1,2 \pm 0,3 \\
& 1,9 \pm 0,5
\end{aligned}
$$

$$
\begin{aligned}
13 & \pm 9 \\
148 & \pm 54 \\
247 & \pm 221 \\
116 & \pm 100 \\
421 & \pm 341
\end{aligned}
$$

$1,8 \pm 0,1$
$2,5 \pm 0,4$
$0,8 \pm 0,7$
$2,1 \pm 0,4$

$2,1 \pm 0,4$

Reninkonzentration $[\mu \mathrm{U} / \mathrm{ml}]$

Noradrenalin [ng/l]

Adrenalin [ng/l]

$13206 \pm 244$

Aldosteron [pg/ml]

$\begin{array}{rr}21 & 94 \pm 167 \\ 19 & 688 \pm 950\end{array}$

8

Ergebnisse im Kruskal-Wallis -Test: Statistisch signifikante Mittelwertunterschiede zwischen den Atemfrequenzgruppen: *** $\mathrm{p}<0,001$; ** $\mathrm{p}=0,001$ bis $<0,01$; * $\mathrm{p}=0,01$ bis 0,05 ; ns = nicht signifikant. 


\subsection{Tachypnoe - Lineare Korrelation und multiple Regressionsanalyse}

Es wurden die linearen Korrelationen zwischen Atemfrequenzen und neurohumoralen bzw. hämodynamischen Parametern untersucht. Um den Einfluß der verschiedenen Parameter auf die Atemfrequenz zu gewichten, wurde im Anschluß daran eine multiple Regressionsanalyse mit den Variablen durchgeführt, die eine statistisch signifikante Korrelation zur Zielgröße zeigten. Die Ergebnisse dieser Regressionsanalysen sind detailliert in Tabelle 3.10 dargestellt.

Die stärksten linearen Korrelationen zeigten die Atemfrequenzen mit den Herzfrequenzen ( $r=0,62, p<0,001)$, den Noradrenalinwerten $(r=0,47, p<0,001)$ und dem mittleren arteriellen Druck $(r=-0,42, p=0,001)$.

Die Plasma-Renin-Aktivität und die Reninkonzentration korrelierten zwar ebenfalls gut mit der Höhe der Atemfrequenz ( $r=0,65, \mathrm{p}<0,001$ bzw. $r=0,50, \mathrm{p}=0,002)$, sie wurden jedoch aufgrund der zwei unterschiedlichen in dieser Studie verwendeten Meßmethoden aus der multiplen Regressionsanalyse ausgeschlossen.

Klassische hämodynamische Parameter, wie der $\mathrm{Q}_{\mathrm{p}} / \mathrm{Q}_{\mathrm{s}}$-Quotient $(\mathrm{r}=0,27, \mathrm{p}=0,03)$ oder der Index des systemischen Herzzeitvolumens $(r=-0,32, p=0,01)$, wiesen schwächere Korrelationen mit den Atemfrequenzen auf (Tabelle 3.10). Paradoxerweise zeigte sich eine signifikant positive Korrelation zwischen Atemfrequenzen und Ejektionsfraktionen mit höheren Auswurffraktionen bei ausgeprägterer Tachypnoe $(r=0,3, p=0,03)$.

Das Adrenalin wies im Gegensatz zum Noradrenalin keinen statistischen Zusammenhang mit den Atemfrequenzen auf.

Die Herzfrequenz zeigte sich auch in der multiplen Regression als der dominierende Faktor in der entwickelten Regressionsgleichung (Regressionskoeffizient =0,41, p =0,002). Der maximal erreichte $\mathrm{R}^{2}$-Wert für die Gleichung war 0,6 $(\mathrm{r}=0,78)$ und ergab sich unter Einbeziehung der Parameter Herzfrequenz, Noradrenalin, mittlerer arterieller Druck, Ejektionsfraktion, Verhältnis von pulmonalem zu systemischem Herzzeitvolumen und Index des systemischen Herzzeitvolumens. Dies bedeutet, daß 60 \% der beobachteten Streuung der Atemfrequenzen durch die in die Gleichung aufgenommenen Variablen erklärt werden können. Ihre Regressionskoeffizienten und die dazugehörigen Irrtumswahrscheinlichkeiten sind der Tabelle $3.10 \mathrm{zu}$ entnehmen. 
Tabelle 3.10: Lineare Korrelationen und Ergebnisse der multiplen Regressionsanalyse bei 63 Säuglingen mit Links-Rechts-Shunt hinsichtlich der Bedeutung neurohumoraler und hämodynamischer Parameter für die Entstehung der Tachypnoe. R-Wert der multiplen Regression: $\mathrm{R}^{2}=0,6 ; \mathrm{r}=0,78$.

Regressionsgleichung: y = 0,41 x HF + 0,18 x NA + (-0,23) x MAP + 0,27 x EF + 0,27 x $\mathrm{Q}_{\mathrm{p}} / \mathrm{Q}_{\mathrm{s}}+0,15$ x $\mathrm{Q}_{\mathrm{s}}$ Index $-32,6$

\begin{tabular}{|c|c|c|c|c|}
\hline & \multicolumn{2}{|c|}{ Lineare Korrelation } & \multicolumn{2}{|c|}{ Multiple Regression } \\
\hline & $\begin{array}{l}\text { Korrelations- } \\
\text { koeffizient }\end{array}$ & p-Wert & $\begin{array}{l}\text { Regressions- } \\
\text { koeffizient }\end{array}$ & p-Wert \\
\hline Herzfrequenz $\left[\mathrm{min}^{-1}\right]$ (HF) & $0,62 * * *$ & $<0,001$ & 0,41 & 0,002 \\
\hline Noradrenalin [ng/l] (NA) & $0,47 * * *$ & $<0,001$ & 0,18 & 0,16 \\
\hline Mittlerer arterieller Druck [mmHg] (MAP) & $-0,42 * *$ & 0,001 & $-0,23$ & 0,08 \\
\hline Ejektionsfraktion [\%] (EF) & $0,3 *$ & 0,03 & 0,27 & 0,25 \\
\hline $\mathrm{Q}_{\mathrm{p}} / \mathrm{Q}_{\mathrm{s}}$ & $0,27 *$ & 0,03 & 0,27 & 0,04 \\
\hline $\mathrm{Q}_{\mathrm{S} \text { Index }}\left[\mathrm{l} / \mathrm{min} / \mathrm{m}^{2}\right]$ & $-0,32 *$ & 0,01 & 0,15 & 0,30 \\
\hline Plasma-Renin-Aktivität [ng/ml/h] & $0,65 * * *$ & $<0,001$ & - & - \\
\hline Reninkonzentration $[\mu \mathrm{U} / \mathrm{ml}]$ & $0,50 * *$ & 0,002 & - & - \\
\hline PVRI $\left[E \times \mathrm{m}^{2}\right]$ & $-0,30 *$ & 0,03 & - & - \\
\hline Aldosteron [pg/ml] & $0,37 * *$ & 0,007 & - & - \\
\hline Adrenalin [ng/l] & 0,07 ns & 0,6 & - & - \\
\hline
\end{tabular}

Statistisch signifikante lineare Korrelationen mit den Atemfrequenzen: *** $\mathrm{p}<0,001 ;{ }^{* *} \mathrm{p}=0,001$ bis $<0,01 ;{ }^{*} \mathrm{p}=0,01$ bis 0,05 ; $\mathrm{ns}=$ nicht signifikant. In der multiplen Regressionsanalyse waren $\mathrm{p}$-Werte bis $<0,3$ zugelassen (Kapitel 2.4.4).

Abkürzungen: $\mathrm{R}^{2}$ : Bestimmtheitsmaß der multiplen Regression; r: Multipler Regressionskoeffizient; $\mathrm{Q}_{\mathrm{p}} / \mathrm{Q}_{\mathrm{s}}$ : Verhältnis aus pulmonalem zu systemischem Herzzeitvolumen; $\mathrm{Q}_{\mathrm{s} \text { Index }}$ : Systemisches Herzzeitvolumen pro Körperoberfläche (KOF); PVRI: pulmonary vascular resistance index, Index für den pulmonalvaskulären Widerstand.

Das Renin wurde trotz hoher Korrelationen auf Grund der zwei unterschiedlichen Bestimmungsmethoden in der Studie aus der multiplen Regressionsanalyse ausgeschlossen. 


\subsection{Gedeihstörung - Auswertung nach Gedeihgruppen}

Die Analyse der Patientendaten hinsichtlich der Gedeihstörung erfolgte mit Hilfe der gleichen statistischen Methoden wie die Auswertung der Tachypnoe (Kapitel 2.4).

Zuerst werden im Folgenden die Verteilungen der Gewichtsperzentilen bei Geburt und zum Untersuchungszeitpunkt (Abbildung 3.4 und 3.5), im Anschluß daran die Unterschiede der klinischen, hämodynamischen und neurohumoralen Parameter zwischen Säuglingen mit normaler und mit reduzierter Gewichtszunahme betrachtet (Tabelle 3.11 bis 3.13).

\subsubsection{Verteilung der Gewichtsperzentilen bei Geburt und zum Untersuchungszeitpunkt}

Wie aus Abbildung 3.4 hervorgeht, war das Körpergewicht der Säuglinge bei Geburt annähernd normalverteilt. Nur ein Kind (1,5 \%) lag unterhalb der 3. Gewichtsperzentile. Zum Untersuchungszeitpunkt dagegen lagen 50 \% der Säuglinge ( $\mathrm{N}=35)$ mit ihrem Gewicht unterhalb der 3. Perzentile und $26 \%(\mathrm{~N}=18)$ zwischen der 3. und 10. Perzentile. Das heißt, $76 \%$ aller Patienten waren per definitionem hypo- oder dystroph. Nur zwei Säuglinge lagen oberhalb der 50. Perzentile (Abbildung 3.5). Der Anteil eutropher bzw. nicht untergewichtiger Säuglinge sank damit von 91 \% auf 24 \% von der Geburt bis zum Untersuchungszeitpunkt.

Abbildung 3.4: Verteilung der Gewichtsperzentilen zum Zeitpunkt der Geburt bei den untersuchten Säuglingen mit angeborenem Herzfehler und Links-Rechts-Shunt

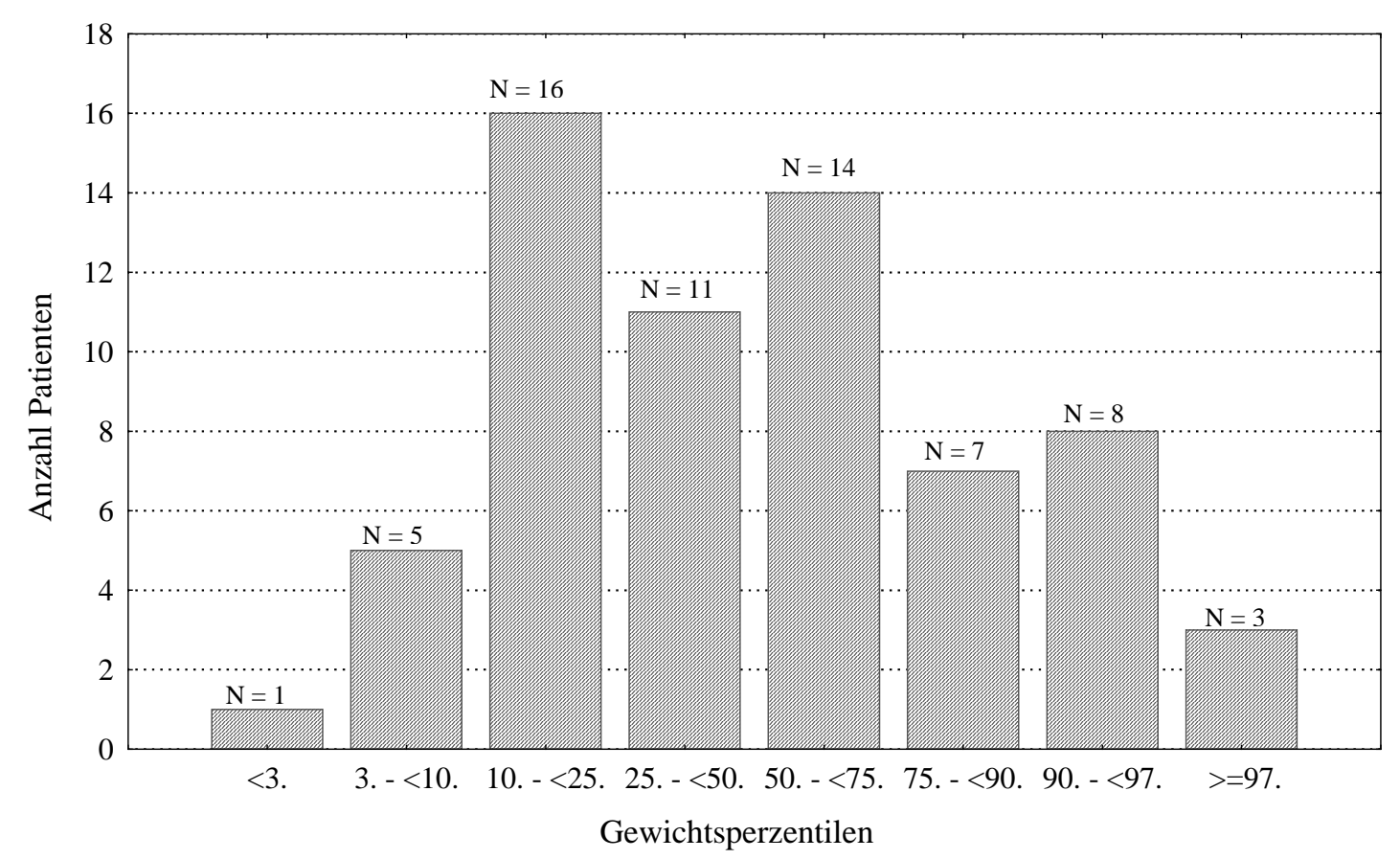




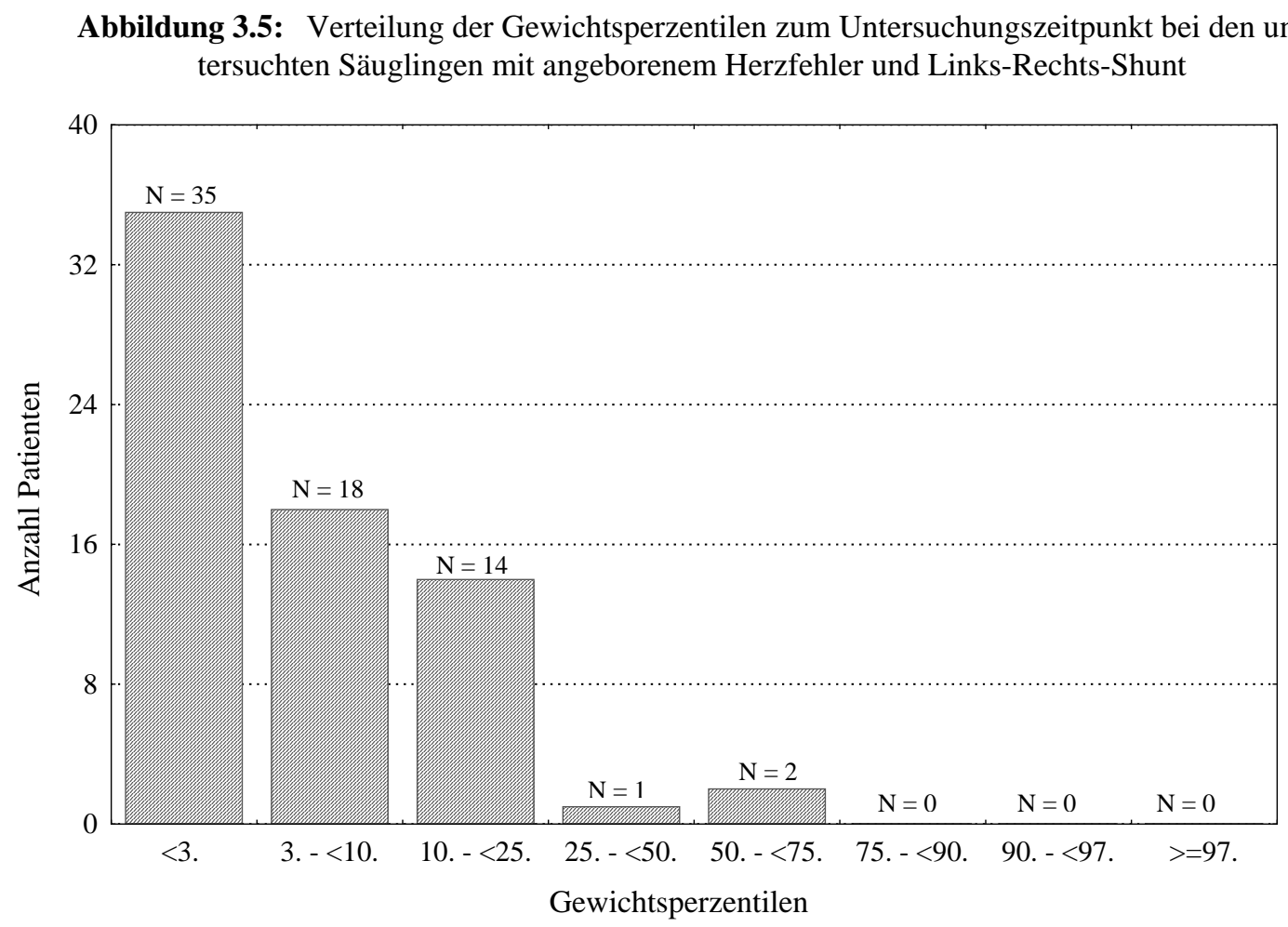

\subsubsection{Klinische Parameter}

Auch bei Betrachtung der Tabelle 3.11 wird die Relevanz der Gedeihstörung im untersuchten Patientenkollektiv deutlich: Weniger als die Hälfte der Säuglinge (42 \%) nahmen normal an Gewicht zu (> 400 g/Monat). Dagegen betrug die Gewichtszunahme bei 35 \% der Säuglinge $(\mathrm{N}=24)$ zwischen 200 und 400 Gramm pro Monat und bei $23 \%(\mathrm{~N}=16)$ sogar weniger als 200 Gramm pro Monat.

Diese Gedeihstörung war bei den Studienpatienten weder mit einer niedrigeren Kalorienzufuhr noch mit einem niedrigen Geburtsgewicht assoziiert. So lag in allen drei Gruppen die mittlere tägliche Kalorienaufnahme pro Kilogramm Körpergewicht zwischen $90 \pm 25$ und $107 \pm 24$ kcal/kg KG/d und war damit normokalorisch. Die mittleren Geburtsgewichte unterschieden sich nicht signifikant zwischen den Gruppen und entsprachen den Geburtsgewichten gesunder, eutropher Neugeborener.

Im Vergleich zu den gut und mäßig gedeihenden Säuglingen (Gewichtszunahme $>400$ bzw. 200-400 g/Monat) wurden bei Säuglingen mit schwerer Gedeihstörung gehäuft Ernährungsprobleme beobachtet. So erbrachen 38 \% der Säuglinge mit einer Gewichtszunahme von weniger als 200 Gramm pro Monat, wogegen dies nur bei 24 \% bzw. 21 \% der Säuglinge mit 
einer mäßigen oder guten Gewichtszunahme der Fall war. Der Anteil ganz oder teilweise über eine nasogastrale Sonde ernährter Säuglinge stieg mit zunehmender Gedeihproblematik deutlich von $14 \%$ auf $21 \%$ bzw. $50 \%$ an.

\subsubsection{Hämodynamische und neurohumorale Parameter}

Der pulmonalvaskuläre Widerstandsindex war der einzige hämodynamische Parameter, der statistisch signifikante Unterschiede zwischen normal und schlecht gedeihenden Säuglingen mit Links-Rechts-Shunt zeigte $(p=0,03)$, ohne daß jedoch eine eindeutige Tendenz der Werte zu erkennen war (Tabelle 3.12). Die übrigen Parameter unterschieden sich nicht statistisch signifikant zwischen den Gruppen.

Mit zunehmender Gedeihproblematik zeigte sich eine Tendenz zu höheren Hormonspiegeln im Blut. Im Vergleich zu den Säuglingen mit normaler Gewichtszunahme (> 400 g/Monat) wiesen Säuglinge mit einer Gewichtszunahme von < 200 Gramm pro Monat im Durchschnitt 1,95-fach höhere Noradrenalinspiegel und eine 2,1-fache Reninkonzentration auf. Der beobachtete Anstieg dieser Hormonspiegel erreichte jedoch keine statistische Signifikanz im Gruppenvergleich. Die Plasma-Renin-Aktivität, das Adrenalin und das Aldosteron zeigten keine entsprechende Tendenz. Die genauen Meßwerte sind aus Tabelle 3.11 ersichtlich. 
Tabelle 3.11: Klinische und neurohumorale Parameter der untersuchten Säuglinge mit Links-Rechts-Shunt eingeteilt entsprechend ihrer mittleren Gewichtsentwicklung

\begin{tabular}{|c|c|c|c|c|c|c|c|c|c|c|c|c|c|}
\hline \multirow[t]{2}{*}{ Gewichtsentwicklung [g/Monat]: } & \multicolumn{2}{|c|}{ Richtwerte $^{1}$} & \multicolumn{3}{|c|}{$>400$} & \multicolumn{3}{|c|}{$200-400$} & \multicolumn{3}{|c|}{$<200$} & \multirow[b]{2}{*}{ Signifikanz } & \multirow[b]{2}{*}{ p-Wert } \\
\hline & 1. Trimenon & 2. Trimenon & $\mathrm{N}$ & $\mathrm{x}$ & $\pm s$ & $\mathrm{~N}$ & $\mathrm{x}$ & $\pm s$ & $\mathrm{~N}$ & $\mathrm{x}$ & $\pm s$ & & \\
\hline Alter [Monate] & $0-4$ & $5-8$ & 29 & 4,5 & $\pm 1,9$ & 24 & 4,9 & $\pm 2,5$ & 16 & 3,6 & $\pm 2,4$ & ns & 0,32 \\
\hline Geburtsgewicht [kg] & - & - & 26 & 3,0 & $\pm 0,6$ & 23 & 3,3 & $\pm 0,5$ & 15 & 3,1 & $\pm 0,6$ & ns & 0,28 \\
\hline Gewicht [kg] & - & - & 29 & 5,4 & $\pm 1,1$ & 24 & 5,0 & $\pm 1,1$ & 16 & 4,3 & $\pm 1,5$ & $*$ & 0,03 \\
\hline Gewichtsentwicklung [g/Monat] & $675-1060$ & $315-490$ & 29 & 516 & \pm 109 & 24 & 304 & \pm 60 & 16 & 17 & \pm 165 & $* * *$ & $<0,001$ \\
\hline Kalorienaufnahme [kcal/kg KG/d] & $91-109$ & $90-95$ & 18 & 93 & \pm 16 & 12 & 107 & \pm 24 & 10 & 90 & \pm 25 & ns & 0,29 \\
\hline \multicolumn{14}{|l|}{ Medikamente } \\
\hline Furosemid [mg/kg KG/d] & \multicolumn{2}{|c|}{$1-2 \mathrm{mg} / \mathrm{kg} \mathrm{KG} / \mathrm{ED} 1-3 \mathrm{x} / \mathrm{d}$} & 10 & 1,9 & $\pm 1,3$ & 11 & 2,1 & $\pm 1,1$ & 10 & 2,1 & $\pm 1,1$ & ns & 0,59 \\
\hline Spironolacton [mg/kg KG/d] & \multicolumn{2}{|c|}{$3-5$} & 11 & 2,7 & $\pm 1,3$ & 18 & 2,6 & $\pm 0,7$ & 11 & 2,9 & $\pm 0,5$ & ns & 0,36 \\
\hline$\beta$-Methyldigoxin [nmol/l] & \multicolumn{2}{|c|}{$0,9-2,6$} & 14 & 1,2 & $\pm 0,7$ & 16 & 1,0 & $\pm 0,6$ & 11 & 1,1 & $\pm 0,7$ & ns & 0,75 \\
\hline Propanolol [mg/kg KG/d] & \multicolumn{2}{|c|}{$2-3$} & 3 & 1,4 & $\pm 0,1$ & 6 & 2,0 & $\pm 0,4$ & 1 & 2,0 & & ns & 0,07 \\
\hline Captopril [mg/kg KG/d] & \multicolumn{2}{|c|}{$1-2$} & 0 & & & 0 & & & 2 & 0,7 & $\pm 0,5$ & - & - \\
\hline \multicolumn{14}{|l|}{ Neurohumorale Aktivität } \\
\hline Plasma-Renin-Aktivität [ng/ml/h] & $7-24$ & $2-10$ & 10 & 20 & \pm 18 & 7 & 67 & \pm 65 & 9 & 61 & \pm 68 & ns & 0,49 \\
\hline Reninkonzentration $[\mu \mathrm{U} / \mathrm{ml}]$ & $11-148$ & $17-174$ & 16 & 289 & \pm 546 & 11 & 494 & \pm 629 & 7 & 614 & \pm 570 & ns & 0,07 \\
\hline Noradrenalin [ng/l] & $509-855$ & $341-505$ & 23 & 410 & \pm 257 & 17 & 610 & \pm 449 & 11 & 800 & \pm 752 & ns & 0,20 \\
\hline Adrenalin [ng/l] & $8-104$ & $35-159$ & 23 & 72 & \pm 117 & 17 & 126 & \pm 153 & 12 & 118 & \pm 140 & ns & 0,29 \\
\hline Aldosteron [pg/ml] & $300-2010$ & $70-390$ & 23 & 604 & \pm 634 & 16 & 1508 & \pm 1742 & 14 & 852 & \pm 721 & ns & 0,11 \\
\hline
\end{tabular}

Anteil der Gruppe

Anteil der Gruppe

Anteil der Gruppe

\begin{tabular}{lccc}
\hline Erbrechen & $24 \%$ & $21 \%$ & $38 \%$ \\
Nasogastrale Sonde & $14 \%$ & $21 \%$ & $50 \%$ \\
$<3$ Perzentile & $35 \%$ & $67 \%$ & $56 \%$ \\
3. bis $<=10$. Perzentile & $35 \%$ & $17 \%$ & $25 \%$ \\
\hline
\end{tabular}

Ergebnisse im Kruskal-Wallis -Test: Statistisch signifikante Mittelwertunterschiede zwischen den Gedeihgruppen: ${ }^{* * *} \mathrm{p}<0,001 ;{ }^{* *} \mathrm{p}=0,001$ bis $<0,01 ; * \mathrm{p}=0,01$ bis 0,05 ; ns $=$ nicht signifikant.

${ }^{1}$ : Für Furosemid: mg/kg KG/ED 1 - 3 x/d: Milligramm pro Kilogramm Körpergewicht pro Einzeldosis 1 - 3 x pro Tag. Plasma-Renin-Aktivität und Aldosteron in Anlehnung an FISELIER et al. 1983; Reninkonzentration: KRÜGER et al. 1998; Noradrenalin und Adrenalin: EICHLER 1989; Gewichtsentwicklung: WHO MULTICENTRE GROWTH REFERENCE STUDY GROUP 2006; Kalorienaufnahme: FLEISCHER MICHAELSEN et al. 2003; DEUTSCHE GESELLSCHAFT FÜR ERNÄHRUNG et al. 2008. 
Tabelle 3.12: Hämodynamische Parameter der untersuchten Säuglinge mit Links-Rechts-Shunt eingeteilt entsprechend ihrer mittleren Gewichtsentwicklung

\begin{tabular}{|c|c|c|c|c|c|c|c|c|c|c|}
\hline \multirow{2}{*}{$\begin{array}{c}\text { Gewichtsentwicklung } \\
\text { [g/Monat]: }\end{array}$} & \multirow[t]{2}{*}{ Richtwerte $^{1}$} & \multicolumn{3}{|c|}{$>400$} & \multicolumn{2}{|r|}{$200-400$} & \multicolumn{2}{|r|}{$<200$} & \multirow[b]{2}{*}{ Signifikanz } & \multirow[b]{2}{*}{ p-Wert } \\
\hline & & $\mathrm{N}$ & & $\pm \mathrm{s}$ & $\mathrm{N}$ & $x \pm s$ & $\mathrm{~N}$ & $\mathrm{x} \pm \mathrm{s}$ & & \\
\hline Herzfrequenz $\left[\mathrm{min}^{-1}\right]$ & $135-165$ & 29 & 126 & \pm 10 & 24 & $126 \pm 14$ & 16 & $133 \pm 12$ & ns & 0,10 \\
\hline Ejektionsfraktion [\%] & $64-83$ & 24 & 63 & \pm 8 & 18 & $68 \pm 6$ & 16 & $65 \pm 7$ & ns & 0,11 \\
\hline LVedP [mmHg] & $7-10$ & 27 & 9 & \pm 2 & 23 & $9 \pm 3$ & 16 & $10 \pm 3$ & ns & 0,64 \\
\hline $\mathrm{VO}_{2 \text { Index }}\left[\mathrm{ml} / \mathrm{min} / \mathrm{m}^{2}\right]$ & $110-150$ & 14 & 130 & \pm 25 & 11 & $132 \pm 21$ & 6 & $128 \pm 27$ & ns & 0,92 \\
\hline $\mathrm{Q}_{\mathrm{p}} / \mathrm{Q}_{\mathrm{s}}$ & 1 & 29 & 3,4 & $\pm 1,7$ & 24 & $4,3 \pm 3,2$ & 16 & $3,0 \pm 1,0$ & ns & 0,17 \\
\hline $\mathrm{Q}_{\mathrm{p} \text { Index }}\left[\mathrm{ml} / \mathrm{min} / \mathrm{m}^{2}\right]$ & $3,7-5,5$ & 28 & 7,8 & $\pm 3,3$ & 24 & $9,4 \pm 4,7$ & 16 & $7,1 \pm 2,4$ & ns & 0,13 \\
\hline $\mathrm{Q}_{\text {s Index }}\left[\mathrm{ml} / \mathrm{min} / \mathrm{m}^{2}\right]$ & $3,7-5,5$ & 28 & 2,5 & $\pm 0,8$ & 24 & $2,6 \pm 1,1$ & 16 & $2,4 \pm 0,5$ & ns & 0,60 \\
\hline RAP [mmHg] & $1-4$ & 28 & & \pm 2 & 24 & $5 \pm 2$ & 16 & $6 \pm 2$ & ns & 0,48 \\
\hline LAP [mmHg] & $4-7$ & 23 & 9 & \pm 3 & 20 & $9 \pm 4$ & 16 & $8 \pm 3$ & ns & 0,80 \\
\hline PAP [mmHg] & $12-20$ & 27 & 34 & \pm 13 & 23 & $33 \pm 12$ & 15 & $35 \pm 15$ & ns & 0,88 \\
\hline MAP [mmHg] & $65-80$ & 28 & 59 & \pm 7 & 24 & $62 \pm 11$ & 16 & $57 \pm 9$ & ns & 0,17 \\
\hline SVRI $\left[E \times m^{2}\right]$ & $12-22$ & 28 & 23,7 & $\pm 6,1$ & 24 & $24,2 \pm 8,3$ & 16 & $22,4 \pm 5,8$ & ns & 0,73 \\
\hline PVRI [E $\left.x \mathrm{~m}^{2}\right]$ & $1,3-2,9$ & 23 & 3,6 & $\pm \quad 1,6$ & 19 & $2,6+1,2$ & 15 & $4,3 \pm 2,6$ & $*$ & 0,03 \\
\hline $\mathrm{SAO}_{2}[\%]$ & $93-97$ & 28 & 94 & \pm 5 & 24 & $93 \pm 7$ & 16 & $92 \pm 6$ & ns & 0,45 \\
\hline
\end{tabular}

Ergebnisse der unifaktoriellen Varianzanalyse (ANOVA): Statistisch signifikante Mittelwertunterschiede zwischen den Gedeihgruppen: *** $\mathrm{p}<0,001 ; * * \mathrm{p}=0,001$ bis $<0,01 ; * \mathrm{p}=0,01$ bis 0,05 ; ns = nicht signifikant.

Abkürzungen: LVedP: left ventricular enddiastolic pressure, linksventrikulärer enddiastolischer Druck; $\mathrm{VO}_{2}$ Index: Sauerstoffaufnahme pro Körperoberfläche (KOF); $\mathrm{Q}_{\mathrm{p}} / \mathrm{Q}_{\mathrm{s}}$ : Verhältnis aus

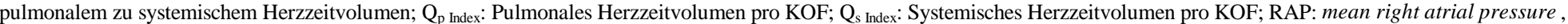
mittlerer rechtsatrialer Druck; LAP: mean left atrial pressure, mittlerer linksatrialer Druck; PAP: mean pulmonary artery pressure, mittlerer Pulmonalarteriendruck; MAP: mean

arterial pressure, mittlerer arterieller Druck; SVRI: systemic vascular resistance index, Index für den systemvaskulären Widerstand; PVRI: pulmonary vascular resistance index, Index für den pulmonalvaskulären Widerstand; $\mathrm{SAO}_{2}$ : Arterielle Sauerstoffsättigung.

': In Anlehnung an HEXEL (1996), MASSIN und VON BERNUTH (1997), PARK (1999) und APITZ (2002). 


\subsection{Gedeihstörung - Lineare Korrelation und multiple Regressionsanalyse}

Innerhalb der neurohumoralen Parameter korrelierten die Höhe der Noradrenalinspiegel $(r=-0,48, p<0,001)$ und die Plasma-Renin-Aktivität $(r=-0,43, p=0,03)$ statistisch signifikant invers mit der Gewichtszunahme. Auch die Herzfrequenzen zeigten signifikant inverse Korrelationen mit der Gewichtsentwicklung $(r=-0,31, p=0,02)$. Die Reninkonzentration korrelierte knapp oberhalb des festgelegten Signifikanzniveaus mit der Gewichtszunahme $(r=-0,33, p=0,06)$. Alle anderen untersuchten Parameter erwiesen sich als nicht signifikant korrelierend (Tabelle 3.13).

Der Versuch, ein schlüssiges multiples Regressionsmodell zur Erklärung des Symptoms Gedeihstörung zu entwickeln, wurde mit einem $\mathrm{R}^{2}=0,37$ als höchst erreichtem Wert beendet. D.h. nur $37 \%$ der beobachteten Streuung konnten durch die Variablen in der Gleichung erklärt werden. Dieses Ergebnis ergab sich unter Einbeziehung der Parameter Herzfrequenz, Noradrenalin und des probeweise aufgenommenen systemischen Herzzeitvolumen-Index. Die jeweiligen Regressionskoeffizienten und die dazugehörigen Irrtumswahrscheinlichkeiten p sind der Tabelle 3.13 zu entnehmen.

Tabelle 3.13: Lineare Korrelation und Ergebnisse der multiplen Regressionsanalyse bei 63 Säuglingen mit Links-Rechts-Shunt hinsichtlich der Bedeutung neurohumoraler und hämodynamischer Parameter für die Entstehung der kardialen Gedeihstörung. R-Wert der multiplen Regression: $\mathrm{R}^{2}=0,37 ; \mathrm{r}=0,61$.

Regressionsgleichung: $y=-0,3 \times \mathrm{HF}+(-0,41) \times \mathrm{NA}+(-0,18) \times Q_{\mathrm{s}}+1511,6$

\begin{tabular}{|c|c|c|c|c|}
\hline & \multicolumn{2}{|c|}{ Lineare Korrelation } & \multicolumn{2}{|c|}{ Multiple Regression } \\
\hline & $\begin{array}{l}\text { Korrelations- } \\
\text { koeffizient }\end{array}$ & p-Wert & $\begin{array}{l}\text { Regressions- } \\
\text { koeffizient }\end{array}$ & p-Wert \\
\hline Herzfrequenz $\left[\mathrm{min}^{-1}\right]$ & $-0,31 * *$ & 0,02 & $-0,30$ & 0,08 \\
\hline Noradrenalin [ng/l] & $-0,48 * * *$ & $<0,001$ & $-0,41$ & 0,01 \\
\hline $\mathrm{Q}_{\mathrm{s} \text { Index }}\left[\mathrm{l} / \mathrm{min} / \mathrm{m}^{2}\right]$ & 0,15 ns & 0,26 & $-0,18$ & 0,25 \\
\hline Plasma-Renin-Aktivität [ng/ml/h] & $-0,43 *$ & 0,03 & - & - \\
\hline Reninkonzentration $[\mu \mathrm{U} / \mathrm{ml}]$ & $-0,33$ ns & 0,06 & - & - \\
\hline Kalorienaufnahme [kcal/kg/d] & 0,12 ns & 0,49 & - & - \\
\hline Ejektionsfraktion [\%] & $-0,08$ ns & 0,55 & - & - \\
\hline $\mathrm{Q}_{\mathrm{p}} / \mathrm{Q}_{\mathrm{s}}$ & $-0,001 \mathrm{~ns}$ & 0,995 & - & - \\
\hline $\mathrm{Q}_{\mathrm{p} \text { Index }}\left[\mathrm{l} / \mathrm{min} / \mathrm{m}^{2}\right]$ & 0,07 ns & 0,62 & - & - \\
\hline PVRI [E x m²] & $-0,01$ ns & 0,92 & - & - \\
\hline
\end{tabular}

Statistisch signifikante lineare Korrelationen mit der Gewichtsentwicklung: *** $\mathrm{p}<0,001 ; * * \mathrm{p}=0,001$ bis $<0,01 ; * \mathrm{p}=0,01$ bis 0,05; ns = nicht signifikant. In der multiplen Regressionsanalyse waren p-Werte bis <0,3 zugelassen (Kapitel 2.4.4).

Abkürzungen: R²: Bestimmtheitsmaß der multiplen Regression; r: Multipler Regressionskoeffizient; $\mathrm{Q}_{\mathrm{p}} / \mathrm{Q}_{\mathrm{s}}$ : Verhältnis aus pulmonalem zu systemischem Herzzeitvolumen; $Q_{p \text { Index }}$ : Pulmonales Herzzeitvolumen pro Körperoberfläche (KOF); $Q_{s}$ Index: Systemisches Herzzeitvolumen pro KOF; PVRI: pulmonary vascular resistance index, Index für den pulmonalvaskulären Widerstand. 


\section{Diskussion der Methodik und der Ergebnisse}

Um die Gültigkeit des neurohumoralen Herzinsuffizienzmodells am eigenen Patientengut zu überprüfen, wurde im Rahmen dieser Arbeit die Beziehung zwischen klinischer Symptomatik und sowohl traditionellen hämodynamischen Parametern als auch aktuell interessierenden neurohumoralen Parametern bei Säuglingen mit angeborenem Herzfehler und Links-RechtsShunt untersucht.

Im folgenden Kapitel werden zunächst die in der Arbeit verwendeten Methoden erörtert. Anschließend werden die in Kapitel 3 dargestellten Ergebnisse in Hinblick auf die der Arbeit zugrunde liegende Hypothese diskutiert, zuerst die Ergebnisse zum Thema Tachypnoe (Kapitel 4.2), dann diejenigen zum Thema Gedeihstörung (Kapitel 4.3).

\subsection{Diskussion der Methodik}

\subsubsection{Retrospektive Datenerhebung}

Bei retrospektiven Datenerhebungen erweist es sich im Vergleich zu prospektiven Studien mitunter als schwierig, für alle Studienpatienten alle interessierenden Parameter zu ermitteln. Diese Reduzierung der Fallzahlen einzelner Parameter kann die statistische Aussagekraft einer Studie einschränken. Dennoch wird in vielen Fällen die retrospektive Datenerhebung als guter Kompromiß gewählt, da sie klinische Machbarkeit mit vertretbarer Validität der Daten verbindet. Auch die vorliegende Studie beruht auf einer retrospektiven Datenerhebung. Um die Beeinflussung der Ergebnisse durch niedrigere Patientenzahlen so weit wie möglich zu reduzieren, wurde ein möglichst großer Stichprobenumfang gewählt und damit die Ausgangsfallzahl erhöht.

\subsubsection{Erhebung der hämodynamischen Parameter}

Die Herzkatheteruntersuchungen wurden bei den Säuglingen in Sedierung und Lokalanästhesie durchgeführt. Dadurch kann es zu einer Beeinflussung der hämodynamischen Parameter kommen, insbesondere durch ein Absinken des systemvaskulären Widerstands oder des mittleren arteriellen Drucks. Dies ist bei der Interpretation der Ergebnisse zu bedenken.

Die Sauerstoffaufnahme $\left(\mathrm{VO}_{2}\right)$ wurde nur bei 31 der 70 untersuchten Säuglinge während der Herzkatheteruntersuchung direkt gemessen, da diese Methode erst seit 1998 in der Abteilung zur Verfügung stand. Bis 1998 wurde die Sauerstoffaufnahme anhand von Normtabellen geschätzt (HILL und RAHIMTULLA 1965). Dies stellte ein zu der Zeit übliches Vorgehen dar. Da signifikante Unterschiede zwischen direkt gemessenen und geschätzten $\mathrm{VO}_{2}$-Werten beschrieben wurden, besonders im frühen Säuglingsalter und bei Säuglingen mit großem Links- 
Rechts-Shunt (NETZ et al. 1987), wurden in die Ergebnistabellen nur die 31 gemessenen $\mathrm{VO}_{2}$-Werte aufgenommen. Ihre Mittelwerte aus den einzelnen Patientenuntergruppen stimmten gut mit den bis 1998 verwendeten geschätzten $\mathrm{VO}_{2}$-Werten überein (Tabelle 3.2, 3.4, 3.6, 3.8 und 3.12).

\subsubsection{Mögliche Beeinflussung der Katecholaminspiegel durch Agitation}

Bei der Bestimmung neurohumoraler Parameter aus Blutproben nicht sedierter Säuglinge ist eine Beeinflussung der Noradrenalinwerte durch Agitation (z. B. Schreien, Aufregung, Angst) zu diskutieren (CANDITO et al. 1993). Bei einer akuten Freisetzung von Katecholaminen im Rahmen der Blutentnahme wäre ein Anstieg beider Hormonspiegel, also des Noradrenalins und des Adrenalins, zu erwarten. Die Adrenalinspiegel der hier untersuchten Säuglinge waren jedoch in allen Gruppen normwertig und nur die Noradrenalinspiegel bei den tachypnoeischen Säuglingen erhöht (Tabelle 3.5). Niedrige Noradrenalin- und Reninspiegel (362 \pm 219 ng/l bzw. $177 \pm 227 \mu \mathrm{U} / \mathrm{ml}$ ) bei den Säuglingen ohne Tachypnoe sind ein weiterer Hinweis für den geringen Einfluß von Agitation auf die in der Studie gemessenen neurohumoralen Parameter. Unterstützt werden diese Überlegungen durch entsprechende Ergebnisse anderer Autoren (ROSS et al. 1987; WU JR et al. 1996).

\subsubsection{Bestimmung des Renins}

Bis 1997 wurde das Renin am Universitätsklinikum Göttingen indirekt über die sogenannte Plasma-Renin-Aktivität bestimmt, d.h. über eine Messung der von ihm gebildeten Menge an Angiotensin I. Später wurde diese Methode durch die direkte Bestimmung des immunreaktiven Renins abgelöst (Kapitel 2.3.3). Verschiedene Studien zeigten zwar wiederholt hohe und signifikante Korrelationen ( $\mathrm{r}=0,87$ bis 0,98, $\mathrm{p}<0,001$ ) zwischen den Bestimmungsmethoden sowohl im Kindes- als auch im Erwachsenenalter (BRONS und THAYSSEN 1983; BLAZY et al.1989). Letztlich spiegeln sich jedoch in den Meßwerten der beiden Methoden zwei unterschiedliche Substanzen wider (Angiotensin I bzw. Renin), so daß eine gemeinsame statistische Auswertung nicht sinnvoll erschien. Deshalb wurden die diesbezüglichen Ergebnisse in der deskriptiven Statistik getrennt analysiert ( $\mathrm{N}=27$ bzw. $\mathrm{N}=34$ ) und aus der multiplen Regressionsanalyse ausgeschlossen. Bei der Interpretation der Ergebnisse ist dies zu bedenken.

\subsubsection{Festlegung von Referenzwerten für die neurohumoralen Parameter}

Es gestaltete sich als schwierig, einheitliche, allgemein gültige Normwerte insbesondere für die untersuchten neurohumoralen Parameter für das Säuglingsalter zu ermitteln. Die Publikationen zu diesem Thema unterscheiden sich methodisch, überschneiden sich in den gewählten 
Altersgruppen und beruhen auf oft kleinen Fallzahlen. Ein Vergleich wird so erschwert. Das

gilt insbesondere für die Katecholamine, bei denen zudem eine große Streuungsbreite der Werte beobachtet wurde. Auch für die Plasma-Renin-Aktivität und die Aldosteronspiegel im Blut wurde eine große Streuung der Werte bei jungen Säuglingen berichtet (FISELIER et al. 1983). Die letztlich ausgewählten Werte stellen jeweils einen möglichst guten Kompromiß dar und sind deshalb als Richtwerte zu verstehen.

Da in verschiedenen Studien keine signifikanten Unterschiede der Hormonwerte zwischen Mädchen und Jungen beobachtet wurden (FISELIER et al. 1983, KRÜGER et al. 1998), wurden in dieser Arbeit die Daten für beide Geschlechter gemeinsam ausgewertet.

\subsubsection{Das Erfassen einer Gedeihstörung}

Ein grundsätzliches Problem bei der Untersuchung des Ernährungszustands besteht in der fehlenden Einheitlichkeit der verwendeten Begriffe zur Beschreibung klinisch bedeutsamer Ernährungsdefizite bei Erwachsenen und Kindern. Die DGEM-Leitlinie „Enterale Ernährung: Ernährungsstatus“ von 2003 beschreibt die Situation wie folgt: „In der deutschsprachigen Literatur werden zahlreiche Begriffe synonym oder überschneidend verwendet (z. B. Malnutrition, Mangelernährung, Fehlernährung). Andererseits werden gleiche Begriffe unterschiedlich interpretiert.“ (PIRLICH et al. 2003, S.10).

Darüber hinaus besteht kein Konsens über die zu verwendenden anthropometrischen Indizes sowie deren jeweilige Grenzwerte. In der internationalen Literatur werden häufig umschreibende Begriffe wie „failure to thrive“, „growth delay“ oder „reduced weight gain“ verwendet, die oft lediglich relative Beziehungen zum Gedeihen gesunder gleichaltriger Kinder herstellen, ohne einheitliche Indizes zur Beurteilung des Ernährungszustands zu verwenden und ohne klare Grenzwerte für eine Abweichung zu nennen (WILCOX et al. 1989). Vergleiche zwischen Patienten werden so erschwert.

In der vorliegenden Arbeit wurde der Begriff „Gedeihstörung“ als möglichst „neutrale“ Bezeichnung für ein gestörtes, das heißt fehlendes oder unzureichendes Gedeihen der untersuchten Säuglinge mit angeborenem Herzfehler verwendet, der es vermeidet, mögliche Ursachen, wie zum Beispiel „Unter-, Fehl- oder Mangelernährung“ zu implizieren.

Der in der pädiatrischen Literatur häufig benutzte Ausdruck „dystroph“ bzw. „Dystrophie“ bezeichnet definitionsgemäß den Zustand eines Kindes, dessen Körpergewicht unterhalb der dritten Gewichtsperzentile für das entsprechende Alter liegt. Damit trifft der Begriff den Sachverhalt der hier interessierenden kardialen Gedeihstörung nur zu einem Teil: Viele der betroffenen Kinder fallen im Krankheitsverlauf zwar mit ihrem Gewicht und z.T. ihrer Länge 
unter die dritte Perzentile, strenggenommen sind sie jedoch bereits zu einem viel früheren Zeitpunkt von einer Gedeihstörung betroffen - nämlich bereits dann, wenn sie signifikant weniger an Gewicht zunehmen als gesunde, gleichaltrige Kinder und als Folge ein Perzentilensprung nach unten auftritt. Allerdings scheint ein Perzentilensprung nach unten als alleiniges Kriterium für das Erkennen einer Gedeihstörung auch nicht geeignet zu sein (OLSEN et al. 2007a). Außerdem gibt es auch Kinder, die laut Definition aufgrund ihres absoluten Körpergewichts dystroph sind, die aber aktuell altersentsprechend normal an Gewicht zunehmen. Das heißt, die Entwicklung des Gewichts über einen gewissen Zeitraum ist ebenfalls wichtig, nicht allein das absolute Gewicht zu einem Zeitpunkt.

Bei der Auswahl einer geeigneten Methode zur Erfassung des Gedeihens war außerdem zu bedenken, daß die Datenerhebung in dieser Arbeit retrospektiv erfolgte. Für die Untersuchung des Gedeihens kamen deshalb grundsätzlich nur solche Parameter in Frage, die im klinischen Alltag routinemäßig bei möglichst vielen Patienten bestimmt wurden und somit retrospektiv erhoben werden konnten.

Um der beschriebenen methodischen Problematik gerecht zu werden, wurde in der vorliegenden Arbeit neben den Gewichtsperzentilen als erstem Anhaltspunkt für den Ernährungsstatus der Kinder zusätzlich ein spezieller Herzinsuffizienz-Score für Säuglinge verwendet, der die aktuelle Gewichtsentwicklung der Säuglinge im Untersuchungszeitraum berücksichtigt. Die dort gewählten Gewichtsgrenzen sind verglichen mit der Gewichtsentwicklung gesunder Säuglinge recht niedrig angesetzt, haben sich jedoch in klinischen Studien bewährt (BUCHHORN et al. 2000b).

Bei der Auswertung zeigte es sich, daß tatsächlich ein nicht unerheblicher Teil der untersuchten Säuglinge trotz einer während des Untersuchungszeitraumes guten Gewichtszunahme (> 400 g/Monat) hinsichtlich ihres aktuellen Körpergewichts unterhalb der dritten bzw. zwischen der dritten und zehnten Perzentile lag. Ähnliche Beobachtungen wurden in der Gruppe der Kinder mit mäßiger Gewichtszunahme (200-400 g/Monat) gemacht.

Diese Diskrepanz zwischen Score und Perzentilen ist möglicherweise damit zu erklären, daß die Kinder hier in einer stabilen Krankheitsphase untersucht wurden, in der ein Teil von ihnen recht gut an Gewicht zunahm, daß aber auch diese Kinder in der Vergangenheit während instabilerer Phasen schlechter gediehen waren. Es zeigt sich hier, daß, wie bei OLSEN et al. (2007b) als häufiges methodisches Problem thematisiert, die Überschneidung zwischen zwei Methoden nur partiell ist, und betroffene Kinder deshalb häufig nur durch eine Methode erfaßt werden. 
Weitere gängige Methoden zur Beurteilung des Ernährungsstatus werden im Folgenden beispielhaft genannt und im Hinblick auf ihre Anwendbarkeit in der vorliegenden Arbeit erörtert: Die Hautfaltendicke als Maß für das subkutane Fettgewebe, z. B. über dem Musculus triceps, läßt sich zwar einfach und schnell bestimmen, die Technik erfordert jedoch eine gewisse Übung, um reproduzierbare Resultate zu erlangen (PIRLICH et al. 2003). Außerdem wird die Hautfaltendicke in der Kinderklinik Göttingen nicht routinemäßig erfaßt und erwies sich somit als ungeeignet für eine retrospektive Datenerhebung.

Verschiedene Indizes, die zum Beispiel das Körpergewicht eines Kindes zu seinem Alter, seiner Länge oder seiner Körperoberfläche in Beziehung setzen, sind zwar grundsätzlich leicht und mit wenig Aufwand bestimmbar, da sie aus klinischen Basisdaten errechnet werden. Keines dieser Kriterien hat sich jedoch letztlich in klinischen Studien als überlegen herausgestellt, den Ernährungszustand eines Kindes sicher zu erfassen und Risikopatienten zu identifizieren. Vielmehr unterschieden sie sich gravierend in ihrer Einschätzung des Schweregrades einer Gedeihstörung in einem untersuchten, identischen Patientenkollektiv (OLSEN et al. 2007b). In der internationalen Literatur wird, wie auch in der vorliegenden Arbeit, besonders häufig die Gewichtsentwicklung als Kriterium zur Beurteilung des Gedeihens verwendet. Das Gewicht hatte sich in seiner Aussagekraft als gleichwertig, wenn nicht sogar überlegen gegenüber den Indizes dargestellt (RAYNOR und RUDOLF 2000).

Blutparameter wie Serum-Albumin, Natrium und Chlorid, Harnstoff, Triglyzeride oder Cholesterin sowie auch katabole und anabole Hormone wie Insulin, Wachstumshormon oder Kortisol, die im Zusammenhang mit einer Untersuchung des Ernährungsstatus bestimmt werden, wurden in der jetzigen Studie nicht berücksichtigt. Dies liegt einerseits daran, daß sie retrospektiv häufig nicht erhoben werden konnten. Zum Anderen schienen sie zur Identifizierung einer kardialen Gedeihstörung nicht geeignet, da es in der Regel verschiedene Ursachen für eine pathologische Abweichung ihrer Werte gibt. Sie haben vielmehr einen ergänzenden Stellenwert, so daß es grundsätzlich von Interesse wäre, die Parameter weiter zu untersuchen.

Die in diesem Kapitel beschriebenen Methoden, inklusive der für die Arbeit ausgewählten, erscheinen vor dem Hintergrund der mit ihnen einher gehenden methodischen Einschränkungen als sinnvoller Kompromiß zur Untersuchung des Gedeihens im Rahmen von Studien. Für die klinische Praxis ist es letztlich essentiell, das Gesamtbild aus Wachstum, Entwicklung, Ernährungsstatus und psychosozialen Faktoren eines Patienten über einen gewissen Zeitraum zu beobachten (RAYNOR und RUDOLF 2000). 


\subsubsection{Erfassung der Kalorienaufnahme}

Die Qualität der Berechnungen zur täglichen Kalorienaufnahme hing stark von der Genauigkeit der dokumentierten Nahrungsaufnahme ab. Säuglinge mit zu unpräzisen Aufzeichnungen wurden aus der Auswertung ausgeschlossen. Hierdurch wurde die Fallzahl für einzelne Parameter vermindert. Die Berechnung der Kalorienaufnahme und damit der Vergleich zwischen den Kindern wurde durch das Fehlen einer standardisierten Säuglingsnahrung erschwert. Nahrungsverluste, wie zum Beispiel durch Erbrechen, waren retrospektiv schwer zu quantifizieren (Menge, Abstand zu der vorhergehenden Mahlzeit). Eine mögliche Überschätzung der Kalorienzufuhr infolge dieses methodischen Problems ist daher nicht auszuschließen. Das Erbrechen wird in Tabelle 3.1 aufgeführt, statistisch jedoch nicht weiter ausgewertet. Trotz dieser möglichen Beeinflussungen stimmten die Ergebnisse der Ernährungsanalyse gut mit den Ergebnissen anderer Autoren überein (SALZER et al. 1989).

\subsubsection{Angeborene gastrointestinale Fehlbildungen und genetische Syndrome}

Angeborene Fehlbildungen des Gastrointestinaltraktes und das Vorliegen eines genetischen Syndroms bei Kindern können Einfluß auf ihr Gedeihen haben. Häufig werden betroffene Patienten aus entsprechenden Untersuchungen ausgeschlossen. Da in der vorliegenden Studie Kinder mit zusätzlicher gastrointestinaler Fehlbildung, wie z. B. einer Duodenalstenose, nur nach erfolgreich abgeschlossener operativer Korrektur berücksichtigt wurden, schien eine relevante Beeinflussung der Studienergebnisse durch diese Fehlbildungen vernachlässigbar.

Neunzehn der hier untersuchten Säuglinge wiesen einen atrioventrikulären Septumdefekt (AVSD) auf. Da eine hohe Koinzidenz zwischen dem Auftreten dieses Herzfehlers und einer Trisomie 21 besteht, und je nach Literaturquelle etwa 50 \% der Patienten mit einem AVSD zusätzlich eine Trisomie 21 haben (DUNLOP et al. 2004), war im untersuchten Patientenkollektiv entsprechend die Anzahl an Säuglingen mit Down-Syndrom verhältnismäßig erhöht ( $\mathrm{N}=19$, davon 15 Patienten mit AVSD). Eine nicht kardial bedingte Gedeihstörung mußte bei diesen Kindern in Betracht gezogen werden. Da diese Patienten jedoch einen wichtigen Anteil des in der vorliegenden Arbeit besonders interessierenden Patientenkollektivs mit großem, bedeutsamen Links-Rechts-Shunt ausmachen, wurden sie bewußt in der Studie belassen. Die Tatsache, daß diese Säuglinge zum Zeitpunkt der Untersuchung über alle Gedeihgruppen relativ gleichmäßig verteilt waren, unterstützte diese Entscheidung (Gewichtszunahme > 400 g/Monat: $\mathrm{N}=$ 8; 200-400 g/Monat: $\mathrm{N}=6$; < 200 g/Monat: $\mathrm{N}=5$ ). Für die fünf Patienten mit anderen genetischen Syndromen wurde Ähnliches beobachtet. 


\subsection{Diskussion der Ergebnisse - Tachypnoe}

\subsubsection{Analyse der hämodynamischen Parameter}

\subsubsection{Ventrikelfunktion und Ejektionsfraktion}

Während bei Erwachsenen vor allem eine myokardiale Pumpschwäche als hämodynamische Ursache der chronischen Herzinsuffizienzsymptomatik gilt und dies in der Vergangenheit auch bei Kindern vielfach vermutet wurde, haben inzwischen Untersuchungen bei Kindern mit angeborenen Herzfehlern und klinischer Herzinsuffizienz sowohl echokardiographisch als auch invasiv unbeeinträchtigte Pumpfunktionen der systemischen Ventrikel gezeigt (WAGGONER et al. 1985; KIMBALL et al. 1991; BUCHORN et al. 2001b).

Im untersuchten Patientenkollektiv konnte eine unbeeinträchtigte linksventrikuläre Funktion anhand normaler Ejektionsfraktionen, links- und rechtsatrialer Drücke und linksventrikulärer enddiastolischer Drücke nachgewiesen werden (Tabelle 3.4). Die Ergebnisse der oben genannten Arbeitsgruppen wurden so bestätigt. Die Ejektionsfraktionen korrelierten sogar signifikant positiv mit den Atemfrequenzen im Sinne ansteigender Ejektionsfraktionen bei zunehmender Tachypnoe, vermutlich verursacht durch einen positiv inotropen Effekt des Sympathikus auf das gesunde Säuglingsmyokard.

\subsubsection{Pulmonale hämodynamische Parameter}

Anders als bei Erwachsenen wurde bei Kindern mit angeborenem Herzfehler und LinksRechts-Shunt traditionell vor allem die Lungenüberflutung sowie eine pulmonale Widerstandserhöhung als Ursache der klinischen Symptomatik und so auch der Tachypnoe angesehen (KIMBALL et al. 1991).

In der vorliegenden Studie zeigte sich nur eine mäßige Korrelation zwischen der Größe des Links-Rechts-Shunts und den Atemfrequenzen $(r=0,27, p=0,03)$ (Tabelle 3.10). Im Vergleich der Atemfrequenzgruppen war eine Tendenz zu höheren $\mathrm{Q}_{\mathrm{p}} / \mathrm{Q}_{\mathrm{s}}$-Werten bei zunehmender Tachypnoe zu erkennen ( $\mathrm{p}=0,07)$ (Tabelle 3.4). Auch die Tatsache, daß sich der $\mathrm{Q}_{\mathrm{p}} / \mathrm{Q}_{\mathrm{s}}{ }^{-}$ Wert als einziger pulmonaler Parameter in das multiple Regressionsmodell integrieren ließ, spricht für eine gewisse Bedeutung dieses Parameters (Tabelle 3.10).

Die übrigen Parameter des Lungenkreislaufs zeigten kaum einen statistischen Zusammenhang mit den Atemfrequenzen der Säuglinge. Deutlich erhöhte pulmonalarterielle Drücke und eine gesteigerte Lungendurchblutung wiesen auf die hämodynamische Relevanz der vorliegenden Herzfehler hin. Die Werte waren jedoch bei eupnoeischen und tachypnoeischen Säuglingen gleichermaßen erhöht, so daß sie als Prädiktoren für das Auftreten von Tachypnoe im untersuchten Patientenkollektiv nicht geeignet waren. 
Prinzipiell ist bei einem Links-Rechts-Shunt-Vitium mit pulmonaler Überflutung im Verlauf mit einem Anstieg des pulmonalvaskulären Widerstands zu rechnen. Durch diesen Widerstandsanstieg kommt es zu einem Rückgang der Lungenüberflutung und damit in der Regel zunächst zu einer Besserung der klinischen Symptomatik. Eine entsprechende Korrelation zwischen pulmonalvaskulärem Widerstandsindex (PVRI) und Tachypnoe wurde bei den hier untersuchten Patienten nur in geringem Maße gefunden $(r=-0,3, p=0,03)$. Es gelang nicht, den PVRI sinnvoll in das multiple Regressionsmodell zu integrieren (Tabelle 3.10). Eine Ursache hierfür mag sein, daß die Säuglinge bereits vor dem Auftreten einer bedeutsamen Widerstandserhöhung operiert wurden.

Insgesamt ließ sich für die pulmonalen Parameter nur ein recht schwacher statistischer Zusammenhang mit dem Auftreten von Tachypnoe aufzeigen. Dies spricht gegen eine alleinige Gültigkeit des traditionellen hämodynamischen Erklärungskonzepts, so wie entsprechend dem aktuellen neurohumoralen Herzinsuffizienzmodell zu erwarten.

\subsubsection{Systemische hämodynamische Parameter}

Mit dem mittleren arteriellen Druck (MAP) erwies sich ein Parameter des systemischen Kreislaufs neben der Herzfrequenz statistisch als stärkster hämodynamischer Prädiktor für das Auftreten von Tachypnoe. Er korrelierte deutlich negativ mit den Atemfrequenzen $(r=-0,42$, $\mathrm{p}=0,001$ ) und wies auch in der Varianzanalyse signifikante Unterschiede zwischen den Gruppen auf ( $p=0,004)$ (Tabelle 3.4). Tachypnoeische Säuglinge wiesen im Mittel deutlich niedrigere arterielle Drücke auf als eupnoeische Säuglinge. Darüber hinaus ließ sich der MAP als ein bedeutsamer Parameter in die multiple Regressionsgleichung aufnehmen (Tabelle 3.10). Die Ergebnisse stehen im Einklang mit Resultaten von BUCHHORN et al. (2001b), die ebenfalls die besondere Bedeutung eines erniedrigten arteriellen Drucks für die Pathogenese der Herzinsuffizienz bei Säuglingen mit Links-Rechts-Shunt beschrieben.

Das systemische Herzzeitvolumen zeigte einen schwächeren statistisch signifikanten Zusammenhang mit der Atemfrequenz in der Varianzanalyse und den linearen Korrelationen ( $r=-0,32, p=0,01$ ) (Tabelle 3.4 und 3.10). Da sich der $Q_{s}$-Index auch als einer von sechs Parametern in die multiple Regressionsgleichung integrieren ließ, ist ihm hier insgesamt, ähnlich wie bei GIDDING und BESSEL (1993), eine gewisse prädiktive Bedeutung zuzusprechen.

\subsubsection{Die pathophysiologische Bedeutung eines niedrigen mittleren arteriellen Drucks}

Der arterielle Blutdruck ergibt sich vereinfacht als Produkt aus dem systemischen Herzzeitvolumen $\left(\mathrm{Q}_{\mathrm{s}}\right)$ und dem systemvaskulären Widerstand (SVR) (Arterieller Druck $\left.=Q_{s} \times S V R\right)$. 
Daraus ergeben sich für den Organismus grundsätzlich zwei Möglichkeiten, einem erniedrigten mittleren arteriellen Druck entgegen zu wirken: Zum einen kann das systemische Herzzeitvolumen gesteigert werden, zum anderen kann der systemvaskuläre Widerstand angehoben werden, um einen ausreichenden peripheren Perfusionsdruck aufrechtzuerhalten und die Sauerstoffversorgung des Organismus zu gewährleisten. Diese Blutdruckregulation kann kurzfristig reflektorisch über eine Veränderung der Herztätigkeit und des Gefäßtonus, vermittelt über das vegetative Nervensystem, erreicht werden (Kapitel 4.2.6), langfristig unter anderem durch einen Anstieg des Blutvolumens aufgrund vermehrter Wasser- und Salzretention in den Nieren (Kapitel 4.2.5).

Eine Steigerung des systemischen Herzzeitvolumens ist bei Patienten mit Links-RechtsShunt, bei denen ein Teil der Auswurfleistung des linken Herzens über den Shunt abfließt und deren Ventrikel schon kräftig pumpen, häufig nicht ausreichend möglich. Dies bestätigte sich in der vorliegenden Untersuchung, in der ein erniedrigter mittlerer $\mathrm{Q}_{\mathrm{s}}$-Index in allen Atemfrequenzgruppen beobachtet wurde, der mit zunehmender Tachypnoe weiter abfiel (Tabelle 3.4). Der zu erwartende Anstieg des systemvaskulären Widerstands konnte in der jetzigen Untersuchung nicht nachgewiesen werden (23,5 \pm 6,8 $\mathrm{E} \times \mathrm{m}^{2}$; Tabelle 3.2 und 3.4).

Buchhorn et al. (2000a) lieferten dafür eine mögliche Erklärung: Sie beobachteten bei jungen Säuglingen mit Links-Rechts-Shunt, daß die postpartal zunächst weitgehend altersentsprechend hypotonen Blutdruckwerte ihrer Patienten im weiteren Verlauf nur verzögert anstiegen und erst im Alter von mehreren Monaten normale Werte erreichten. Als Ursache der verzögerten Anpassung in dieser Altersgruppe wurde ein inadäquater Anstieg des systemvaskulären Widerstands bei arterieller Hypotension trotz Freisetzung potenter Vasokonstriktoren wie Noradrenalin und Angiotensin II vermutet, dessen Ursache noch unklar ist. Diskutiert wurde eine verminderte Wirkung der Vasokonstriktoren durch eine geringere Ansprechbarkeit ihrer Rezeptoren oder ein Überwiegen vasodilatatorischer Substanzen, wie z. B. eine erhöhte endogene Stickstoffmonoxidbildung, möglicherweise getriggert durch Zytokine (TAKAYA et al. 2000). Dieser Aspekt wurde im Rahmen der vorliegenden Arbeit nicht weiter untersucht, er spielt jedoch auch für die hier beobachteten Säuglinge möglicherweise eine Rolle.

\subsubsection{Die Sauerstoffversorgung des peripheren Gewebes}

Angesichts des anhaltend erniedrigten mittleren arteriellen Drucks und damit geringerem Perfusionsdruck stellt sich bei diesen Patienten zunächst die Frage nach einer adäquaten peripheren Sauerstoffversorgung: Wie von BERMAN et al. (1987) gezeigt, steigt bei vermindertem systemischen Herzzeitvolumen $\left(\mathrm{Q}_{\mathrm{s}}\right)$ und damit vermindertem Sauerstofftransport $\left(S O T=Q_{s} \times\right.$ arterieller Sauerstoffgehalt $)$ die arteriovenöse Sauerstoffausschöpfung $\left(\mathrm{AVDO}_{2}\right)$ 
im Blut an, die Sauerstoffaufnahme $\left(\mathrm{VO}_{2}\right)$ bleibt jedoch bis zu einem „kritischen Wert“ des Sauerstofftransports normal. Erst wenn der Sauerstofftransport diesen kritischen Wert unterschritten hat, kommt es bei maximaler Sauerstoffausschöpfung zu einem Absinken der Sauerstoffaufnahme.

In der jetzigen Untersuchung belegten normale $\mathrm{VO}_{2}$ Index - Werte in allen Atemfrequenzgruppen, daß dieser kritische Wert offenbar nicht erreicht wurde (Mittelwert in der Studienpopulation $130 \pm 23 \mathrm{ml} / \mathrm{min} / \mathrm{m}^{2}$ ), eine Kompensation wurde erreicht. Bei den Kindern wurde keine relevante Laktatazidose nachgewiesen (BUCHHORN, nicht veröffentlichte Daten). Für die von GIDDING und BESSEL (1993) vertretene pathophysiologische Interpretation eines peripheren Sauerstoffmangels als Ursache der klinischen Symptomatik bei Patienten mit Ventrikelseptumdefekt ergaben sich in dieser Studie somit keine Hinweise.

\subsubsection{Die neurohumorale Aktivierung bei Säuglingen mit Links-Rechts-Shunt und Herzinsuffizienz}

Entsprechend HARRIS (1987) sind alle kompensatorischen Mechanismen der Blutdruckregulation im Organismus auf eine Aufrechterhaltung des arteriellen Drucks ausgelegt, um durch diesen die ausreichende Durchblutung und damit Versorgung der Gewebe zu gewährleisten. Ein erniedrigter mittlerer arterieller Druck, wie er bei Säuglingen mit Links-RechtsShunt beobachtet wird, ist in diesem Sinn als ein zentraler hämodynamischer „Trigger“ für eine neurohumorale Aktivierung bei diesen Säuglingen anzusehen, insbesondere des ReninAngiotensin-Aldosteron-Systems sowie auch des sympathischen Nervensystems (HARRIS 1987; BUCHHORN et al. 2001b).

In der vorliegenden Studie konnte diese neurohumorale Aktivierung bei Säuglingen mit schwerer Tachypnoe anhand deutlich erhöhter Hormonspiegel bestätigt werden: Die PlasmaRenin-Aktivität (PRA) stieg bei Säuglingen mit schwerer Tachypnoe im Vergleich zu Säuglingen ohne Tachypnoe auf das 8,8-fache an $(\mathrm{p}=0,005)$, die Reninkonzentration auf das 5,1fache ( $\mathrm{p}=0,003)$, das Noradrenalin (NA) auf das 2,9-fache $(\mathrm{p}<0,001)$ und das Aldosteron auf das 2,3-fache $(\mathrm{p}=0,01)$ (Tabelle 3.5). Alle diese Hormonwerte korrelierten positiv mit den Atemfrequenzen (NA: $r=0,47, p<0,001$; PRA: $r=0,65$, $<<0,001$; Reninkonzentration: $r=0,50, p=0,002$; Aldosteron: $r=0,37, p=0,007$ ) (Tabelle 3.10). Entsprechend früherer Publikationen (ROSS et al. 1987; WU JR et al. 1996) wurden weitgehend normale Adrenalinwerte in allen Gruppen gefunden. Säuglinge ohne Tachypnoe wiesen altersentsprechend normale Noradrenalin- und Reninspiegel auf trotz relevanter Links-Rechts-Shunts.

Die neurohumorale Aktivierung bei den symptomatischen Säuglingen gleicht der bekannten 
neurohumoralen Aktivierung bei chronisch herzinsuffizienten Erwachsenen mit myokardialer Insuffizienz (PACKER 1993). Sie unterstützt die Gültigkeit des neurohumoralen Herzinsuffizienzmodells auch für die hier untersuchten Säuglinge mit Links-Rechts-Shunt. Die Ergebnisse stehen zudem im Einklang mit den Resultaten anderer pädiatrischer Arbeitsgruppen sowie den Erfolgen einer Betablocker-Therapie bei herzinsuffizienten Kindern in klinischen Studien (ROSS et al. 1987; WU JR et al. 1996; LÄER et al. 2002; NISHIYAMA et al. 2009).

Es ist bekannt, daß gesunde Säuglinge in den ersten Lebenstagen und -wochen höhere Reninwerte haben als ältere Säuglinge und Kinder und daß diese Hormonspiegel mit zunehmendem Alter der Kinder dann rasch abfallen (KRÜGER et al. 1998). Entsprechendes wurde für das Aldosteron und die Plasma-Renin-Aktivität berichtet (FISELIER et al. 1983). Für das Noradrenalin gibt es unterschiedliche Angaben in der Literatur (EICHLER et al. 1989; CANDITO et al. 1993).

Angesichts dieser Tatsache fiel in der vorliegenden Arbeit auf, daß die Säuglinge mit den höchsten Atemfrequenzen, die die stärkste neurohumorale Stimulation aufwiesen, im Durchschnitt jünger waren (2,6 \pm 1,7 Monate) als die Säuglinge mit normalen oder gering erhöhten Atemfrequenzen (5,7 \pm 1,8 bzw. 4,4 \pm 2,4 Monate; Tabelle 3.5). Dies ist dadurch erklärbar, daß bei den stark tachypnoeischen Säuglingen auf Grund der Schwere der Symptomatik bereits in jüngerem Alter die präoperative Herzkatheteruntersuchung und somit die Datenerhebung erfolgte.

Es stellt sich die Frage, inwiefern lediglich das junge Alter der Kinder als Ursache für die hohen Hormonwerte bei schwerer Tachypnoe anzusehen ist. Da die Hormonspiegel der in der Arbeit untersuchten jüngsten Säuglinge noch deutlich höher lagen als die entsprechenden Werte gesunder, gleichaltriger Säuglinge (FISELIER et al. 1983; KRÜGER et al. 1998), erscheint dies unwahrscheinlich. Auch bei einer Auswertung allein der jungen Säuglinge (1. Trimenon; Tabelle 3.7) zeigte sich ein Anstieg der Hormonwerte bei zunehmender Tachypnoe, wobei die tachypnoeischen Säuglinge auch hier überwiegend deutlich höhere Hormonspiegel aufwiesen als gleichaltrige gesunde Säuglinge. Die Werte unterschieden sich allerdings bis auf das Noradrenalin nicht mehr statistisch signifikant zwischen den Atemfrequenzgruppen, möglicherweise weil in dieser Auswertung die Gruppen zu klein waren und die Streuung der Werte groß. Eine besonders starke neurohumorale Aktivierung bei jungen Säuglingen mit Herzinsuffizienz infolge eines Links-Rechts-Shunts wurde auch bei BUCHHORN et al. (2000a) beschrieben. 


\subsubsection{Die Bedeutung des Renin-Angiotensin-Aldosteron-Systems (RAAS)}

Das Renin-Angiotensin-Aldosteron-System ist an der mittel- und langfristigen Blutdruckregulation beteiligt. Eine Aktivierung, ausgelöst durch einen akuten Abfall des arteriellen Blutdrucks, führt über die Stimulation renaler Barorezeptoren zu einer vermehrten Freisetzung von Renin. Durch Renin wird Angiotensinogen zu Angiotensin I und dieses durch angiotensin-converting-enzyme (ACE) zu Angiotensin II umgewandelt. Angiotensin II hebt als stärkster Vasokonstriktor des Organismus den systemvaskulären Widerstand an und bewirkt gleichzeitig eine vermehrte Ausschüttung von Aldosteron in den Nebennierenrinden. Aldosteron verursacht eine vermehrte Natrium- und damit Wasserretention in den distalen Nierentubuli und führt so zu einer Erhöhung des venösen Blutstroms zum Herzen. Über einen Anstieg der Vorhofdrücke kommt es zu einer vermehrten Vordehnung des Herzens und so zu einer Steigerung des kardialen Auswurfs (Frank-Starling-Mechanismus). Dies trägt zu einer Anhebung des arteriellen Blutdrucks bei.

Im Säuglingsalter ist der arterielle Mitteldruck physiologisch niedrig, und der Schwellenwert der renalen Autoregulation liegt nur knapp unterhalb der physiologischen Blutdruckwerte. Daher verursacht der erniedrigte arterielle Blutdruck bei Säuglingen mit Links-Rechts-ShuntVitien eine anhaltende Aktivierung des Renin-Angiotensin-Aldosteron-Systems. Zusätzlich verstärkt eine Verschiebung des renalen Schwellenwertes durch die Sympathikusaktivierung bei diesen Patienten die RAAS-Aktivierung (BUCHHORN 2002).

Durch die kompensatorische Flüssigkeitsretention kann es zu peripheren Ödemen und einem vermehrten pulmonalen Wassergehalt kommen, welcher den Gasaustausch in der Lunge einschränkt und so mit zu Dyspnoe bzw. Tachypnoe beiträgt.

\subsubsection{Die Bedeutung des sympathischen Nervensystems}

Das vegetative Nervensystem ist insbesondere an der kurzfristigen Blutdruckregulation beteiligt. Ein Abfall des arteriellen Blutdrucks führt zu einer verminderten Erregung sinoaortaler Barorezeptoren. Über eine hierdurch bedingte verminderte Hemmung vegetativer Kerngebiete im Hirnstamm kommt es zu einer gesteigerten Aktivierung des sympathischen Nervensystems. Ausdruck einer anhaltenden Aktivierung sind erhöhte Noradrenalinspiegel im Blut, wie sie zum Beispiel bei herzinsuffizienten Patienten beobachtet werden. Noradrenalin gilt als Indikator für die sympathische Aktivität (GOLDSTEIN 1981). Es bewirkt über alpha-1adrenerge Rezeptoren eine starke systemische Vasokonstriktion und kann so über einen Anstieg des systemvaskulären Widerstands den arteriellen Blutdruck direkt anheben. Darüber hinaus wirkt Noradrenalin am Herzen über beta-1-adrenerge Rezeptoren positiv chronotrop, dromotrop und inotrop und kann über diesen Anstieg der Herzfrequenz sowie der Kontrakti- 
lität das systemische Herzzeitvolumen $\left(Q_{s}=\right.$ Herzfrequenz $\times$ Schlagvolumen $)$ und damit letztlich den arteriellen Blutdruck erhöhen (Arterieller Druck $=Q_{s} \times S V R$ ) (Kapitel 4.2.2). Ein erhöhter Sympathikotonus trägt über die alpha-1-adrenerge Vasokonstriktion und folgende Minderperfusion der Nieren sowie direkt beta-adrenerg (Reninfreisetzung) zu einer Aktivierung des RAAS bei.

\subsubsection{Die Herzfrequenzen}

Ein Anstieg der Herzfrequenzen, wie er im Rahmen einer gesteigerten Sympathikusaktivierung zu erwarten ist, wurde in der vorliegenden Arbeit bestätigt: In der Gesamtauswertung aller Patienten zeigte sich ein Anstieg der Herzfrequenzen parallel zu steigenden Noradrenalinspiegeln bei zunehmender Tachypnoe ( $<$ 0,001) (Tabelle 3.4). Auf der Basis der Korrelationen und der multiplen Regressionsanalyse erwies sich die Herzfrequenz dabei als der stärkste statistische Prädiktor für das Auftreten von Tachypnoe im untersuchten Patientenkollektiv $(\mathrm{r}=0,62, \mathrm{p}<0,001)$ (Tabelle 3.10).

Da in der Gesamtauswertung der Daten ein Altersunterschied zwischen eupnoeischen und tachypnoeischen Säuglingen auffiel (Tabelle 3.5), wurden die Daten ergänzend getrennt für das erste und zweite Trimenon ausgewertet (Tabelle 3.6 bis 3.9). Hierbei konnte der erwartete Herzfrequenzanstieg bei zunehmender Tachypnoe für die Säuglinge im ersten Trimenon bestätigt werden, parallel zu zunehmenden Noradrenalinspiegeln (Tabelle 3.6). Im zweiten Trimenon dagegen unterschieden sich die mittleren Herzfrequenzen nicht signifikant zwischen den Atemfrequenzgruppen trotz auch hier pathologisch erhöhter Noradrenalinwerte bei den tachypnoeischen Kindern (Tabelle 3.8). Das dritte Trimenon wurde auf Grund der zu kleinen Patientenzahl nicht separat ausgewertet.

Es ist möglich, daß die in den Zweitanalysen auftretenden teils kleinen Patientenzahlen Ursache für die verlorengegangenen statistischen Signifikanzen sind. Vor dem Hintergrund früherer Arbeiten ist jedoch eine herabgesetzte Ansprechbarkeit beta-adrenerger Rezeptoren bei chronisch erhöhter Sympathikusaktivität („Down-Regulation“) als Ursache für den ausbleibenden Herzfrequenzanstieg trotz erhöhter Katecholaminspiegel wahrscheinlich (TASK FORCE OF THE EUROPEAN SOCIETY OF CARDIOLOGY AND THE NORTH AMERICAN SOCIETY OF PACING AND ELECTROPHYSIOLOGY 1996). Eine verminderte myokardiale Beta-Rezeptor-Dichte sowie eine gestörte Informationsweiterleitung zwischen Beta-Rezeptor und Adenylatzyklase im Sinne eines post-Rezeptor-Defektes wurden hierfür verantwortlich gemacht (KOZLIK-FELDMANN et al. 1993). Das Ausbleiben des erwarteten Herzfrequenzanstiegs im zweiten Trimenon kann so als Zeichen dieser progredienten Down- 
Regulation der myokardialen Beta-Rezeptoren mit zunehmendem Alter der Säuglinge gedeutet werden. Diese scheint bei jungen Säuglingen noch nicht so ausgeprägt zu sein, gewinnt mit zunehmendem Alter jedoch an Relevanz.

Die Untersuchungsergebnisse unterstützen die Ergebnisse von GIDDING und BESSEL (1993), entsprechend derer erhöhte Herzfrequenzen ein wichtiges hämodynamisches Korrelat zum Schweregrad der klinischen Herzinsuffizienz bei Säuglingen darstellen, wobei die prädiktive Bedeutung der Herzfrequenz in der Studie mit zunehmendem Alter der Säuglinge durch die einsetzende Down-Regulation verloren geht. Die Anwendung von Scores, in denen erhöhte Herzfrequenzen als Kriterium zur Einschätzung der Schwere klinischer Herzinsuffizienz bei Säuglingen gewählt wurden, wird damit mit zunehmendem Alter der Säuglinge in Frage gestellt. Die Relevanz der Down-Regulation für die untersuchten Säuglinge konnte dagegen an einem mit dem eigenen vergleichbaren Patientenkollektiv anhand negativer Auswirkungen auf den postoperativen Verlauf gezeigt werden (BUCHHORN et al. 2002b).

Die in der Gesamtanalyse beobachteten signifikanten Mittelwertunterschiede für die übrigen hämodynamischen Parameter gingen in der Zweitanalyse verloren. Es zeigte sich jedoch auch hier ein Abfall des mittleren arteriellen Drucks bei den schwer tachypnoeischen Säuglingen im Vergleich zu den eu- bzw. gering tachypnoeischen Säuglingen im ersten Trimenon (Tabelle 3.6). Auch Zeichen einer neurohumoralen Aktivierung ließen sich bei schwerer Tachypnoe beobachten. Das Noradrenalin wies dabei als einziges der Hormone signifikante Unterschiede zwischen den Gruppen auf (Tabelle 3.7).

Die Ergebnisse der altersgetrennten Zweitauswertung müssen mit einer gewissen Vorsicht betrachtet werden, da die zugrundeliegenden Patientenzahlen in den einzelnen Untergruppen zum Teil klein sind und die Standardabweichungen insbesondere bei den neurohumoralen Parametern groß. Die Beobachtungen stützen jedoch insgesamt die Vermutung, daß die neurohumorale und insbesondere die sympathische Aktivierung eine besondere Rolle in der Pathogenese der Herzinsuffizienz auch bei Säuglingen mit angeborenem Herzfehler und LinksRechts-Shunt spielt. Eine Überprüfung der Resultate an einem größeren Patientenkollektiv wäre wünschenswert.

\subsubsection{Herzfrequenzvariabilität und kardiorespiratorische Reflexe}

Der vermutete Einfluß der Sympathikusaktivierung auf die Atemfrequenzen konnte in einer Subgruppe der hier untersuchten Säuglinge durch die Analyse der Herzfrequenzvariabilität untermauert werden. Es zeigten sich signifikant erniedrigte Werte für bestimmte Herzfrequenzvariabilitätsparameter bei den Säuglingen mit Tachypnoe (BUCHHORN et al. 2001d).

Eine reduzierte Herzfrequenzvariabilität gilt bei herzinsuffizienten Kindern und Erwachsenen 
als sensitives, nicht invasives Maß für eine autonome Imbalance, die als Folge einer gesteigerten Sympathikusaktivierung mit hohen Noradrenalinspiegeln und einer gleichzeitig verminderten Parasympathikusaktivität bei Herzinsuffizienz entsteht (MASSIN und VON BERNUTH 1998; NOLAN et al. 1998). Eine reduzierte Herzfrequenzvariabilität erwies sich ebenso wie die erhöhten Noradrenalinspiegel bei herzinsuffizienten Erwachsenen als prognostisch ungünstig und korrelierte mit dem Schweregrad klinischer Herzinsuffizienz bei Erwachsenen und Kindern (SZABO et al. 1995; NOLAN et al. 1998; BUCHHORN et al. 2002a; MOTZ et al. 2005).

Die beobachtete inverse Korrelation zwischen der Herzfrequenzvariabilität und einer erhöhten Chemosensitivität bei herzinsuffizienten Erwachsenen wird als mögliche pathophysiologische Erklärung für die Tachypnoe dieser Patienten diskutiert (PONIKOWSKI et al. 1997; PONIKOWSKI et al. 1998): Es wurde postuliert, daß eine erhöhte Chemosensitivität zu einer verstärkten ventilatorischen Reaktion und Tachypnoe bei Erwachsenen mit chronischer Herzinsuffizienz führt (CHUA et al. 1997b; PONIKOWSKI und BANASIAK 2001). Die erhöhte arterielle exzitatorische Chemosensitivität wird auch als einer der Faktoren angesehen, die zu einer verstärkten Erregung des zentralen autonomen Nervensystems führen. Sie könnte so mit eine Ursache der anhaltenden sympathischen Aktivierung bei herzinsuffizienten Patienten sein (FLORAS 1993).

Bei gesunden Erwachsenen ist zudem eine antagonisierende Wechselwirkung zwischen exzitatorischen Chemorezeptoren und inhibitorischen arteriellen und kardiopulmonalen Barorezeptoren bekannt (SOMERS et al. 1991). Bei herzinsuffizienten Patienten wurde eine abgestumpfte Antwort der Barorezeptoren beobachtet (MANCIA et al. 1992; PONIKOWSKI et al. 2001). Durch die verminderte inhibitorische Wirkung kann es zu einer weiteren Zunahme der exzitatorischen Aktivität der Chemorezeptoren, z. B. auf das sympathische Nervensystem, kommen (PONIKOWSKI et al. 1997).

Als weitere wichtige Ursache der gesteigerten Ventilation und anhaltenden sympathischen Aktivierung bei herzinsuffizienten Erwachsenen wird in den letzten Jahren die erhöhte Aktivität muskulärer Ergorezeptoren diskutiert (PIEPOLI et al. 1996; PONIKOWSKI et al. 2001; KACZMAREK et al. 2004; WITTE et al. 2008). Die erhöhte Ergorezeptoraktivität geht wie die erhöhte Chemosensitivität mit einer ungünstigen Prognose einher (PONIKOWSKI und BANASIAK 2001; GIANNONI et al. 2009).

Angesichts der nachgewiesenen autonomen Imbalance auch bei den hier untersuchten, symptomatischen Säuglingen mit angeborenem Herzfehler und Links-Rechts-Shunt erscheint es 
möglich, daß bei ihnen ähnliche Mechanismen zur Entstehung der Tachypnoe beitragen wie bei herzinsuffizienten Erwachsenen. Bei Kindern findet sich hierzu allerdings kaum Literatur.

\subsection{Diskussion der Ergebnisse - Gedeihstörung}

\subsubsection{Bedeutung der Gedeihstörung}

Die kardiale Gedeihstörung bzw. Kachexie tritt als typisches klinisches Symptom der chronischen Herzinsuffizienz sowohl bei Erwachsenen als auch bei Kindern mit angeborenem Herzfehler auf und ist mit einer signifikant schlechteren Prognose im Vergleich zu nichtkachektischen, herzinsuffizienten Patienten verknüpft (ANKER et al. 1997a; CHOUDHARY et al. 1999). In der vorliegenden Studie wurde die Relevanz dieses Themas für das untersuchte Patientenkollektiv bestätigt: Fünfzig Prozent der untersuchten Säuglinge lagen zum Untersuchungszeitpunkt mit ihrem Gewicht unterhalb der 3. Perzentile und $26 \%$ zwischen der 3. und 10. Perzentile (Abbildung 3.5). Das heißt, 76 \% der Patienten waren per definitionem hypo- oder dystroph und somit entsprechend den vorgenannten Risiken, wie z. B. perioperativen Komplikationen und einer erhöhten perioperativen Sterblichkeit (Kapitel 1.5), besonders gefährdet. Weniger als die Hälfte der Säuglinge (42 \%) nahm normal an Gewicht zu (Tabelle 3.11).

\subsubsection{Analyse der klinischen Parameter}

\subsubsection{Ernährung und Energiestoffwechsel}

Im Gegensatz zu früheren Untersuchungen (THOMMESSEN et al. 1992; BARTON et al. 1994) unterschied sich die tägliche Kalorienaufnahme pro Kilogramm Körpergewicht im hier untersuchten Patientenkollektiv nicht signifikant zwischen normal und schlecht gedeihenden Kindern. Sie lag für alle Gruppen im Bereich der empfohlenen Kalorienmengen für Säuglinge (FLEISCHER MICHAELSEN et al. 2003; DEUTSCHE GESELLSCHAFT FÜR ERNÄHRUNG et al. 2008). Bei Säuglingen mit schwerer Herzinsuffizienz und Trinkschwäche wurde eine normale Kalorienzufuhr durch Fütterung über eine nasogastrale Sonde gewährleistet.

Das Ergebnis entspricht Beobachtungen früherer Publikationen, in denen ebenfalls keine signifikante Beziehung zwischen Gedeihstörung und reduzierter Kalorienaufnahme bei herzinsuffizienten Säuglingen und Kindern gefunden worden war (SALZER et al. 1989). Untersuchungen bei Erwachsenen zeigten vergleichbare Ergebnisse (ZHAO und ZENG 1997). Eine alternativ postulierte Proteinmangelversorgung wurde in der jetzigen Studie nicht untersucht. Andere Arbeitsgruppen hatten normale Serum-Albuminspiegel (SALZER et al. 1989) sowie eine eher hohe Proteinaufnahme bei herzinsuffizienten Kindern mit Gedeihstörung gefunden 
(HANSEN und DORUP 1993) und als Argument gegen einen Proteinmangel als Ursache der Gedeihstörung angeführt.

Für die häufig vertretene Auffassung, daß eine schwere Herzinsuffizienz einen erhöhten Energieumsatz verursache, beispielsweise durch erhöhte Atemfrequenzen oder eine pulmonale Hypertonie (MENON und POSKITT 1985; FORCHIELLI et al. 1994), ergab sich in der jetzigen Studie kein Hinweis. Die $\mathrm{VO}_{2}$-Werte, die als ein Maß für den Energieumsatz gelten, variierten zwischen den Gruppen nur wenig und waren nicht signifikant erhöht bei zunehmender Gedeihschwäche (Tabelle 3.12). Die Ergebnisse stimmten mit frühen Untersuchungen HUSEs et al. (1975) überein, die angesichts vergleichbarer $\mathrm{VO}_{2}$-Werte für gesunde und herzinsuffiziente Säuglinge einen Hypermetabolismus als Ursache der Gedeihstörung für unwahrscheinlich gehalten hatten. Die bekannte, positive Korrelation zwischen Grundumsatz und Herzfrequenzen ließ sich in der jetzigen Studie nicht aufzeigen, möglicherweise weil die Säuglinge in Sedierung untersucht wurden. Einschränkend muß bei der Bewertung dieser Ergebnisse auf die recht kleine Patientenzahl $(\mathrm{N}=31)$ mit direkt gemessenen $\mathrm{VO}_{2}$-Werten hingewiesen werden.

Bei Säuglingen mit ausgeprägter Herzinsuffizienz wurden gehäuft Ernährungsprobleme wie Erbrechen beobachtet. Mittels nasogastraler Sondierung der schwer symptomatischen Säuglinge wurde zwar eine adäquate Kalorienzufuhr erreicht, rezidivierendes Erbrechen schränkte jedoch eine höhere Kalorienaufnahme oft ein. Als mögliche Ursache für das vermehrte Erbrechen ist eine verzögerte und eingeschränkte Magenentleerung bei Säuglingen mit Herzinsuffizienz in Betracht zu ziehen, wie sie von CAVELL (1981a und b) beschrieben wurde. Als Ursache dieser Magenentleerungsstörung wurden ein reduzierter Blutfluß im Splanchnikusgebiet beziehungsweise eine venöse Stauung im Bereich des Darmes, bedingt durch die Herzinsuffizienz, diskutiert. Beide könnten zu einer Veränderung der Magenentleerung beitragen. Andere Autoren berichteten hingegen von nur geringen Störungen der gastrointestinalen Funktion bei Säuglingen mit angeborenem Herzfehler unabhängig von der Art und dem Schweregrad der Erkrankung und schlossen daraus auf eine große Zirkulationsreserve des Darms (SONDHEIMER und HAMILTON 1978).

\subsubsection{Geburtsgewicht und Frühgeburtlichkeit}

Ein Hinweis auf eine erst postpartal zunehmende Gedeihstörung der herzinsuffizienten Säuglinge ist die in den Abbildungen 3.4 und 3.5 deutliche Verschiebung der Gewichtsperzentilen mit zunehmendem Alter der Säuglinge: Erkennbar ist ein starker Anstieg des Anteils dystropher Säuglinge von 1,5\% auf $50 \%$ und ein entsprechender Abfall des Anteils eutropher 
(bzw. nicht untergewichtiger) Säuglinge von $91 \%$ auf $24 \%$ von der Geburt bis zum Untersuchungszeitpunkt. Bei Geburt war das Gewicht der untersuchten Säuglinge im Gegensatz zu früheren Publikationen im Mittel nicht erniedrigt (Tabelle 3.1) (LEVY et al. 1978; KRAMER et al. 1990). Es ließ sich kein Zusammenhang zwischen dem Auftreten einer späteren Gedeihstörung und einem niedrigeren Geburtsgewicht erkennen (Tabelle 3.11). SALZER et al. (1989) hatten ähnliche Ergebnisse gezeigt.

Die Frühgeburtlichkeit als möglicher Prädiktor für eine Gedeihstörung wurde in der jetzigen Arbeit nur deskriptiv untersucht. Bei Berücksichtigung der Frühgeburtlichkeit in den Perzentilen war keines der sieben betroffenen Kinder bei Geburt dystroph. Zum Zeitpunkt der Datenerhebung nahmen vier der sieben Säuglinge gut an Gewicht zu (> 400 g/Monat). Nur zwei der Säuglinge nahmen weniger als 200 Gramm pro Monat zu. Ein Zusammenhang zwischen kardialer Gedeihstörung und Frühgeburtlichkeit konnte für die untersuchten Patienten nicht nachgewiesen werden.

\subsubsection{Analyse der hämodynamischen Parameter}

Der pulmonalvaskuläre Widerstandsindex war der einzige hämodynamische Parameter, der statistisch signifikante Unterschiede zwischen normal und schlecht gedeihenden Säuglingen aufwies. Es war jedoch keine eindeutige Tendenz der Werte zu erkennen (Tabelle 3.12).

Im Gegensatz zu früheren Untersuchungen erwiesen sich in der vorliegenden Arbeit weder die Größe des Links-Rechts-Shunts oder die Ventrikelfunktion, noch ein reduzierter peripherer Blutfluß oder eine pulmonale Hypertonie als Vorhersageparameter für das Auftreten einer Gedeihstörung (LEVY et al. 1978; KIMBALL et al. 1991; GIDDING und BESSEL 1993; LEITE et al. 1995). Vielmehr stellte sich die Gedeihstörung wie bei herzinsuffizienten Erwachsenen (ANKER und SHARMA 2002) auch bei den hier untersuchten Säuglingen mit Links-Rechts-Shunt als weitgehend unabhängig von den klassischen hämodynamischen Markern der Schwere der chronischen Herzinsuffizienz dar.

\subsubsection{Analyse der neurohumoralen Parameter}

Innerhalb der neurohumoralen Parameter kann die beobachtete signifikant inverse Korrelation zwischen Gewichtszunahme und Noradrenalinspiegeln $(r=-0,48, p<0,001)$ als Hinweis für einen Einfluß der bereits erläuterten autonomen Imbalance auf das Gedeihen bei Säuglingen mit angeborenem Herzfehler gewertet werden. Auch die Korrelation zwischen Gewichtsentwicklung und Plasma-Renin-Aktivität $(r=-0,43, p=0,03)$ deutet auf eine neurohumorale Aktivierung bei Säuglingen mit schwerer Gedeihstörung. In der Varianzanalyse wurde ein Anstieg der Noradrenalinspiegel und Reninkonzentrationen auf annähernd das Doppelte bei 
Säuglingen mit schlechter Gewichtszunahme deutlich, erreichte jedoch keine statistische Signifikanz (Tabelle 3.11). Wie in Tabelle 3.11 und 3.13 erkennbar, lassen die Ergebnisse zum Renin insgesamt keine eindeutigen Schlüsse zu, möglicherweise bedingt durch zu niedrige Patientenzahlen auf Grund der zwei unterschiedlichen Bestimmungsmethoden. Die Bedeutung des Renins für die Pathogenese der Herzinsuffizienz läßt sich in der vorliegenden Arbeit für die Gedeihstörung somit nicht sicher nachweisen.

Bei herzinsuffizienten Erwachsenen wird eine Erhöhung katabol wirkender Hormone und „Streßhormone“ wie Adrenalin, Noradrenalin und Kortisol sowie eine parallel verminderte Wirkung anaboler Hormone (u.a. Wachstumshormon, Testosteron, Dehydroepiandrosteron) durch verminderte Blutspiegel oder eine Resistenzentwicklung beobachtet (ANAND et al. 1989; ANKER et al. 1997b). Dies wird als Zeichen einer schweren katabol-anabolen Imbalance bei herzinsuffizienten Erwachsenen mit Kachexie interpretiert, die mit einer signifikant schlechteren Prognose der Patienten verknüpft ist (ANKER et al. 1997a; ANKER et al. 1999). Es wurde postuliert, daß die neurohumorale Aktivierung und die veränderte katabol-anabole Balance zu einem Fortschreiten der chronischen Herzinsuffizienz in Richtung kardialer Kachexie führen (ANKER et al. 1997b).

Vor dem Hintergrund dieser Ergebnisse bei Erwachsenen ist die neurohumorale Aktivierung bzw. die damit verbundene autonome Imbalance, die sich in der vorliegenden Studie bereits für das Symptom Tachypnoe als bedeutender pathogenetischer Faktor dargestellt hat, auch für die Gedeihstörung bei Säuglingen mit Links-Rechts-Shunt als relevanter Faktor zu werten, wenn auch möglicherweise nicht in demselben Ausmaß $\left(\mathrm{R}^{2}=0,37\right.$ in der multiplen Regression; Tabelle 3.13). Es besteht die Vermutung, daß die neurohumorale Aktivierung mit hohen Noradrenalinspiegeln im Blut auch bei den hier untersuchten Säuglingen dazu beiträgt, daß die betroffenen Patienten keinen anabolen Stoffwechsel beginnen.

Im Rahmen der vorliegenden retrospektiven Untersuchung läßt sich diese Vermutung nicht abschließend beantworten, da unter anderem relevante Hormone nicht untersucht wurden. Umfassendere, prospektive Studien an einer größeren Patientenzahl wären deshalb wünschenswert.

Zudem muß der Einfluß weiterer wichtiger Faktoren auch bei den untersuchten Säuglingen mit Links-Rechts-Shunt diskutiert werden, wie beispielsweise erhöhte Zytokinspiegel als Ausdruck einer generellen Immunaktivierung und erhöhte BNP- bzw. NT-proBNP-Spiegel im Blut, deren Bedeutung man bei chronisch herzinsuffizienten Erwachsenen und Kindern mitt- 
lerweile erkannt hat (ANKER und SHARMA 2002; CARDARELLI und LUMICAO 2003; CANTINOTTI et al. 2008).

\subsection{Ausblick: Immunaktivierung und erhöhtes BNP bei chronischer Herz- insuffizienz}

Bei Erwachsenen mit chronischer Herzinsuffizienz wird innerhalb der Zytokine insbesondere den erhöhten TNFa-Spiegeln eine wichtige Bedeutung bei der Entstehung der Herzinsuffizienz und speziell der kardialen Kachexie zugesprochen (ANKER und COATS 1999). Auch bei Säuglingen mit Links-Rechts-Shunt-Vitium wurden erhöhte TNF-Rezeptor-Spiegel im Blut als Ausdruck einer Immunaktivierung nachgewiesen. Es wurde postuliert, daß die Immunaktivierung auch bei diesen Kindern eine wesentliche Rolle in der Pathogenese der Herzinsuffizienz spielt (BUCHHORN et al. 2001a). Erhöhte TNFa-Spiegel wirken dabei unter anderem direkt zytotoxisch und führen über Wechselwirkungen mit anderen Zytokinen und Hormonen (z. B. Katecholaminen) zu einem gesteigerten Proteinkatabolismus (PACKER 1995). Ein Abfall erhöhter TNF-Rezeptor-Spiegel unter einer Therapie mit Betablockern bei herzinsuffizienten Säuglingen mit Links-Rechts-Shunt belegte dabei die Interaktion zwischen Immunaktivierung und neurohumoraler Aktivierung, parallel zu entsprechenden Beobachtungen bei Erwachsenen (BUCHHORN et al. 2001a; WERNER et al. 2002).

Ein weiterer Forschungsschwerpunkt der letzten Jahre ist das vor allem in den Ventrikelmyozyten gebildete BNP bzw. NT-proBNP. Als Marker für eine ventrikuläre Dysfunktion spielen diese Parameter inzwischen sowohl diagnostisch als auch prognostisch und therapeutisch eine wichtige Rolle bei chronisch herzinsuffizienten Erwachsenen und Kindern (LUCHNER et al. 2003; KOCH et al. 2006; AUERBACH et al. 2010). Auch Kinder mit Herzinsuffizienz als Folge eines Links-Rechts-Shunts zeigten erhöhte BNP- bzw. NT-proBNP-Spiegel bei erhaltener myokardialer Funktion. Die Höhe der BNP- bzw. NT-proBNP-Spiegel korrelierte dabei signifikant mit verschiedenen Parametern der Volumen- bzw. Druckbelastung sowie der Schwere der klinischen Symptomatik bei Säuglingen und älteren Kindern mit Vorhof- bzw. Ventrikelseptumdefekt (WU YR et al. 2005; OZHAN et al. 2007). Auch gibt es Hinweise für einen relevanten Zusammenhang zwischen erhöhten BNP-Spiegeln und einem schlechten Gedeihen bei Säuglingen und Kleinkindern mit und ohne Ventrikelseptumdefekt (PAUL et al. 2009; MÄNHARDT et al. 2010). Die pathophysiologische Bedeutung dieser Beobachtungen bedarf weiterer Untersuchungen. 
Die Parameter der Immunaktivierung sowie das BNP bzw. NT-proBNP wurden im Rahmen der vorliegenden retrospektiven Arbeit nicht untersucht, da sie zum Zeitpunkt der Datenerhebung noch nicht routinemäßig in der Abteilung bestimmt wurden. Angesichts der positiven Resultate anderer Studien an vergleichbaren Patientenkollektiven könnten diese Faktoren ein interessanter Ansatzpunkt für weitere Forschungen bei den hier untersuchten Säuglingen mit Links-Rechts-Shunt sein, um die komplexen pathophysiologischen Mechanismen, die zur Entstehung der Herzinsuffizienz und ihrem Fortschreiten führen, weiter zu erschließen. 


\section{Zusammenfassung}

Die Ursachen der Herzinsuffizienzsymptomatik bei Kindern mit angeborenem Herzfehler und Links-Rechts-Shunt sind nach wie vor nicht vollständig geklärt. Seit den späten 1990er Jahren wurde das traditionelle, auf hämodynamischen Ansätzen beruhende Erklärungskonzept zunehmend durch das sog. „,neurohumorale Herzinsuffizienzmodell“ abgelöst, das einer neurohumoralen Aktivierung eine wichtige Rolle bei der Entstehung der Herzinsuffizienz zuweist. Letzteres stellt mittlerweile die Basis medikamentöser Therapien bei herzinsuffizienten Erwachsenen und Kindern dar, wie z. B. die Behandlung mit Betablockern. Im Gegensatz zu Erwachsenen, bei denen eine Vielzahl an Studien das Modell bestätigt, ist die Datenlage bei Kindern jedoch nach wie vor recht dünn, insbesondere im Bereich der pathophysiologischen Grundlagen.

Ziel der vorliegenden Arbeit war es daher, die Gültigkeit des neurohumoralen Herzinsuffizienzmodells für das Säuglingsalter am eigenen Patientengut zu überprüfen. Dazu wurden die Daten von 70 Säuglingen mit angeborenem Herzfehler und Links-Rechts-Shunt hinsichtlich verschiedener klinischer, hämodynamischer und neurohumoraler Parameter an Hand der typischen Symptome Tachypnoe und Gedeihstörung retrospektiv untersucht.

Ein wesentliches Ergebnis ist, daß das Symptom Tachypnoe bei den untersuchten Säuglingen im Sinne des neurohumoralen Herzinsuffizienzmodells deutlich stärker durch neurohumorale Parameter vorhergesagt wird als durch die klassischen hämodynamischen. Dies wurde sowohl durch die unifaktoriellen Varianzanalysen als auch durch die linearen Korrelationen und multiplen Regressionsanalysen bestätigt. Von den Parametern des Lungenkreislaufs wies lediglich der $\mathrm{Q}_{\mathrm{p}} / \mathrm{Q}_{\mathrm{s}}-$ Wert eine Tendenz zu höheren Werten bei Tachypnoe auf ( $\left.\mathrm{p}=0,07\right)$. Seitens der systemischen Parameter war vor allem ein erniedrigter mittlerer arterieller Druck prädiktiv für das Auftreten von Tachypnoe $(p=0,004)$. Dagegen zeigten Säuglinge mit schwerer Tachypnoe eine bedeutende neurohumorale Aktivierung mit hohen Hormonspiegeln, einhergehend mit höheren Herzfrequenzen $(p<0,001)$ im Vergleich zu eupnoeischen Säuglingen (NA: $\mathrm{p}<0,001$; PRA: $\mathrm{p}=0,005$; Reninkonzentration: $\mathrm{p}=0,003$; Aldosteron: $\mathrm{p}=0,01$ ). Die Hormonwerte und die Herzfrequenzen korrelierten positiv mit den Atemfrequenzen (NA: $r=0,47, p<0,001$; PRA: $r=0,65, p<0,001$; Reninkonzentration: $r=0,50, p=0,002$; Aldosteron: $\mathrm{r}=0,37, \mathrm{p}=0,007$; HF: $\mathrm{r}=0,62, \mathrm{p}<0,001$ ).

Für die Gedeihstörung gelang es im Gegensatz zur Tachypnoe nicht, mit Hilfe der multiplen Regression ein geeignetes Modell zur Erklärung des schlechten Gedeihens der Säuglinge zu entwickeln, das den $\mathrm{R}^{2}$-Wert von 0,37 überschritt. Sie war weder mit einem niedrigeren Geburtsgewicht, einer niedrigeren Kalorienzufuhr oder einem erhöhten Energieumsatz assoziiert. 
Während sich ein schlechtes Gedeihen als weitgehend unabhängig von den klassischen hämodynamischen Markern der Schwere der chronischen Herzinsuffizienz darstellte, zeigte sich jedoch eine Tendenz zu höheren Noradrenalin- und Reninspiegeln bei zunehmender Gedeihstörung ( $p=0,2$ bzw. $p=0,07)$. Auch Korrelationen zwischen den Noradrenalinspiegeln $(r=-0,48, p<0,001)$ bzw. der Plasma-Renin-Aktivität $(r=-0,43, p=0,03)$ und der Gewichtsentwicklung wiesen auf eine neurohumorale Aktivierung bei den Säuglingen mit schwerer Gedeihstörung hin. Trotz des schwachen Regressionsergebnisses besteht daher die Vermutung, daß die neurohumorale Aktivierung ebenso wie für die Tachypnoe auch für die Gedeihstörung der untersuchten Säuglinge von Bedeutung ist, wenn auch möglicherweise nicht in demselben Ausmaß. 


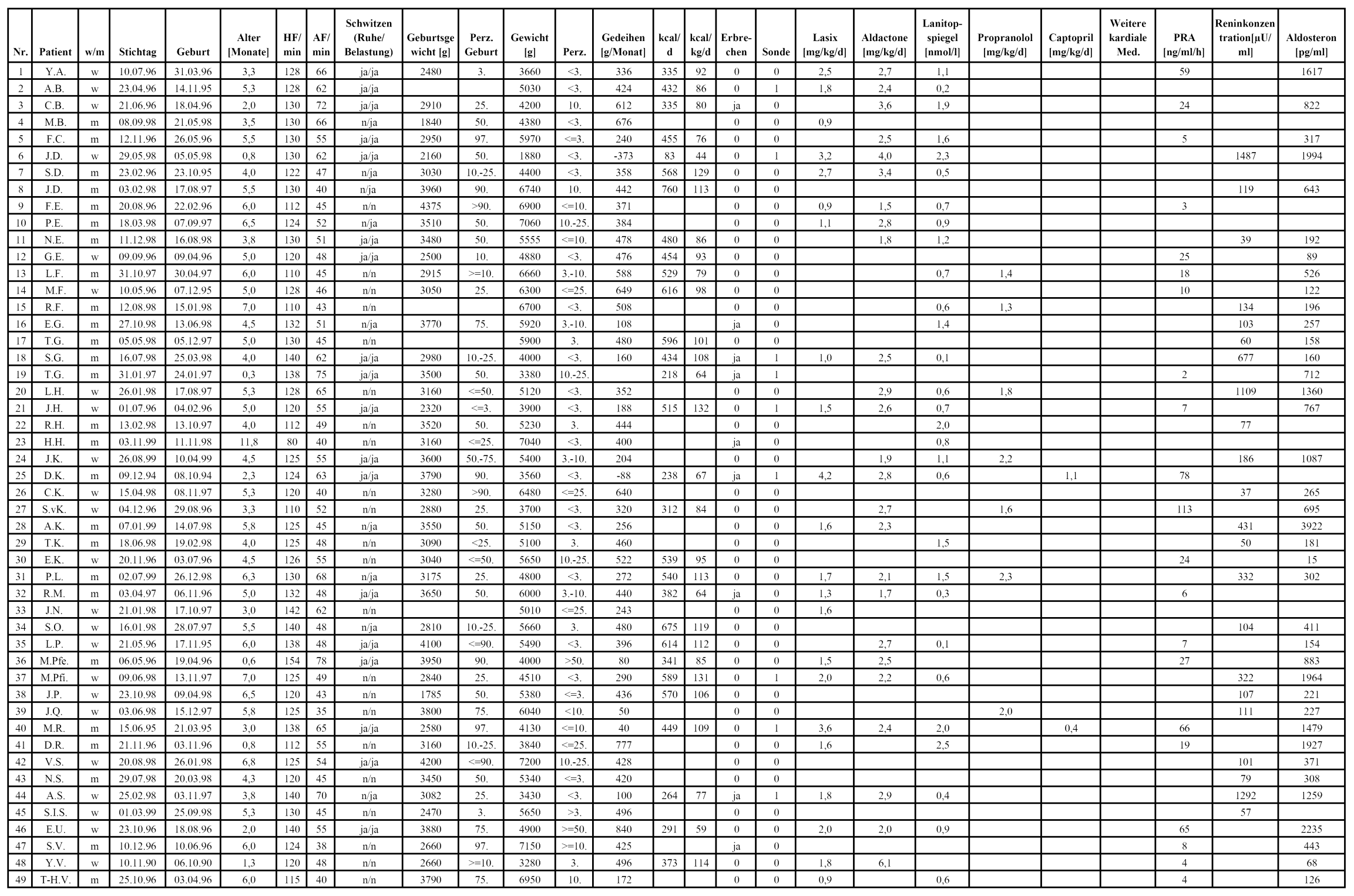




\begin{tabular}{|c|c|c|c|c|c|c|c|c|c|c|c|c|c|c|c|c|c|c|c|c|c|c|c|c|c|c|}
\hline Nr. & Patient & $\mathrm{w} / \mathrm{m}$ & Stichtag & \begin{tabular}{|l|} 
Geburt \\
\end{tabular} & $\begin{array}{c}\text { Alter } \\
\text { [Monate] }\end{array}$ & $\begin{array}{l}\mathrm{HF} / \\
\mathrm{min}\end{array}$ & $\begin{array}{l}\mathrm{AF} / \\
\mathrm{min}\end{array}$ & \begin{tabular}{|c}
$\begin{array}{c}\text { Schwitzen } \\
\text { (Ruhe/ } \\
\text { Belastung) }\end{array}$
\end{tabular} & \begin{tabular}{|c} 
Geburtsge \\
wicht $|\mathrm{g}|$
\end{tabular} & \begin{tabular}{|c} 
Perz. \\
Geburt
\end{tabular} & \begin{tabular}{|c} 
Gewicht \\
[g]
\end{tabular} & Perz. & \begin{tabular}{|c} 
Gedeihen \\
{$[\mathrm{g} /$ Monat $\mathrm{I}$}
\end{tabular} & $\begin{array}{c}\text { kcal/ } \\
\mathrm{d}\end{array}$ & $\mid \begin{array}{l}\mathrm{kcal} / \\
\mathrm{kg} / \mathrm{d}\end{array}$ & 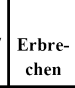 & Sonde & $\begin{array}{c}\text { Lasix } \\
{[\mathrm{mg} / \mathrm{k} / \mathrm{d} / \mathrm{d}]}\end{array}$ & \begin{tabular}{|l} 
Aldactone \\
{$[\mathrm{mg} / \mathrm{kg} / \mathrm{d}]$}
\end{tabular} & \begin{tabular}{|c} 
Lanitop- \\
spiegel \\
[nmol/] \\
\end{tabular} & $\begin{array}{c}\text { Propranolol } \\
{[\mathrm{mg} / \mathrm{kg} / \mathrm{d}]}\end{array}$ & $\begin{array}{l}\text { Captopril } \\
{[\mathbf{m g} / \mathbf{k} / \mathrm{g} / \mathrm{d}]}\end{array}$ & $\begin{array}{c}\text { Weitere } \\
\text { kardiale } \\
\text { Med. }\end{array}$ & $\left.\begin{array}{c}\text { PRA } \\
{[\mathrm{ng} / \mathrm{m} / \mathrm{h}]}\end{array}\right]$ & $\left|\begin{array}{c}\text { Reninkonzen } \\
\text { tration[uU/ } \\
\text { ml] }\end{array}\right|$ & \begin{tabular}{|c} 
Aldosteron \\
{$[\mathrm{pg} / \mathrm{m} \mathrm{m} \mid]$}
\end{tabular} \\
\hline \begin{tabular}{|l}
50 \\
\end{tabular} & C.V. & $\mathrm{m}$ & 11.02 .99 & \begin{tabular}{|l|l|}
24.04 .98 \\
\end{tabular} & 9,5 & 116 & 45 & $n / n$ & 2670 & $<=10$. & 7060 & \begin{tabular}{|c|}
$<$ \\
\end{tabular} & 275 & & & 0 & 0 & & & & & & & & 25 & \\
\hline 51 & M.W. & $\mathrm{m}$ & 13.03 .98 & \begin{tabular}{|l}
09.01 .98 \\
\end{tabular} & 2,0 & 158 & 72 & $\mathrm{ja} / \mathrm{ja}$ & 2660 & 10. & 3600 & $<$. & 440 & 361 & 100 & $\mathrm{ja}$ & 1 & 5,4 & 2.5 & 0,8 & & & & & 470 & 1085 \\
\hline \begin{tabular}{|l}
52 \\
\end{tabular} & C.Z. & $\mathrm{m}$ & 26.03 .98 & \begin{tabular}{|l|l|}
13.01 .98 \\
\end{tabular} & 2,5 & 150 & 74 & $\mathrm{ja} / \mathrm{ja}$ & 3850 & 90. & 4050 & 3. & 240 & 453 & 112 & ja & 1 & 5,0 & 3,7 & 1,0 & & & & & 540 & 81 \\
\hline \begin{tabular}{|l}
53 \\
\end{tabular} & L.Z. & w & 10.10 .96 & \begin{tabular}{|l|l|}
21.03 .96 \\
\end{tabular} & 6,5 & 118 & 46 & $\mathrm{n} / \mathrm{n}$ & 2750 & $>=10$. & 4920 & $<3$. & -15 & & & 0 & 0 & & 3,1 & 1,3 & & & & 15 & & 477 \\
\hline \begin{tabular}{|l|l|}
54 \\
\end{tabular} & N.E-B. & $\mathrm{w}$ & 13.04 .99 & \begin{tabular}{|l|l|}
03.02 .99 \\
\end{tabular} & 2,5 & 128 & 68 & $\mathrm{ja} / \mathrm{ja}$ & 2960 & 25. & 3780 & \begin{tabular}{|l|l|}
$3 .-10$. \\
\end{tabular} & 435 & \begin{tabular}{|l|l}
407 \\
\end{tabular} & \begin{tabular}{|l|}
108 \\
\end{tabular} & $\mathrm{ja}$ & 1 & 1,6 & 2,6 & 1,2 & & & \begin{tabular}{|l|} 
Esidrix 2,1 \\
\end{tabular} & & 2150 & 619 \\
\hline \begin{tabular}{|l|l|}
55 \\
\end{tabular} & A.S. & $\mathrm{w}$ & 16.08 .99 & \begin{tabular}{|l|l|}
01.03 .99 \\
\end{tabular} & 5,5 & 140 & 45 & $\mathrm{n} / \mathrm{n}$ & 2550 & 10. & 5140 & \begin{tabular}{|l}
$<3$ \\
\end{tabular} & 125 & & & 0 & 0 & & & & & & & & 191 & 999 \\
\hline \begin{tabular}{|l|}
56 \\
\end{tabular} & N.Z. & $\mathrm{w}$ & 15.09 .98 & \begin{tabular}{|l|l|}
31.08 .98 \\
\end{tabular} & 0,5 & 134 & 52 & $n / j a$ & 3100 & 25. & 3020 & $>=10$. & 120 & 253 & 84 & 0 & 1 & & & & & & & & 434 & \\
\hline \begin{tabular}{|l|}
57 \\
\end{tabular} & J-M.M. & $w$ & 24.08 .99 & \begin{tabular}{|l|l|}
21.04 .99 \\
\end{tabular} & 4,0 & 140 & 59 & $\mathrm{n} / \mathrm{n}$ & 3210 & 50. & 4435 & \begin{tabular}{|c|}
$<3$ \\
\end{tabular} & 257 & & & $\mathrm{ja}$ & 1 & 1,8 & 3,4 & 1,0 & & & & & 2150 & 1148 \\
\hline \begin{tabular}{|l|l|}
58 \\
\end{tabular} & N.G. & $\mathrm{m}$ & 10.12 .97 & \begin{tabular}{|l|l|}
17.10 .97 \\
\end{tabular} & 1,5 & 130 & 60 & $\mathrm{ja} / \mathrm{ja}$ & 3960 & 90. & 4400 & 25. & 360 & 340 & 77 & $\mathrm{ja}$ & 1 & & 2.3 & 2,7 & & & & & 107 & 636 \\
\hline \begin{tabular}{|l|}
59 \\
\end{tabular} & A.K. & $\mathrm{m}$ & 19.05 .99 & \begin{tabular}{|l|l|}
21.07 .98 \\
\end{tabular} & 9,5 & 130 & 55 & $\mathrm{ja} / \mathrm{ja}$ & 2700 & \begin{tabular}{|l|l|}
$75 .-90$. \\
\end{tabular} & 6160 & \begin{tabular}{|c|}
3 \\
\end{tabular} & 440 & 525 & 85 & $\mathrm{ja}$ & 1 & & 2,4 & 1,9 & 1,5 & & & & 115 & 1177 \\
\hline \begin{tabular}{|l|}
60 \\
\end{tabular} & M.U. & $\mathrm{m}$ & 01.07 .99 & \begin{tabular}{|l|l|}
01.05 .99 \\
\end{tabular} & 2,0 & 130 & 55 & $\mathrm{n} / \mathrm{ja}$ & 2770 & 10. & 3575 & $<=3$. & 253 & & & 0 & 0 & & & & & & & & 27 & 319 \\
\hline 61 & S.S. & $w$ & 14.08 .96 & \begin{tabular}{|l|l|}
18.06 .96 \\
\end{tabular} & 2,0 & 140 & 80 & $\mathrm{ja} / \mathrm{ja}$ & 3710 & \begin{tabular}{|l}
$50 .-75$. \\
\end{tabular} & 3880 & $<=10$. & 258 & 310 & 80 & $\mathrm{ja}$ & 1 & 2,3 & 3,9 & 1,2 & & & & 157 & & 6193 \\
\hline \begin{tabular}{|l|}
62 \\
\end{tabular} & N.O. & $\mathrm{w}$ & 07.12 .99 & \begin{tabular}{|l|}
30.06 .99 \\
\end{tabular} & 5,3 & 122 & 45 & $\mathrm{n} / \mathrm{n}$ & 2560 & $<=10$. & 4555 & \begin{tabular}{|c|}
$<3$. \\
\end{tabular} & 238 & & & 0 & 0 & & 1,1 & & 2,6 & & & & & \\
\hline 63 & \begin{tabular}{|l} 
A-S.R. \\
\end{tabular} & $\mathrm{w}$ & 13.05 .96 & \begin{tabular}{|l|l|}
1.5 .1996 \\
\end{tabular} & 1,0 & 150 & 70 & $\mathrm{ja} / \mathrm{ja}$ & 3330 & 50. & 3000 & 3. & -330 & 276 & 92 & $\mathrm{ja}$ & & 2,0 & 3,3 & & & & & 145 & & 625 \\
\hline \begin{tabular}{|l|}
64 \\
\end{tabular} & J.D. & $\mathrm{w}$ & 10.09 .99 & 29.6 .19999 & 2,5 & 120 & 55 & $n / j a$ & 2650 & $>=10$. & 3910 & $<3$. & 500 & 340 & 87 & & & 1,0 & 3,2 & & & & & & & \\
\hline \begin{tabular}{|l|}
65 \\
\end{tabular} & F.H. & $\mathrm{m}$ & 16.11 .99 & \begin{tabular}{|l|l|}
14.5 .19999 \\
\end{tabular} & 6,0 & 110 & 40 & $\mathrm{n} / \mathrm{n}$ & 2800 & $>=10$. & 6100 & \begin{tabular}{|l|l}
$<3$ \\
\end{tabular} & 350 & & & & & & & & & & & & & \\
\hline \begin{tabular}{|l|}
66 \\
\end{tabular} & $\begin{array}{l}\text { H.O. } \\
\end{array}$ & $\mathrm{m}$ & 21.03 .96 & 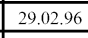 & 0,8 & 131 & \begin{tabular}{|l|}
65 \\
\end{tabular} & $\mathrm{n} / \mathrm{ja}$ & 3820 & 90. & $\begin{array}{l}3650 \\
\end{array}$ & \begin{tabular}{|l|l|}
$10 .-25$ \\
\end{tabular} & 272 & 509 & 139 & 0 & 0 & & & 1,2 & & & & 124 & & 4002 \\
\hline \begin{tabular}{|l|}
67 \\
\end{tabular} & C-H.O. & $\mathrm{m}$ & 12.09 .96 & 23.08 .96 & 0,8 & 145 & 86 & $\mathrm{ja} / \mathrm{ja}$ & 2460 & $s=3$. & 2400 & \begin{tabular}{|l|}
$<3$. \\
\end{tabular} & $\begin{array}{l}-70 \\
\end{array}$ & 241 & 101 & $\mathrm{ja}$ & 1 & 1,7 & 2,1 & 1,6 & & & & 194 & & 2442 \\
\hline \begin{tabular}{|l|}
68 \\
\end{tabular} & Y.D. & $\mathrm{m}$ & 09.12 .99 & 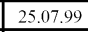 & 5,0 & 125 & 55 & $\mathrm{n} / \mathrm{n}$ & 3250 & 25. & 4740 & \begin{tabular}{|l|l} 
\\
\end{tabular} & 364 & $\begin{array}{l}648 \\
\end{array}$ & \begin{tabular}{|l|}
137 \\
\end{tabular} & 0 & 0 & & 2,1 & & 1,5 & & & & 202 & 323 \\
\hline \begin{tabular}{|l|l|}
69 \\
\end{tabular} & A.K-G. & $\mathrm{m}$ & 31.10 .96 & 0 & 8,0 & 1125 & $\begin{array}{l}55 \\
\end{array}$ & $\mathrm{n} / \mathrm{n}$ & & & 6350 & $<<3$. & 0 & & & 0 & 0 & & 3.2 & 1.2 & & & & 15 & & 231 \\
\hline \begin{tabular}{|l|}
70 \\
\end{tabular} & LF. & $\mathrm{m}$ & 14010100 & $\mid 0508.99$ & 5,3 & $\mid 128$ & 35 & $n$ & 3120 & $\frac{10-25}{10}$ & 5580 & $<3$ & 509 & & & ia & 0 & 1,1 & 1.8 & 1.2 & & & & & 928 & $\begin{array}{l}1829 \\
\end{array}$ \\
\hline
\end{tabular}




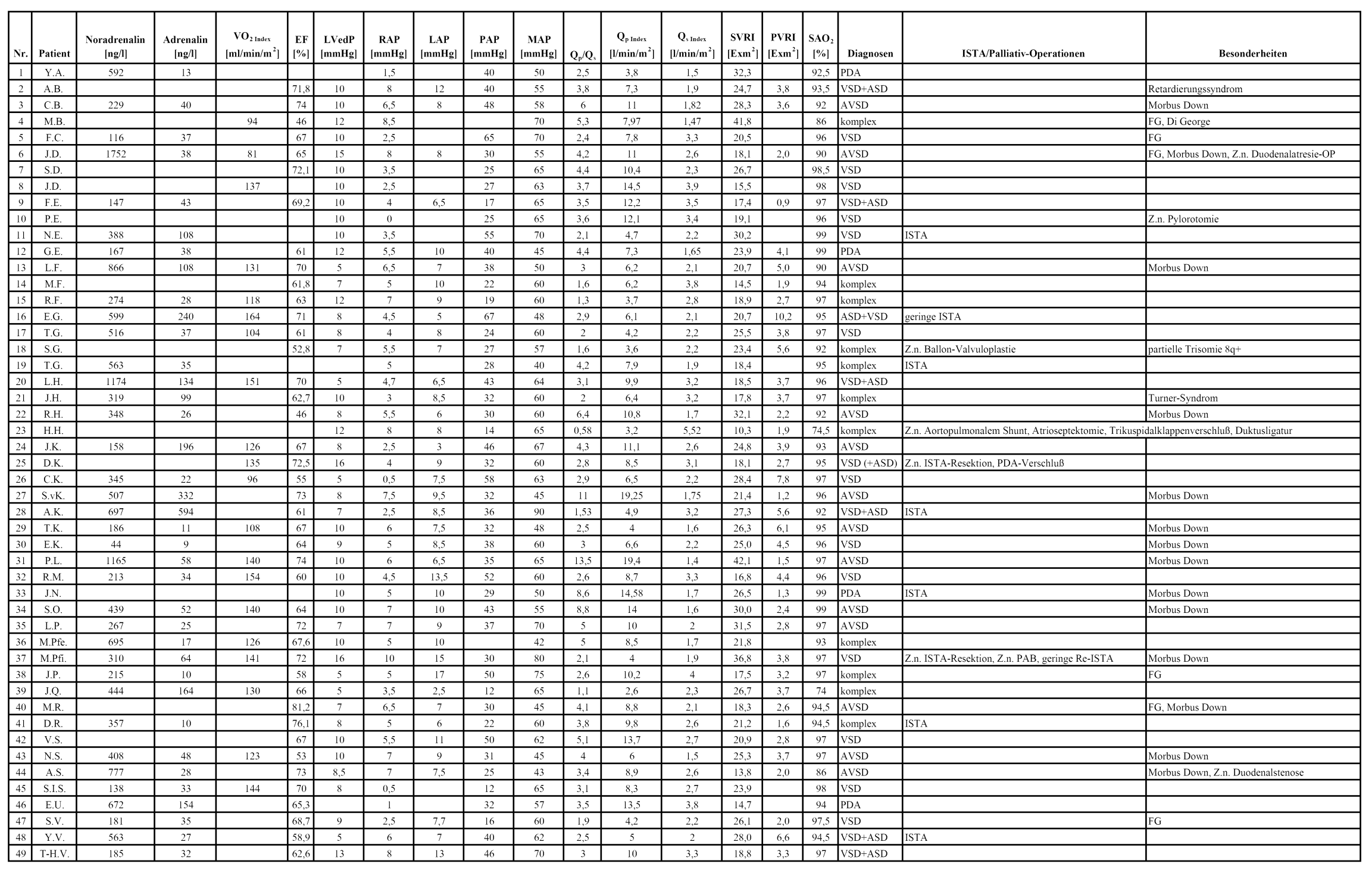




\begin{tabular}{|c|c|c|c|c|c|c|c|c|c|c|c|c|c|c|c|c|c|c|c|}
\hline Nr. & \begin{tabular}{|l|l} 
Patient \\
\end{tabular} & $\begin{array}{c}\text { Noradrenalin } \\
{[\mathbf{n} / \mathrm{g} /]}\end{array}$ & $\begin{array}{c}\text { Adrenalin } \\
{[\mathbf{n g} / \mathrm{I}}\end{array}$ & $\begin{array}{c}\mathrm{VO}_{\text {: Indax }} \\
{\left[\mathrm{ml} / \mathrm{min} / \mathrm{m}^{2}\right]}\end{array}$ & $\begin{array}{c}\mathrm{EF} \\
{[\%]}\end{array}$ & \begin{tabular}{|c|} 
LVedP \\
[mmHg]
\end{tabular} & $\begin{array}{c}\text { RAP } \\
\text { [mmHg] }\end{array}$ & \begin{tabular}{c|} 
LAP \\
{$[\mathrm{mmHg}]$} \\
\end{tabular} & \begin{tabular}{|c|} 
PAP \\
{$[\mathrm{mmHg}]$} \\
\end{tabular} & \begin{tabular}{|c|} 
MAP \\
ImmHg]
\end{tabular} & $\mathrm{Q}_{\mathrm{p}} / \mathbf{Q}_{\mathrm{s}}$ & $\begin{array}{c}\mathbf{Q}_{\mathrm{P} \text { rinex }} \\
\left.\| / \mathrm{min} / \mathrm{m}^{2}\right]\end{array}$ & $\begin{array}{c}Q_{\text {sndele }} \\
{\left[/ / \mathbf{m i n} / \mathbf{m}^{2}\right]}\end{array}$ & \begin{tabular}{|c|} 
SVRI \\
$\left|E^{2} x^{2}\right|$
\end{tabular} & \begin{tabular}{|c|} 
PVRI \\
[Exm $\left.^{2}\right]$
\end{tabular} & $\begin{array}{l}\mathrm{SAO}_{2} \\
{[\%]}\end{array}$ & Diagnosen & ISTA/Palliativ-Operationen & Besonderheiten \\
\hline 50 & \begin{tabular}{|c|c|}
$C . V$. & \\
\end{tabular} & & & 162 & 62,1 & 5 & \begin{tabular}{|l|l}
4 \\
\end{tabular} & 20 & 26 & 62 & 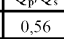 & 2.25 & \begin{tabular}{|l|l|}
4 & \\
\end{tabular} & 14,5 & 2,7 & 73 & komplex & Z.n. Ballon-Atrioseptostomie & \\
\hline 51 & M.W. & & & & & & & & & & 4 & & & & & & AVSD & & Morbus Down, zerebrale Anfille \\
\hline 52 & $c 7$ & 764 & 133 & 96 & \begin{tabular}{|l|}
79 \\
\end{tabular} & 10 & 4 & 111 & 23 & 52 & 4 & 64 & 1.6 & 300 & 19 & 77 & komplex & & \\
\hline 53 & L.Z. & 200 & 10 & & 62,5 & 8 & 4,5 & 13 & 55 & 70 & 2,5 & 6,75 & 2,7 & 24,3 & 6,2 & 98,5 & VSD & & \\
\hline 54 & \begin{tabular}{|l|l} 
N.E.B.B. \\
\end{tabular} & 541 & 83 & 180 & & 10 & 5,5 & 8 & 17 & 60 & 3,3 & 7,3 & 2,2 & 24,8 & $\frac{1,2}{1,2}$ & \begin{tabular}{|l|l|}
89 \\
\end{tabular} & AVSD & milde ISTA & \\
\hline 55 & A.S. & 411 & 15 & 130 & 63,8 & 12 & 10 & 10 & 55 & 65 & 3,7 & 6,3 & 1,7 & 32,4 & 7,1 & 92 & AVSD & & Morbus Down \\
\hline 56 & \begin{tabular}{|l}
$N . Z$. \\
N
\end{tabular} & 761 & 174 & & 52,8 & 8 & 4,5 & 5 & 40 & 60 & 2,6 & 4 & 1,5 & 37,0 & 8,8 & 88,5 & AVSD & milde ISTA & Morbus Down, Z.n. Duodenalstenose \\
\hline 57 & J-M.M. & 395 & 23 & 122 & 58 & 10 & 9 & 8 & 36 & 70 & 8,8 & 13,2 & 1,5 & 40,7 & 2,1 & \begin{tabular}{|l|l|}
97 & \\
\end{tabular} & AVSD & & Morbus Down \\
\hline 58 & \begin{tabular}{|l|l} 
N.G. \\
\end{tabular} & 998 & 36 & & 71 & 3 & 7 & 5 & 35 & 70 & 3,3 & 7,9 & 2,4 & 26,3 & 3,8 & 88 & komplex & Z.n. Rashkind & \\
\hline 59 & A.K. & 998 & 129 & 159 & 72 & 5 & 7 & 7 & 19 & 60 & 1,5 & 4 & 2,5 & 21,2 & 3,0 & 76 & komplex & Z.n. ISTA-Resektion, Z.n. PAB & FG, Fehlbildungssyndrom \\
\hline 60 & M.U. & 167 & 30 & 118 & 68 & 14 & 5,5 & 12,5 & 55 & 60 & 6,2 & 15,5 & 2,5 & 21,8 & 2,7 & 96 & komplex & & \\
\hline 61 & S.S. & 1106 & 264 & & & 10 & 7,5 & 6,5 & 30 & 55 & 4,3 & 9,1 & 2,2 & 21,6 & 2,6 & 92 & komplex & Z.n. Rashkind, PAB u Atriosepptektomie & \\
\hline 62 & N.O. & 245 & 15 & 104 & 76 & 7 & 4,5 & 10 & 40 & 55 & 3.8 & 8,4 & $2,2,2$ & 23,0 & 3,6 & \begin{tabular}{|l|}
96,5 \\
\end{tabular} & VSD & & \\
\hline 63 & A-S.R. & 2655 & 108 & & 71 & 5 & 5 & 10 & 22 & 45 & 2,5 & 5 & 2 & 20,0 & 2,4 & \begin{tabular}{|l|l|}
99 \\
\end{tabular} & komplex & & \\
\hline 64 & \begin{tabular}{|l|l} 
J \\
J.D.
\end{tabular} & 402 & $\frac{30}{30}$ & 130 & & 14 & 3,5 & 14 & $\frac{22}{30}$ & 54 & 2,7 & 8,7 & 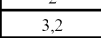 & \begin{tabular}{|l|l|}
$2,0,8$ \\
\end{tabular} & $\frac{1,7}{1,8}$ & \begin{tabular}{|l|l|}
93 \\
\end{tabular} & VSD & & \\
\hline 65 & F.H. & & & 142 & & 5 & 5 & 5 & 25 & 70 & 2 & 9,4 & 4,7 & 13,8 & 2,1 & 98 & VSD & & \\
\hline 66 & H.O. & 1563 & 144 & & 61 & 7 & 5,5 & 8,5 & & 43 & 2,6 & 5,2 & 2 & 18,8 & & 89 & komplex & Z.n. Rashkind & \\
\hline \begin{tabular}{|l|l}
67 & \\
\end{tabular} & C-H.O. & & 491 & & 62 & 12 & 8 & 9 & 30 & 57 & 4 & 8 & 2 & 24,5 & 2.6 & 90 & AVSD & Z.n. ISTA-Resekktion, Re-ISTA & \\
\hline 68 & Y.D. & & & 155 & 56 & 10 & 8 & 8 & 19 & 47 & 1,9 & 5 & 2,6 & 15,0 & 2,2 & 93,5 & VSD+ASD & & Morbus Down \\
\hline $\begin{array}{ll}69 \\
69 \\
\end{array}$ & \begin{tabular}{|l|} 
A.K-G.G. \\
\end{tabular} & & & & \begin{tabular}{|l|l|}
50 \\
60
\end{tabular} & 10 & 4,5 & $\frac{0}{11}$ & 27,5 & $\frac{47}{65}-10 x$ & 3,3 & 8,5 & $\frac{2,6}{2,6}$ & \begin{tabular}{|l|}
$23,3,3$ \\
\end{tabular} & $\frac{1,2}{1,9}$ & \begin{tabular}{|l|l|}
3,38 \\
98 \\
\end{tabular} & \begin{tabular}{|l}
$S \mathrm{SDDF} I$ \\
$\mathrm{ASD}$
\end{tabular} & & \\
\hline \begin{tabular}{|l|}
70 \\
\end{tabular} & L.F. & 931 & 574 & & 67 & 8 & 2 & 7 & 28 & 65 & 1,7 & 5,4 & 3,1 & 20,3 & 3,9 & \begin{tabular}{|c|}
97 \\
97
\end{tabular} & VSD+ASD & & \\
\hline
\end{tabular}

Abkürzungen: w/m: weiblich/männlich; HF: Herzfrequenz; AF: Atemfrequenz; Perz.: Perzentile; kcal/d bzw. kcal/kg/d: Energiezufuhr in Kilokalorien pro Tag bzw. Kilokalorien pro Kilogramm Körpergewicht pro Tag; Med.: Medikamente; PRA: Plasma-Renin-Aktivität; $\mathrm{VO}_{2}$ Index: Sauerstoffaufnahme pro Körperoberfläche (KOF); EF: Ejektionsfraktion; LVedP: left ventricular enddiastolic pressure, linksventrikulärer enddiastolischer Druck; RAP: mean right atrial pressure, mittlerer rechtsatrialer Druck; LAP: mean left atrial pressure, mittlerer linksatrialer Druck; PAP: mean pulmonary artery pressure, mittlerer Pulmonalarteriendruck; MAP: mean arterial pressure, mittlerer arterieller Druck; $\mathrm{Q}_{\mathrm{p}} / \mathrm{Q}_{\mathrm{s}}$ : Verhältnis aus pulmonalem zu systemischem Herzzeitvolumen; $\mathrm{Q}_{\mathrm{p}}$ Index: Pulmonales Herzzeitvolumen pro KOF: $Q_{\text {ser }}$ : Systemisches Herzzeitvolumen pro KOF. SVRI: systemic vascular resistance index, Index für den systemvaskulären Widerstand; PVRI: pulmonary vascular Herzzeitvolumen pro KOF; $Q_{s}$ Index: Systemisches Herzzeitvolumen pro KOF; SVRI: systemic vascular resistance index, Index für den systemvaskulären Widerstand; PVRI: pulmonary vascular
resistance index, Index für den pulmonalvaskulären Widerstand; $\mathrm{SAO}_{2}$ : Arterielle Sauerstoffsättigung: PDA: Persistierender Ductus arteriosus Botalli; ASD; Vorhofseptumdefekt; VSD: resistance index, Index für den pulmonalvaskulären Widerstand; $\mathrm{SAO}_{2}$ : Arterielle Sauerstoffsättigung; PDA: Persistierender Ductus arteriosus Botalli; ASD: Vorhofsep
Ventrikelseptumdefekt; AVSD: Atrioventrikulärer Septumdefekt; Z.n.: Zustand nach; ISTA: Aortenisthmusstenose; OP: Operation; PAB: Pulmonalarterielles Banding; FG: Frühgeburt. 


\section{Literaturverzeichnis}

Anand IS, Ferrari R, Kalra GS, Wahi PL, Poole-Wilson PA, Harris PC (1989): Edema of Cardiac Origin - Studies of Body Water and Sodium, Renal Function, Hemodynamic Indexes, and Plasma Hormones in Untreated Congestive Cardiac Failure. Circulation 0, 299 - 305

Anker SD, Coats AJS (1999): Cardiac cachexia: a syndrome with impaired survival and immune and neuroendocrine activation. Chest $\underline{115(3)}, 836$ - 847

Anker SD, Sharma R (2002): The syndrome of cardiac cachexia. Int J Cardiol 85(1), 51 - 66

Anker SD, Ponikowski PP, Varney S, Chua TP, Clark AL, Webb-Peploe KM, Harrington D, Kox WJ, Poole-Wilson PA, Coats AJS (1997a): Wasting as independent risk factor for mortality in chronic heart failure. Lancet 349(9058), 1050 - 1053

Anker SD, Chua TP, Ponikowski P, Harrington D, Swan JW, Kox WJ, Poole-Wilson PA, Coats AJS (1997b): Hormonal Changes and Catabolic/Anabolic Imbalance in Chronic Heart Failure and Their Importance for Cardiac Cachexia. Circulation 96, 526 - 534

Anker SD, Ponikowski PP, Clark AL, Leyva F, Rauchhaus M, Kemp M, Teixeira MM, Hellewell PG, Hooper J, Poole-Wilson PA, et al. (1999): Cytokines and neurohormones relating to body composition alterations in the wasting syndrome of chronic heart failure. Eur Heart J 20, 683 - 693

Apitz J (1978): Akute Herzinsuffizienz. Monatsschr Kinderheilkd 126, 299 - 302

Apitz J: Untersuchungsmethoden: Invasive Herzdiagnostik; in: Pädiatrische Kardiologie Erkrankungen des Herzens bei Neugeborenen, Säuglingen, Kindern und Heranwachsenden, 2., überarb. und erw. Auflage; hrsg. v. Apitz J; Steinkopff Verlag, Darmstadt 2002, 150 - 169

Apitz J, Stoermer J (1967): Über die Lebensaussichten von Säuglingen mit kongenitalen Angiokardiopathien. Monatsschr Kinderheilkd 115, 95 - 102

Artman M, Graham TP Jr (1982): Congestive heart failure in infancy: recognition and management. Am Heart J 103(6), 1040 - 1055

Auerbach SR, Richmond ME, Lamour JM, Blume ED, Addonizio LJ, Shaddy RE, Mahony L, Pahl E, Hsu DT (2010): BNP Levels Predict Outcome in Pediatric Heart Failure Patients: Posthoc Analysis of the Pediatric Carvedilol Trial. Circ Heart Fail 3(5), 606 - 611

Bajcetic M, Kokic Nikolic A, Djukic M, Kosutic J, Mitrovic J, Mijalkovic D, Jovanovic I, Simeunovic S, Spasic MB, Samardzic R (2008): Effects of carvedilol on left ventricular function and oxidative stress in infants and children with idiopathic dilated cardiomyopathy: a 12-month, two-center, open-label study. Clin Ther 30(4), 702 - 714 
Bancalari E, Jesse MJ, Gelband H, Garcia O (1977): Lung mechanics in congenital heart disease with increased and decreased pulmonary blood flow. J Pediatr 90(2), 192 -195

Barton JS, Hindmarsh PC, Scrimgeour CM, Rennie MJ, Preece MA (1994): Energy expenditure in congenital heart disease. Arch Dis Child 70(1), 5 - 9

Baumann T: Atlas der Entwicklungsdiagnostik - Vorsorgeuntersuchungen U1 bis U10/J1. Georg Thieme Verlag, Stuttgart 2002

Bautista-Hernandez V, Sanchez-Andres A, Portela F, Fynn-Thompson F (2011): Current Pharmacological Management of Pediatric Heart Failure in Congenital Heart Disease. Curr Vasc Pharmacol 9(5), 619 - 628

Berman W Jr, Wood SC, Yabek SM, Dillon T, Fripp RR, Burstein R (1987): Systemic oxygen transport in patients with congenital heart disease. Circulation 75(2), 360 - 368

Blazy I, Guillot F, Laborde K, Dechaux M (1989): Comparison of plasma renin and prorenin in healthy infants and children as determined with an enzymatic method and a new direct immunoradiometric assay. Scand J Clin Lab Invest $\underline{49(5)}, 413$ - 418

Blume ED, Canter CE, Spicer R, Gauvreau K, Colan S, Jenkins KJ (2006): Prospective single-arm protocol of carvedilol in children with ventricular dysfunction. Pediatr Cardiol 27(3), 336 - 342

Brandt I (1979): Perzentilkurven für die Gewichtsentwicklung bei Früh- und Reifgeborenen in den ersten fünf Jahren. Kinderarzt 10, 713 - 718

Brons M, Thayssen P (1983): Plasma renin concentration, activity and substrate in normal children. Int J Pediatr Nephrol 4(1), 43 - 46

Brophy JM, Joseph L, Rouleau JL (2001): Beta-Blockers in Congestive Heart Failure. A Bayesian Meta-Analysis. Ann Intern Med 134, 550 - 560

Bruns LA, Chrisant MK, Lamour JM, Shaddy RE, Pahl E, Blume ED, Hallowell S, Addonizio LJ, Canter CE (2001): Carvedilol as therapy in pediatric heart failure: an initial multicenter experience. J Pediatr 138(4), 505 - 511

Buchhorn R (2002): Medikamentöse Therapie der Herzinsuffizienz bei Kindern mit angeborenen Herzfehlern. Dtsch Arztebl 99(39), A 2555 - 2559

Buchhorn R: Chronische Herzinsuffizienz im Kindesalter; in: Leitlinien Kinder- und Jugendmedizin. Loseblattwerk; hrsg. v.: Deutsche Gesellschaft für Kinder- und Jugendmedizin; Urban \& Fischer in Elsevier, o. O. 2006 
Buchhorn R, Bartmus D, Siekmeyer W, Hulpke-Wette M, Schulz R, Bürsch J (1998): BetaBlocker Therapy of Severe Congestive Heart Failure in Infants With Left to Right Shunts. Am J Cardiol 81(11), 1366 - 1368

Buchhorn R, Kießling C, Wessel A, Grunewald RW, Hüfner M, Niedmann PD, Bürsch J (2000a): Neurohumorale Aktivierung bei Patienten mit congenitalen Vitien - Einfluß des Lebensalters,

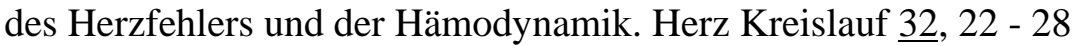

Buchhorn R, Ross RD, Hulpke-Wette M, Bartmus D, Wessel A, Schulz R, Bürsch J (2000b): Effectiveness of low dose Captopril versus Propanolol therapy in infants with severe congestive failure due to left-to-right-shunts. Int J Cardiol 76(2-3), 227 - 233

Buchhorn R, Wessel A, Hulpke-Wette M, Bürsch J, Werdan K, Loppnow H (2001a): Endogenous nitric oxide and soluble tumor necrosis factor receptor levels are enhanced in infants with congenital heart disease. Crit Care Med 29(11), 2208 - 2210

Buchhorn R, Ross RD, Bartmus D, Wessel A, Hulpke-Wette M, Bürsch J (2001b): Activity of the renin-angiotensin-aldosterone and sympathetic nervous system and their relation to hemodynamic and clinical abnormalities in infants with left-to-right shunts. Int J Cardiol 70(3), 225 - 230

Buchhorn R, Hulpke-Wette M, Hilgers R, Bartmus D, Wessel A, Bürsch J (2001c): Propanolol treatment of congestive heart failure in infants with congenital heart disease: The CHF-PROINFANT Trial. Congestive heart failure in infants treated with propanolol. Int J Cardiol 79(23), 167 - 173

Buchhorn R, Hammersen A, Bartmus D, Bürsch J (2001d): The pathogenesis of heart failure in infants with congenital heart disease. Cardiol Young 11, 498 - 504

Buchhorn R, Hulpke-Wette M, Nothroff J, Paul T (2002a): Heart rate variability in infants with heart failure due to congenital heart disease: reversal of depressed heart rate variability by propanolol. Med Sci Monit 8(10), CR 661 - 666

Buchhorn R, Hulpke-Wette M, Ruschewski W, Pregla R, Fielitz J, Hetzer R, Regitz-Zagrosek V (2002b): Beta-receptor downregulation in congenital heart disease: a risk factor for complications after surgical repair? Ann Thorac Surg 73(2), 610 - 613

Buchhorn R, Hulpke-Wette M, Ruschewski W, Ross RD, Fielitz J, Pregla R, Hetzer R, RegitzZagrosek V (2003): Effects of therapeutic beta blockade on myocardial function and cardiac remodelling in congenital cardiac disease. Cardiol Young 13(1), 36 - 43

Candito M, Albertini M, Politano S, Deville A, Mariani R, Chambon P (1993): Plasma catecholamine levels in children. J Chromatogr 617, 304 - 307 
Cantinotti M, Clerico A, Murzi M, Vittorini S, Emdin M (2008): Clinical Relevance of Measurement of Brain Natriuretic Peptide and N-Terminal Pro Natriuretic Peptide in Pediatric Cardiology. Clin Chim Acta 390(1-2): 12 - 22

Cardarelli R, Lumicao TG Jr (2003): B-type natriuretic peptide: a review of its diagnostic, prognostic, and therapeutic monitoring value in heart failure for primary care physicians. J Am Board Fam Pract 16(4), 327 - 333

Carr JG, Stevenson LW, Walden JA, Heber D (1989): Prevalence and hemodynamic correlates of malnutrition in severe congestive heart failure secondary to ischemic or idiopathic dilated cardiomyopathy. Am J Cardiol 63(11), 709 - 713

Cavell B (1981a): Effect of feeding an infant formula with high energy density on gastric emptying in infants with congenital heart disease. Acta Paediatr Scand 70, 513 - 516

Cavell B (1981b): Gastric emptying in infants with congenital heart disease. Acta Paediatr Scand $\underline{70}, 517-520$

Chidsey CA, Harrison DC, Braunwald E (1962): Augmentation of the plasma nor-epinephrine response to exercise in patients with congestive heart failure. Nord Hyg Tidskr 267, 650 - 654

Choudhary SK, Bhan A, Sharma R, Mathur A, Airan B, Saxena A, Kothari SS, Juneja R, Venugopal P (1999): Repair of total anomalous pulmonary venous connection in infancy: experience from a developing country. Ann Thorac Surg 68(1), 155 - 159

Chua TP, Ponikowski P, Webb-Peploe K, Harrington D, Anker SD, Piepoli M, Coats AJS (1997b): Clinical characteristics of chronic heart failure patients with an augmented peripheral chemoreflex. Eur Heart J $\underline{18}, 480$ - 486

Cohn JN, Levine TB, Olivari MT, Garberg V, Lura D, Francis GS, Simon AB, Rector T (1984): Plasma norepinephrine as a guide to prognosis in patients with chronic congestive heart failure. N Engl J Med $\underline{311(13)}, 819$ - 823

Deutsche Gesellschaft für Ernährung, Österreichische Gesellschaft für Ernährung, Schweizerische Gesellschaft für Ernährungsforschung, Schweizerische Vereinigung für Ernährung (Hrsg.): Referenzwerte für die Nährstoffzufuhr, 1. Auflage, 3. korrigierter Nachdruck; Umschau/ Braus, Frankfurt/M 2008

Dunlop KA, Mulholland HC, Casey FA, Craig B, Gladstone DJ (2004): A ten year review of atrioventricular septal defects. Cardiol Young 14(1), 15 - 23

Eichler I, Eichler HG, Rotter M, Kyrle PA, Gasic S, Korn A (1989): Plasma Concentrations of Free and Sulfoconjugated Dopamine, Epinephrine, and Norepinephrine in Healthy Infants and Children. Klin Wochenschr $\underline{67}, 672$ - 675 
Elkayam U, Amin J, Mehra A, Vasquez J, Weber L, Rahimtoola SH (1990): A prospective, randomized, double-blind, crossover study to compare the efficacy and safety of chronic nifedipine therapy with that of isosorbid dinitrate and their combination in the treatment of chronic congestive heart failure. Circulation 82(6), 1954 - 1961

Filippo SD (2007): Beta-adrenergic receptor antagonists and chronic heart failure in children. Ther Clin Risk Manag 3(5), 847 - 854

Fiselier TJW, Lijnen P, Monnens L, van Munster P, Jansen M, Peer P (1983): Levels of renin, angiotensin I and II, angiotensin-converting enzyme and aldosterone in infancy and childhood. Eur J Pediatr 141(1), 3 - 7

Fleischer Michaelsen K, Weaver L, Branca F, Robertson A: Feeding and nutrition of infants and young children. Guidelines for the WHO European Region, with emphasis on the former Soviet countries. (WHO regional publications, European Series, No.87), updated reprint; World Health Organization, Copenhagen 2003

Floras JS (1993): Clinical aspects of sympathetic activation and parasympathetic withdrawal in heart failure. J Am Coll Cardiol 22 (4 Suppl A), 72A - 84A

Forchielli ML, McColl R, Walker WA, Lo C (1994): Children with congenital heart disease: a nutrition challenge. Nutr Rev $\underline{\text { 22(10), }} 348$ - 353

Franciosa JA, Jordan RA, Wilen MM, Leddy CL (1984): Minoxidil in patients with chronic left heart failure: contrasting hemodynamic and clinical effects in a controlled trial. Circulation 70(1), $63-68$

Frobel AK, Hulpke-Wette M, Schmidt KG, Läer S (2009): Beta-blockers for congestive heart failure in children. Cochrane Database Syst Rev (1), CD 007037

Gazetopoulos N, Davies H (1966): Ventilatory Response to Exercise in Patients With Left-toright Shunts. Br Heart J 28, 590 - 598

Giannoni A, Emdin M, Bramanti F, Iudice G, Francis DP, Barsotti A, Piepoli M, Passino C (2009): Combined increased chemosensitivity to hypoxia and hypercapnia as a prognosticator in heart failure. J Am Coll Cardiol 53(21),1975 - 1980

Gidding SS, Bessel M (1993): Hemodynamic Correlates of Clinical Severity in Isolated Ventricular Septal Defekt. Pediatr Cardiol 14, 135 - 139

Goldstein DS (1981): Plasma norepinephrine as an indicator of sympathetic neural activity in clinical cardiology. Am J Cardiol 48(6), 1147 - 1154 
Grossmann A: Tachypnoe; in: Pschyrembel - Klinisches Wörterbuch 2012, 263. Auflage; hrsg. v. Grossmann A unter Mitarbeit der Pschyrembel-Redaktion des Verlages; Walter de Gruyter Verlag, Berlin 2011, 2051

Hansen SR, Dorup I (1993): Energy and nutrient intakes in congenital heart disease. Acta Paediatr 82(2), 166 - 172

Harris P (1987): Congestive cardiac failure: central role of the arterial blood pressure. Br Heart J 58(3), 190 - 203

Hexel SA: Referenzwerte invasiv gemessener Kreislaufparameter zur Beurteilung der Hämodynamik im Kindesalter und ihrer Anwendung bei Patienten mit Williams-Beuren-Syndrom im Hinblick auf deren Blutdruckverhalten. Med. Diss. Göttingen 1996

Hill JR, Rahimtulla KA (1965): Heat balance and the metabolic rate of new-born babies in relation to environmental temperature; and the effect of age and of weight on basal metabolic rate. J Physiol 180, 239 - 265

Hoffman JI (1995): Incidence of congenital heart disease: I. Postnatal incidence. Pediatr Cardiol $\underline{16(3)}, 103-113$

Hoffman JI, Kaplan S (2002): The incidence of congenital heart disease. J Am Coll Cardiol 39(12), 890 - 900

Hoppe UC, Böhm M, Dietz R, Hanrath P, Kroemer HK, Osterspey A, Schmaltz AA, Erdmann E (2005): Leitlinien zur Therapie der chronischen Herzinsuffizienz. Herausgegeben vom Vorstand der Deutschen Gesellschaft für Kardiologie - Herz- und Kreislaufforschung e.V.. Bearbeitet im Auftrag der Kommission für Klinische Kardiologie in Zusammenarbeit mit der Arzneimittelkommission der Deutschen Ärzteschaft. Z Kardiol 94(8), 488 - 509

Howlett G (1972): Lung mechanics in normal infants and infants with congenital heart disease. Arch Dis Child 47, 707 - 715

Hunt SA, Abraham WT, Chin MH, Feldman AM, Francis GS, Ganiats TG, Jessup M, Konstam MA, Mancini DM, Michl K, et al. (2009): 2009 Focused Update Incorporated into the ACC/AHA 2005 Guidelines for the Diagnosis and Management of Heart Failure in Adults: A Report of the American College of Cardiology Foundation/American Heart Association Task Force on Practice Guidelines. J Am Coll Cardiol 53(15), e1 - e90

Huse DM, Feldt RH, Nelson RA, Novak LP (1975): Infants with congenital heart disease. Food intake, body weight, and energy metabolism. Am J Dis Child 129(1), 65 - 69 
Kaczmarek A, Jankowska EA, Witkowski T, Kus-Klinowska A, Ponikowska B, Reczuch K, Borodulin-Nadzieja L, Hanczycowa H, Banasiak W, Ponikowski P (2004): Chronic heart failure. The relationship between increased activity of skeletal muscle ergoreceptors and reduced exercise tolerance. Kardiol Pol 60(4), 322 - 332

Kimball TR, Daniels SR, Meyer RA, Hannon DW, Khoury P, Schwartz DC (1991): Relation of Symptoms to Contractility and Defect Size in Infants with Ventricular Septal Defect. Am J Cardiol 67, 1097 - 1102

Kirk RE: Experimental design: Procedures for the Behavioural Fiances. Brooks/ Cole, Belmont California 1968

Koch A, Zink S, Singer H (2006): B-type natriuretic peptide in paediatric patients with congenital heart disease. Eur Heart J 27, 861 - 866

Kozlik-Feldmann R, Kramer HH, Wicht H, Feldmann R, Netz H, Reinhardt D (1993): Distribution of myocardial beta-adrenoceptor subtypes and coupling to the adenylate cyclase in children with congenital heart disease and implications for treatment. J Clin Pharmacol 33(7), 588 - 595

Kramer HH, Trampisch HJ, Rammos S, Giese A (1990): Birth weight of children with congenital heart disease. Eur J Pediatr 149(11), 752 - 757

Krüger C, Rauh M, Dörr HG (1998): Immunoreactive renin concentrations in healthy children from birth to adolescence. Clin Chim Acta 274(1), 15 - 27

Läer S, Mir TS, Behn F, Eiselt M, Scholz H, Venzke A, Meibohm B, Weil J (2002): Carvedilol therapy in pediatric patients with congestive heart failure: a study investigating clinical and pharmacokinetic parameters. Am Heart J 143(5), 916 - 922

Leite HP, de Camargo Carvalho AC, Fisberg M (1995): Nutritional status of children with congenital heart disease and left-to-right-shunt. The importance of the presence of pulmonary hypertension. Arq Bras Cardiol 65(5), 403 - 407

Levy RJ, Rosenthal A, Miettinen OS, Nadas AS (1978): Determinants of growth in patients with ventricular septal defect. Circulation 57(4), 793 - 797

Loppnow H, Werdan K, Werner C (2002): The enhanced plasma levels of soluble tumor necrosis factor receptors (sTNF-R1; sTNF-R2) and interleukin-10 (IL-10) in patients suffering from chronic heart failure are reversed in patients treated with beta-adrenoceptor antagonists. Auton Autacoid Pharmacol 22(2), 83 - 92

Luchner A, Holmer S, Schunkert H, Riegger GA (2003): Bedeutung der Herzinsuffizienzmarker BNP und NT-proBNP für die Klinik. Dtsch Arztebl 100(50): A3314 - A3321 
Lust F, von Pfaundler M: Krankheiten des Kindesalters - Ihre Erkennung und Behandlung in der Praxis. 3., neubearbeitete Auflage; Urban \& Schwarzenberg Verlag, Berlin 1947

Mancia G, Seravalle G, Giannattasio C, Bossi M, Preti L, Cattaneo BM, Grassi G (1992): Reflex cardiovascular control in congestive heart failure. Am J Cardiol 69(18), 17G - 23G

Mänhardt LB, Norozi K, Müller C, Willaschek C, Kostuch B, Buchhorn R (2010): NT-Pro-BType Natriuretic Peptide Levels in Infants with Failure to Thrive due to Caloric Deprivation. Int J Pediatr 2010, 983468

Massin M, von Bernuth G (1997): Normal ranges of heart rate variability during infancy and childhood. Pediatr Cardiol 18, 297 - 302

Massin M, von Bernuth G (1998): Clinical and haemodynamic correlates of heart rate variability in children with congenital heart disease. Eur J Pediatr 157, 967 - 971

Mayer B, Holmer SR, Hengstenberg C, Lieb W, Pfeifer M, Schunkert H (2005): Functional improvement in heart failure patients treated with beta-blockers is associated with a decline of cytokine levels. Int J Cardiol 103(2), 182 - 186

McMurray JJ, Stewart S (2000): Epidemiology, aetiology, and prognosis of heart failure. Heart $\underline{83}, 596-602$

McMurray JJ, Ray SG, Abdullah I, Dargie HJ, Morton JJ (1992): Plasma endothelin in chronic heart failure. Circulation 85(4), 1374 - 1379

Menon G, Poskitt EM (1985): Why does congenital heart disease cause failure to thrive? Arch Dis Child 60(12), 1134 - 1139

Middlekauff HR, Mark AL (1998): The treatment of heart failure: the role of neurohumoral activation. Intern Med $\underline{\text { 37(2) }}, 112$ - 122

Mitchell IM, Logan RW, Pollock JC, Jamieson MP (1995): Nutritional status of children with congenital heart disease. Br Heart J 73(3), 277 - 283

Mitsui A, Nohta H, Ohkura Y (1985): High-performance liquid chromatography of plasma catecholamines using 1,2-diphenylethylenediamine as precolumn fluorescence derivatization reagent. J Chromatogr $\underline{344}, 61$ - 70

Motz R, Harding P, Quick P, Kramer HH, Allgeier B, Buchhorn R (2005): Is heart rate variability an objective parameter with which to manage treatment of infants with heart failure due to leftto-right shunting? Cardiol Young 15(1), 8 - 12 
Najm HK, Coles JG, Endo M, Stephens D, Rebeyka IM, Williams WG, Freedom RM (1997): Complete atrioventricular septal defects: results of repair, risk factors, and freedom from reoperation. Circulation 96(9 Suppl), II-311 - II-315

Netz H, Schanné U, Pabst W, Rautenburg HW (1987): Zur Messung des Sauerstoffverbrauchs bei gesunden und herzkranken Säuglingen und Kindern. Z Kardiol 76, 51 - 57

Nishiyama M, Park IS, Yoshikawa T, Hatai Y, Ando M, Takahashi Y, Mori K, Murakami Y (2009): Efficacy and safety of carvedilol for heart failure in children and patients with congenital heart disease. Heart Vessels 24(3), 187 - 192

Nolan J, Batin PD, Andrews R, Lindsay SJ, Brooksby P, Mullen M, Baig W, Flapan AD, Cowley A, Prescott RJ, et al. (1998): Prospective study of heart rate variability and mortality in chronic heart failure: results of the United Kingdom heart failure evaluation and assessment of risk trial (UK-heart). Circulation 98(15), 1510 - 1516

Nozaki N, Yamaguchi S, Shirakabe M, Nakamura H, Tomoike H (1997): Soluble tumor necrosis factor receptors are elevated in relation to severity of congestive heart failure. Jpn Circ J 61(8), 657 - 664

Nozohoor S, Nilsson J, Algotsson L, Sjögren J (2011): Postoperative increase in B-type natriuretic Peptide levels predicts adverse outcome after cardiac surgery. J Cardiothorac Vasc Anesth 25(3), $469-475$

Nützenadel W, Zimmer KP (2007): Leitlinien der Gesellschaft für Pädiatrische Gastroenterologie und Ernährung (GPGE) - Gedeihstörung. http://www.uni-duesseldorf.de/AWMF/ll/068002.htm, letzte Aktualisierung 04/2007 (Datum des Abrufs: 15.06.2009)

Olsen EM, Skovgaard AM, Weile B, Jørgensen T (2007a): Risk factors for failure to thrive in infancy depend on the anthropometric definitions used: The Copenhagen County Child Cohort. Paediatr Perinat Epidemiol 21(5), 418 - 431

Olsen EM, Petersen J, Skovgaard AM, Weile B, Jørgensen T, Wright CM (2007b): Failure to thrive: the prevalence and concurrence of anthropometric criteria in a general infant population. Arch Dis Child 92(2), 109 - 114

Ozhan H, Albayrak S, Uzun H, Ordu S, Kaya A, Yazici M (2007): Correlation of plasma B-type natriuretic peptide with shunt severity in patients with atrial or ventricular septal defect. Pediatr Cardiol 28(4), 272 - 275

Packer M (1992): The Neurohormonal Hypothesis: A Theory to Explain the Mechanism of Disease Progression in Heart Failure. J Am Coll Cardiol 20, 248 - 254

Packer M (1993): How should physicians view heart failure? The philosophical and physiological evolution of three conceptual modells of the disease. Am J Cardiol $\underline{71}$, 3-11C 
Packer M (1995): Is Tumor Necrosis Factor an Important Neurohormonal Mechanism in Chronic Heart Failure? Circulation 92, 1379 - 1382

Park MK: Kompendium pädiatrische Kardiologie. Deutsche Übersetzung und Bearbeitung W. Eckrich; Deutscher Ärzte-Verlag, Köln 1999

Paul MA, Backer CL, Binns HJ, Mavroudis C, Webb CL, Yogev R, Franklin WH (2009): B-type natriuretic peptide and heart failure in patients with ventricular septal defect: a pilot study. Pediatr Cardiol 30(8), 1094 - 1097

Picchio FM, Formigari R, Balducci A (2008): Pediatric heart failure. Minerva Cardioangiol 56(3), $311-319$

Piepoli M, Clark AL, Volterrani M, Adamopoulos S, Sleight P, Coats AJ (1996): Contribution of Muscle Afferents to the Hemodynamic, Autonomic, and Ventilatory Responses to Exercise in Patients With Chronic Heart Failure - Effects of Physical Training. Circulation 93, 940 - 952

Pirlich M, Schwenk A, Müller MJ, unter Mitarbeit von Ockenga J, Schmidt S, Schütz T, Selberg O, Volkert D (2003): DGEM-Leitlinie Enterale Ernährung: Ernährungsstatus. Aktuel Ernahrungsmed 28 Suppl 1, S10 - S25

Ponikowski P, Banasiak W (2001): Chemosensitivity in chronic heart failure. Heart Fail Monit $\underline{1(4)}, 126-131$

Ponikowski P, Chua TP, Piepoli M, Ondusova D, Webb-Peploe K, Harrington D, Anker SD, Volterrani M, Colombo R, Mazzuero G, et al. (1997): Augmented Peripheral Chemosensitivity as a Potential Input to Baroreflex Impairment and Autonomic Imbalance in Chronic Heart Failure. Circulation 96, 2586 - 2594

Ponikowski P, Chua TP, Piepoli M, Banasiak W, Anker SD, Szelemej R, Molenda W, Wrabec K, Capucci A, Coats AJS (1998): Ventilatory Response to Exercise Correlates With Impaired Heart Rate Variability in Patients with Chronic Congestive Heart Failure. Am J Cardiol 82, 338 - 344

Ponikowski P, Chua TP, Francis DP, Capucci A, Coats AJ, Piepoli MF (2001): Muscle ergoreceptor overactivity reflects deterioration in clinical status and cardiorespiratory reflex control in chronic heart failure. Circulation 104(19), 2324 - 2330

Potapov EV, Loebe M, Anker S, Stein J, Bondy S, Nasseri BA, Sodian R, Hausmann H, Hetzer R (2003): Impact of body mass index on outcome in patients after coronary artery bypass grafting with and without valve surgery. Eur Heart J 24(21), 1933 - 1941

Raynor P, Rudolf MCJ (2000): Anthropometric indices of failure to thrive. Arch Dis Child 82, 364 - 365 
Ross RD, Daniels SR, Schwartz DC, Hannon DW, Shukla R, Kaplan S (1987): Plasma Norepinephrine Levels in Infants and Children with Congestive Heart Failure. Am J Cardiol 59, $911-914$

Ross RD, Bollinger RO, Pinsky WW (1992): Grading the Severity of Congestive Heart Failure in Infants. Pediatr Cardiol 13, 72 - 75

Salzer HR, Haschke F, Wimmer M, Heil M, Schilling R (1989): Growth and nutritional intake of infants with congenital heart disease. Pediatr Cardiol 10(1), 17 - 23

Samanek M, Slavik Z, Zborilova B, Hrobonova V, Voriskova M, Skovranek J (1989): Prevalence, treatment, and outcome of heart disease in live-born children: a prospective analysis of 91,823 live-born children. Pediatr Cardiol 10(4), 205 - 211

Schmidt E: Nahrungsbedarf und Ernährung; in: Kinderheilkunde, 10. Auflage; hrsg. v. Harnack GA, Koletzko B; Springer-Verlag, Berlin 1997, 127 - 140

Schumacher G: Herzkatheteruntersuchung und Angiographie; in: Klinische Kinderkardiologie: Diagnostik und Therapie der angeborenen Herzfehler, 3., vollkommen überarbeitete und erweiterte Auflage; hrsg. v. Schumacher G, Hess J, Bühlmeyer K u.a.; Springer Verlag, Berlin 2001, 85 - 97

Schumacher G, Schreiber R: Einführung: Einteilung der angeborenen Herzfehler; in: Klinische Kinderkardiologie: Diagnostik und Therapie der angeborenen Herzfehler, 3., vollkommen überarbeitete und erweiterte Auflage; hrsg. v. Schumacher G, Hess J, Bühlmeyer K u.a.; Springer Verlag, Berlin 2001, 3 - 6

Shaddy RE, Tani LY, Gidding SS, Pahl E, Orsmond GS, Gilbert EM, Lemes V (1999): Betablocker treatment of dilated cardiomyopathy with congestive heart failure in children: a multiinstitutional experience. J Heart Lung Transplant 18(3), 269 - 274

Shaddy RE, Boucek MM, Hsu DT, Boucek RJ, Canter CE, Mahony L, Ross RD, Pahl E, Blume ED, Dodd DA, et al. (2007): Carvedilol for children and adolescents with heart failure: a randomized controlled trial. JAMA 298(10), 1171 - 1179

Somers VK, Mark AL, Abboud F (1991): Interaction of baroreceptor and chemoreceptor reflex control of sympathetic nerve activity in normal humans. J Clin Invest 87(6), 1953 - 1957

Sondheimer JM, Hamilton JR (1978): Intestinal function in infants with severe congenital heart disease. J Pediatr 92(4), 572 - 578

Swedberg K, Eneroth P, Kjekshus J, Wilhelmsen L (1990): Hormones regulating cardiovascular function in patients with severe congestive heart failure and their relation to mortality. CONSENSUS Trial Study Group. Circulation 82(5), 1730 - 1736 
Szabo BM, van Veldhuisen DJ, Brouwer J, Haaksma J, Lie KI (1995): Relation between severity of disease and impairment of heart rate variability parameters in patients with chronic congestive heart failure secondary to coronary artery disease. Am J Cardiol 76(10), 713 - 716

Takaya J, Ikemoto Y, Teraguchi M, Nogi S, Kobayashi Y (2000): Plasma nitric oxide products correlate with cardiac index of congenital heart disease. Pediatr Cardiol 21(4), 378 - 381

Task Force of the European Society of Cardiology and the North American Society of Pacing and Electrophysiology (1996): Heart Rate Variability - Standards of Measurement, Physiological Interpretation, and Clinical Use. Circulation $\underline{\text { 93, }} 1043$ - 1065

The Criteria Committee of the New York Heart Association: Diseases of the Heart and Blood Vessels; Nomenclature and Criteria for Diagnosis. 6th edn. Little, Brown and Co., Boston 1964

Thommessen M, Heiberg A, Kase B (1992): Feeding problems in children with congenital heart disease: the impact on energy intake and growth outcome. Eur J Clin Nutr 46(7), 457 - 464

Tjeerdsma G, Szabo BM, van Wijk LM, Brouwer J, Tio RA, Crijns HJ, van Veldhuisen DJ (2001): Autonomic dysfunction in patients with mild heart failure and coronary artery disease and the effects of add-on beta-blockade. Eur J Heart Fail 3(1), 33 - 39

von Basch SSK (1887): Ueber eine Function des Capillardruckes in den Lungenalveolen. Wiener Medizinische Blätter $\underline{15}, 465$ - 467

Waggoner AD, Nouri S, Schaffer MS, Chen SC (1985): Echocardiographic Evaluation of Left Ventricular Function, Mass and Wall Stress in Children with Isolated Ventricular Septal Defect. Tex Heart Inst J 12(2), 163 - 170

Werner C, Loppnow H, Rauchhaus M, Wessel A, Werdan K, Buchhorn R (2002): Cytokines in chronic heart failure: possible interaction in the neurohormonal and the cytokine system at the cAMP level? Eur Cytokine Netw 13(4), 407 - 409

Wessel A, Buchhorn R, Bürsch J (2000): Kreislaufinsuffizienz bei Kindern mit Links-RechtsShunts im Rahmen angeborener Herzfehler - Pathophysiologie und therapeutische Konsequenzen. Klin Pädiatr 212(2), 53 - 59

WHO (World Health Organization) (1995): Physician Guidelines (for GPs) designed to be translated and distributed worldwide to primary care physicians.

WHO Multicentre Growth Reference Study Group (2006): WHO Child Growth Standards based on length/height, weight and age. Acta Paediatr Suppl 450, 76 - 85

Wilcox WD, Nieburg P, Miller DS (1989): Failure to thrive. A continuing problem of definition. Clin Pediatr (Phila) 28(9), 391 - 394 
Witte KK, Notarius CF, Ivanov J, Floras JS (2008): Muscle sympathetic nerve activity and ventilation during exercise in subjects with and without chronic heart failure. Can J Cardiol $\underline{24(4)}, 275-278$

Wu JR, Chang HR, Huang TY, Chiang CH, Chen SS (1996): Reduction in Lymphocyte BetaAdrenergic Receptor Density in Infants and Children With Heart Failure Secondary to Congenital Heart Disease. Am J Cardiol 77, 170 - 174

Wu YR, Chen SB, Huang MR, Zhang YQ, Sun K, Chen S (2005): Diagnostic value of plasma concentration of pro-brain natriuretic peptide in congestive heart failure in pediatric patients with ventricular septal defects. Zhonghua Er Ke Za Zhi 43(3), 161 - 164

Yau KI, Fang LJ, Wu MH (1996): Lung mechanics in infants with left-to-right shunt congenital heart disease. Pediatr Pulmonol 21(1), 42 - 47

Zhao SP, Zeng LH (1997): Elevated plasma levels of tumor necrosis factor in chronic heart failure with cachexia. Int J Cardiol 58, 257 - 261 


\section{Danksagung}

Meinem jetzigen Doktorvater, Herrn PD Dr. Matthias Sigler, danke ich herzlich für die nette und unkomplizierte Übernahme der Betreuung meiner Doktorarbeit und für seine hilfreiche Unterstützung bei der Fertigstellung der Arbeit!

Meinem Doktorvater, Herrn PD Dr. Reiner Buchhorn, der die Anregung zu dieser Arbeit gegeben hat, danke ich herzlich für die Betreuung meiner Dissertation! Ich danke ihm, daß er sich auch spontan immer einen Moment Zeit genommen hat, Ergebnisse zu diskutieren und Fragen zu besprechen, und mir Mut gemacht hat, die Arbeit zu einem Ende zu bringen.

Herrn Prof. Dr. Joachim Bürsch danke ich als ehemaligem Leiter der Abteilung Pädiatrische Kardiologie der Universitätsklinik Göttingen für die Vergabe des Themas dieser Arbeit.

Herrn Dr. Dietmar Bartmus ( $\dagger$ ) bin ich dankbar dafür, daß er mich im Rahmen zweier Famulaturen und weiterer Hospitationen an die Kinderkardiologie herangeführt hat und mir seine Begeisterung für das Fach nahe gebracht hat. Seine menschliche Art im Umgang mit Patienten, sein geduldiges Zeigen und Erklären haben mich beeindruckt.

Herrn Dr. Ullrich Munzel aus der Abteilung für Medizinische Statistik danke ich für die fachkundige Beratung in statistischen Fragen.

Den Damen der Poliklinik der pädiatrischen Kardiologie danke ich, daß sie mir immer wieder beim Suchen von Akten und Unterlagen behilflich waren.

Frau Medefindt, Diätassistentin, danke ich für Informationen über die Zusammensetzung und Zubereitung der Nahrung für die herzkranken Säuglinge in der ehemaligen Milchküche, den Kinderkrankenschwestern auf der Station 2014 des Göttinger Klinikums für Informationen zur klinischen Beobachtung der Säuglinge während des stationären Aufenthaltes. 